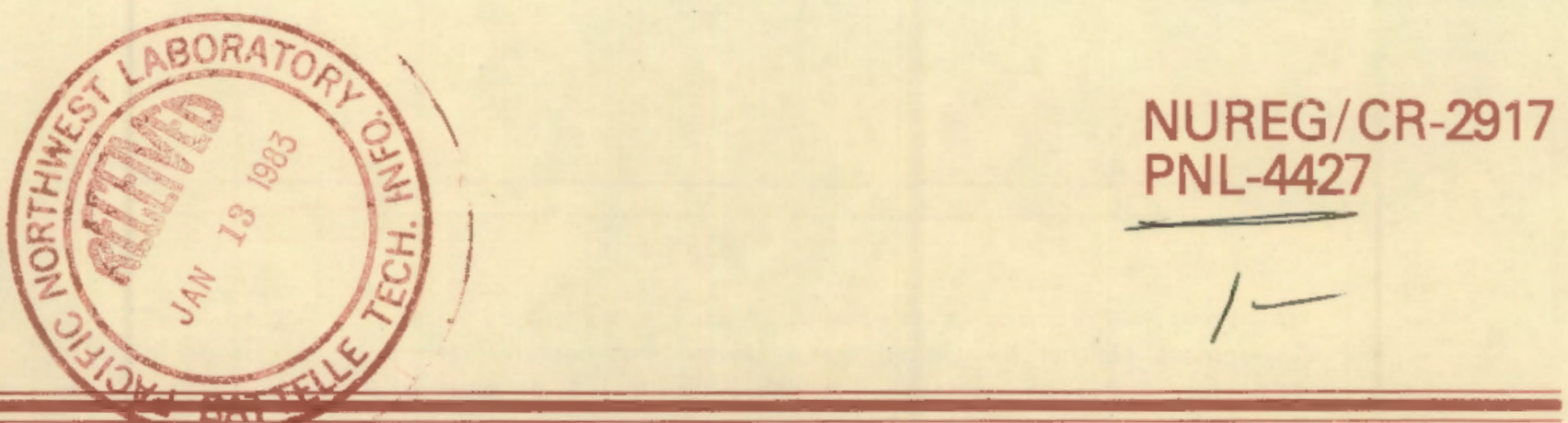

\title{
Review of Ground-Water Flow and Transport Models in the Unsaturated Zone
}

Prepared by C. A. Oster

Pacific Northwest Laboratory

Operated by

Battelle Memorial Institute

Prepared for

U.S. Nuclear Regulatory

Commission 


\section{NOTICE}

This report was prepared as an account of work sponsored by an agency of the United States Government. Neither the United States Government nor any agency thereof, or any of their employees, makes any warranty, expressed or implied, or assumes any legal liability of responsibility for any third party's use, or the results of such use, of any information, apparatus, product or process disclosed in this report, or represents that its use by such third party would not infringe privately owned rights.

\section{Availability of Reference Materials Cited in NRC Publications}

Most documents cited in NRC publications will be available from one of the following sources:

1. The NRC Public Document Room, 1717 H Street, N.W. Washington, DC 20555

2. The NRC/GPO Sales Program, U.S. Nuclear Regulatory Commission, Washington, DC 20555

3. The National Technical Information Service, Springfield, VA 22161

Although the listing that follows represents the majority of documents cited in NRC publications, it is not intended to be exhaustive.

Referenced documents available for inspection and copying for a fee from the NRC Public Document Room include NRC correspondence and ir.ternal NRC memoranda; NRC Office of Inspection and Enforcement bulletins, circulars, information notices, inspection and investigation notices; Licensee Event Reports; vendor reports and correspondence; Commission papers; and applicant and licensee documents and correspondence.

The following documents in the NUREG series are available for purchase from the NRC/GPO Sales Program: formal NRC staff and contractor reports, NRC-sponsored conference proceedings, and NRC booklets and brochures. Also available are Regulatory Guides, NRC regulations in the Code of Federal Regulations, and Nuclear Regulatory Commission /ssuances.

Documents available from the National Technical Information Service include NUREG series reports and technical reports prepared by other federal agencies and reports prepared by the Atomic Energy Commission, forerunner agency to the Nuclear Regulatory Commission.

Documents available from public and special technical libraries include all open literature items, such as books, journal and periodical articles, and transactions. Federal Register notices, federal and state legislation, and congressional reports can usually be obtained from these libraries.

Documents such as theses, dissertations, foreign reports and translations, and non-NRC conference proceedings are available for purchase trom the organization sponsoring the publication cited

Single copies of NRC draft reports are available free upon written request to the Division of Tech. nical Information and Document Control, U.S. Nuclear Regulatory Commission, Washington, DC 20555

Copies of industry codes and standards used in a substantive manner in the NAC regulatory process are maintained at the NRC Library, 7920 Norfolk Avenue, Bethesda, Maryland, and are available there for reference use by the public. Codes and standards are usually copyrighted and may be purchased from the originating organization or, if they are American National Standards, from the American National Standards Institute, 1430 Broadway, New York, NY 10018. 
NUREG/CR-2917

PNL-4427

\section{Review of Ground-Water Flow and Transport Models in the Unsaturated Zone}

Man Jscript Completed: October 1982

Date Published: November 1982

Prepared by

C. A. Oster

Pacific Northwest Laboratory

P. O. Box 999

Rich and, WA 99352

\section{Prepared for}

Division of Waste Management

Office of Nuclear Material Safety and Safeguards

U.S. Nuclear Regulatory Commission

Washington, D.C. 20555

NRC FIN B2220 



\section{SUMMARY}

Models of partially saturated flow and transport in porous media have application in the analysis of existing as well as future low-level radioactive waste facilities located above the water table. An extensive literature search along with telephone and mail correspondence with recognized leading experts in the field, was conducted to identify computer models suitable for studies of low-level radioactive waste facilities located in the unsaturated zone. Fiftyfive existing models were identified as potentialiy useful. Ten of these models were selected for further examination.

This report contains a statement of the ground-water flow-contaminant transport problem, a discussion of those methods used to reduce the physical problem to a computer model, a brief discussion about the data requirements of these modeis. The procedure used to select the ten codes for further discussion is given, along with a list of these models.

Finally, the Appendices contain the data about the fifty-five codes examined. Specifical1y Appendix D contains the detailed discussion of each of the ten selected codes. Included in each discussion are such items which a potential user requires in determining whether the code is suitable for his applications. Appendix $E$ contains brief summary information about each of the fifty-five codes. Included in the summaries are identification data, authors, pertinate references, and model type. 



\section{ACKNOWLEDGMENTS}

This study was sponsored and supported by the Division of Waste Management of the United States Nuclear Regulatory Commission. The author acknowledges the interest and suggestions provided by D. L. Siefken as project leader for NRC. The cooperation and interest shown by the many scientists contacted during this study is acknowledged. The author also expresses appreciation to his collegues at Pacific Northwest Laboratory, R. W. Nelson, E. M. Arnold and G. W. Gee for their interest, suggestions and encouragement throughout the project. Special thanks are also expressed to Toni Jewell, Kay Chase and Diane Burks who performed the word processing and typing responsibilities including the many equations involved in this report. 



\section{CONTENTS}

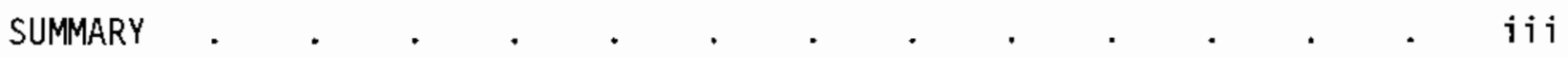

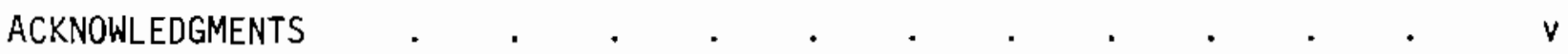

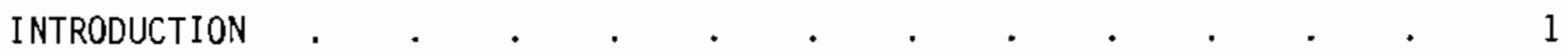

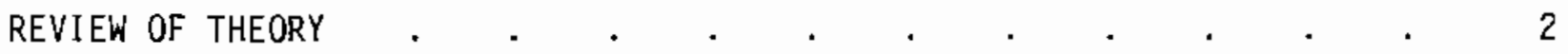

NUMERICAL APPROXIMATIDNS AND FORMULATIDNS $. \quad . \quad$. $\quad . \quad$. 5

DATA REQUIREMENTS . . . . . . . . . . . . . . . . . 10

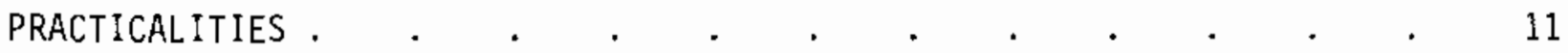

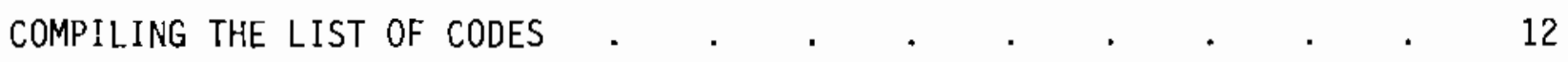

PREFERRED CODES . . . . . . . . . . . . . . . . . . . . 13

OTHER CODES OF POTENTIAL INTEREST . . . . . . . . . . . . . 15

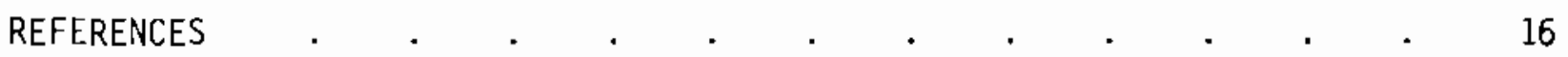

APPENDIX A--PARTIALLY SATURATED AND MULTIPHASE CODES INVENTORIED,

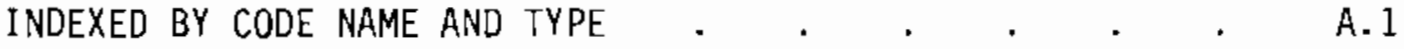

APPENDIX B--SUMMARY CHARTS OF INVENTORIED CODES . . . . . . . . B. 1

APPENDIX C--CODE EVALUATIONS . $\quad . \quad . \quad . \quad . \quad . \quad . \quad . \quad . \quad$ C. 1

APPENDIX D--SUMMARIES OF SELECTED CODES .

APPENDIX E--PARTIALLY SATURATED AND MULTIPHASE CODES INVENTORIED--

SHORT SUMMARIES . . . . . . . . . . . E. 1 

REVIEW OF GROUND-WATER FLOW AND TRANSPORT

MODELS IN THE UNSATURATED ZONE

\section{INTRODUCTION}

The advantages of disposing low-level radioactive wastes in the unsaturated zone above the fluctuations of the water table have been recognized for some time. Indeed several of the existing low-level waste disposal facilities are sited and designed to dispose of the low-level waste in unsaturated media. In addition, proposed regulations for near-surface disposal of low-level wastes (1D CFR 61) would reouire disposal in the unsaturated zone above the fluctuations of the water table unless it can be conclusively demonstrated that the site characteristics will result in diffusion being the predominant mechanism of transport. In all cases except the diffusion-dominated system, migration of radionuclides which may be leached from the low-level waste would be through unsaturated media. Hence, the analysis of potential releases of radionuclides from the disposal units must include flow and transport in partially-saturated media. Although not relying solely on modeling to determine the suitability of a proposed or existing site, modeling can be nevertheless a valuable tool with which to calculate potential migration of radionuclides from the disposal site.

Modeling is also useful when designing a disposal facility. Covers and disposal units must be designed to minimize infiltration and contact of water with the wastes. Again, modeling of the movement of moisture and solute in partially-saturated media can be a valuable tool with which to evaluate the effectiveness of design features such as cover systems, specially-selected vegetative covers, or granular backfill.

But what computer codes should be used? Which natural processes and physical properties should be incorporated, and which can reasonably be ignored, in the models? What are the limitations on the existing computer codes and how do they affect their usefulness at this time? How do these computer codes mate with saturated flow and transport codes? Does adequate documentation exist for the codes? What data requirements are imposed by the selection of the codes? Can the data requirements be reasonably met in the field? Have the codes been verified against field studies?

The Low-Level Waste Licensing Branch (WMLL) of the U.S. Nuclear Regulatory Commission has an immediate need to evaluate potential releases of radionuclides and the effectiveness of design features at both existing and future low-level waste disposal sites. To meet this need, WMLL must proceed based on computer codes currently available, while improving this capability as refinements or new developments permit. WMLL has therefore committed to a program of developing an in-house modeling capability and sharing this capability through prequalification of a group of prospective computer codes for partiallysaturated and saturated flow and transport (Siefken 1982). 
This report contains the results of examining some 55 different models for flow and transport in variably saturated media. The main text contains discussions in general terms of the modeling problem, how the theoretical problem is approximated, data requirements and general comments. Of the 55 models examined, 10 have been selected for further study. An additional 16 were not included on the selected list because documentation was inadequate. An extensive individual discussion for each of the selected codes appears in Appendix $D$.

This study was confined to the examination of information written about each code. No attempt was made to actually run on a computer, any of the codes discussed in this report.

Appendix E contains a short summary for each of the models examined. Each of the 55 models has been assigned an identification number, i.e., an integer from 1 to 55 . The models are listed by sequence number in Appendix $E$ and in most other tables. In addition each model has a name assigned to it. This name is the name used in the literature if the originator(s) used one in his (their) writings. If no name is apparent from the literature a name is assigned, using the primary author's name with a suffix to assure uniqueness of model name. Appendix A contains lists of models indexed by model name to the Appendix $E$ list. Thus given a model name one can go to Appendix A, obtain the model number and locate the associated short summary in Appendix $E$. Appendix $B$ lists by code name the major properties of each code in Appendix E. Appendix C contains the code evaluation form used to determine the selected codes. Appendix $B$ contains the detailed individual discussion for each of the selected codes.

\section{REVIEW OF THEORY}

Hydraulic systems are usually classified according to the zones in which the ground water appears. These zones are known as the saturated, partially saturated and tension-saturated zones. Freeze and Cherry (1979) summarize the properties of each zone as follows:

\section{Saturated Zone:}

1. It occurs below the water table.

2. The soil pores are filled with water, and the volumetric moisture content equals the porosity.

3. The fluid pressure is greater than atmospheric, so the pressure head (measured as gage pressure) is greater than zero.

4. The hydraulic head must be measured with a piezometer.

5. The hydraulic conductivity is a constant; it is not a function of the pressure head. 
Partially Saturated Zone:

1. It occurs above the water table and above the capillary fringe.

2. The soil pores are only partially filled with water; the volumetric moisture content is less than the porosity.

3. The fluid pressure is less than atmospheric; the pressure head is less than zero.

4. The hydraulic head must be measured with a tensiometer.

5. The hydrautic conductivity and the moisture content are both functions of the pressure head.

Tension-Saturated Zone:

1. It occurs between the saturated and unsaturated zones.

2. The soil pores are filled with water.

3. The fluid pressure is less than atmospheric.

The unsaturated or partially saturated zone is also called the zone of aeration or the vadose zone. The tension-saturated zone is sometimes called the capillary fringe region.

Some authors do not distinguish between the tension-saturated zone and the saturated zone since both are saturated. Since our primary interest is in the unsaturated zone, we will not be particularly concerned with the tensionsaturated zone. An excellent discussion of the three zones is given by de Laat (1980).

Ground-water models are generally based on one or more partial differential equations. These equations are derived by combining mathematical statements for the conservation of mass and energy with constitutive equations relating these statements to measureable quantities such as pressure, temperature and concentration. These partial differential equations are the basic equations of ground-water flow and transport. Ground-water flow involves the three space variables and the time variable.

In the general case a set of partial differential equations are used to describe subsurface movement under partially saturated conditions. The equations of interest here are usually labeled the flow, transport and the energy equations. We now consider the general two-phase flow equations. In what follows the subscripts $m$, a and $w$ denote matrix, air and water, respectively. It is also convenient to let $\alpha$ denote one of $\mathrm{m}$, a or $\mathrm{w}$. 
The flow equations have the form

$$
\begin{aligned}
\frac{\partial}{\partial t}\left(\frac{\phi s_{w}}{B_{w}}\right) & =\nabla \cdot \lambda_{w} \nabla \Phi_{w}-q_{w} \\
\frac{\partial}{\partial t}\left(\phi\left[\frac{s_{a}}{B_{a}}+R \frac{s_{w}}{B_{w}}\right]\right) & =\nabla \cdot \lambda_{a} \nabla \Phi_{a}+\nabla \cdot R \lambda_{w} \nabla q_{w}-q_{a}
\end{aligned}
$$

where $\lambda_{\alpha}=\left\langle k_{r_{\alpha}}\right) /\left(B_{\alpha} \mu_{\alpha}\right)$. In the above equations $\phi$ is the porosity, $\Phi$ is the potential, $s$ is the saturation $\left(s_{a}+s_{W}=1\right)$, $B$ is a media volume factor $\left(B_{W}\right.$ is the ratio of the volume of water with air dissolved in it in situ, to the volume of water at standard conditions; $B_{a}$ is the ratio of the volume of air in situ, to the volume of the same gas at standard conditions), $R$ is the ratio of the volume of air dissolved in water to the volume of water, both at standard conditions, $k$ is the intrinsic permeability at saturation, $k_{r a}$ is the relative permeability $\left(0 \leq k_{r \alpha} \leq 1\right), \mu$ is viscosity, and $q$ is a source $/$ sink term.

There is one composition or transport equation for each constituent. They have the form

$$
\begin{aligned}
& \frac{\partial}{\partial t}\left[(1-\phi) \rho_{m} C_{m}\right]+\frac{\partial}{\partial t}\left[\phi s_{a} \rho_{a} C_{a}\right]+\frac{\partial}{\partial t}\left[\phi s_{w} \rho_{w} C_{w}\right] \\
= & \nabla \cdot\left(D_{a} \nabla C_{a}\right)+\nabla \cdot\left(D_{w} \nabla C_{w}\right)-\nabla \cdot\left(\rho_{a} C_{a} V_{a}\right)-\nabla \cdot\left(\rho_{w} C_{w} V_{w}\right)
\end{aligned}
$$

In the above equation $\rho$ is the density, $C$ is the constituent concentration, $D$ is the dispersion coefficient, and $V$ is the velocity in the appropriate phase.

The energy equation has the following form

$$
\begin{aligned}
& \frac{\partial}{\partial \bar{t}}\left(\rho_{m} s_{m} U_{m}\right)+\frac{\partial}{\partial \bar{t}}\left(\rho_{a} s_{a} U_{a}\right)+\frac{\partial}{\partial \bar{t}}\left(\rho_{w} s_{w} U_{w}\right) \\
= & \nabla \cdot \lambda_{a} H_{a} \nabla p+\nabla \cdot \lambda_{w} H_{w} \nabla p+\nabla \cdot T_{c} \nabla T-q_{T}
\end{aligned}
$$

where $U$ is internal energy, $H$ is enthalpy, $T_{C}$ is heat conduction transmicibility, $T$ is temperature, and $q_{T}$ is a heat source/sink term.

One frequently finds the saturation of water $s_{W}$, replaced with the moisture content $\theta$, defined as 


$$
\theta=\phi S_{W}
$$

in the above equations.

It should be noted that $k, k r$ and $\theta$ are functions of position, time and water pressure when in the partially saturated zone. Hence Equations (1), (2) and (3) are nonlinear.

In the completely general case, the Equations (1), (2) and (3) are coupled and must be solved simultaneously. However, in many situations the coupling may be neglected permitting the equations to be solved separately. For example, if the temperature change is unimportant, one may consider an isothermal system and thus eliminate the energy equation entirely. Another example frequently seen involves the flow equations. If the air is static and remains at atmospheric pressure and if one ignores any air dissolved in the water then the second equation of (1) drops out and the first equation becomes Richard's equation for partially saturated flow. Oden (1982) presents an excellent review of fluid flow in porous media as applied by the petroleum industry. This paper is reasonably complete and yet is presented in an elementary straight forward manner.

Most of the codes examined here are based on isothermal assumptions and use only the first equation of (1). In the general classification used here, those codes which solve the flow Equations (1) only are called flow codes. Those which solve only the composition Equations (2) are called transport codes, and those solving both the flow and composition equations are called flow-transport codes.

\section{NUMERICAL APPROXIMATIONS AND FORMULATIONS}

Various methods are used to replace the partial differential Equations (1), (2) and (3) with equations which are tractible by computational methods. The most popular methods can be classjfied into one of three categories, finite differences, integrated finite differences and finite elements. In each case, the partial differential equations are replaced with a system of algebraic equations which are then solved by a variety of techniques.

It is not intended that this section provide a complete discussion of the various numerical methods used in ground-water modeling. Only a broad discussion will be given here. A number of excellent papers exist in the literature and are available to the interested reader. Faust and Mercer (1980) give an excellent discussion of the methods used to deal with the partial differential equations of ground-water flow. Other excellent expositions are given by Narasimhan and Witherspoon (1977a, 1977b).

The discussion below is largely confined to the two-dimensional geometry. The treatment of boundary conditions is generally ignored. For illustrative purposes consider a special case of the flow equation 


$$
\nabla \cdot K \nabla h=c \frac{\partial h}{\partial t}
$$

where $K$ is the hydraulic conductivity, $h$ is the hydraulic head, and $c$ is the specific storage or specific fluid capacity.

The basic goal of numerical methods is to discretize the region of interest into appropriately small subregions then apply the same conservation principles to each subregion. One source of error in the numerical process is this discretization procedure. To minimize this error, one chooses the subregions sufficiently small so that the various descriptive properties associated with the subregion do not vary significantly over the subregion.

A number of methods are available for defining the shape and size of this subregion and its relationship to the flow region. Figure 1 shows an arbitrary flow region (a) and three methods for numerically treating it. The three methods shown are (b) finite differences, (c) integrated finite differences, and (d) finite elements. The classical finite difference method (FOM) constructs the subregions such that bounding surfaces are perpendicular to the coordinate axes and located midway between nodes as shown in Figure 1(b). For this method, the problem of mass conservation is one of equivalent velocity gradients assuming linear velocity variations within the subregion.

In applying the FDM to the required equation, a finite difference grid is imposed on the region of interest and the nodes identified. At each node, one replaces the derivatives in the partial differential equation with appropriate finite difference quotients. The end result is a difference equation which relates the unknown or variable sought at a specific node to each of its neighbors. One such equation is obtained for each node where the unknown is to be determined.

The integrated finite difference method (IFDM) utilizes a somewhat less regular grid. The region of interest is divided into smaller areas. Thomas (1973) calls these areas nodal areas, since they each contain a node which is connected to its neighbors by appropriate difference equations. Generally, the properties throughout the nodal area are taken to be those of the node itself.

In applying the IFDM to a partial differential equation, the discretizing grid is imposed on the region of interest and the nodes (and nodal areas) identified. The IFDM is not applied directly to the partial differential equation. It is applied to an integral equation obtained by spatially integrating over a conveniently small finite subregion $\Gamma$, the divergence theorems permits the replacement of the area integral by a line integral over the boundary $\partial \Gamma$ of $I$. Thus from (5) one has

$$
c A \frac{\partial h}{\partial t}=\int_{\partial \Gamma} K_{\nabla h} \cdot \hbar d s
$$




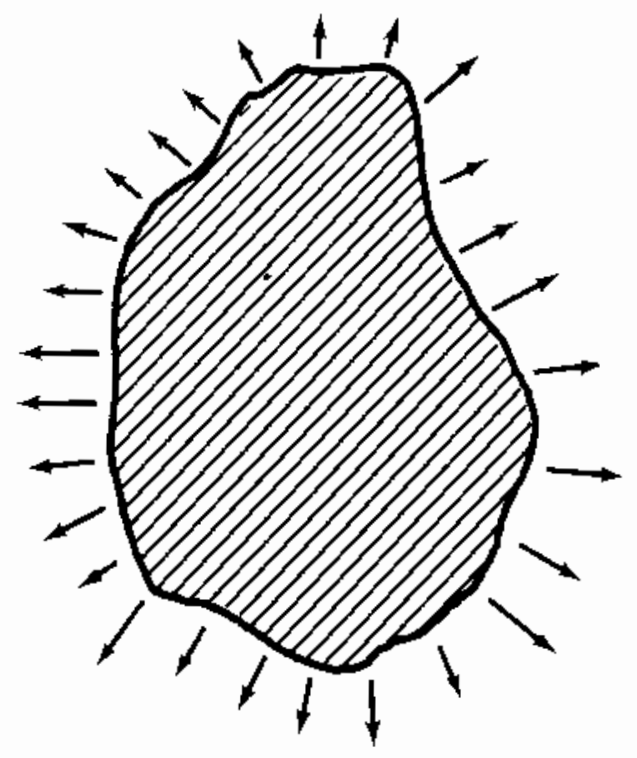

(a) THEORETICAL FLOW REGION

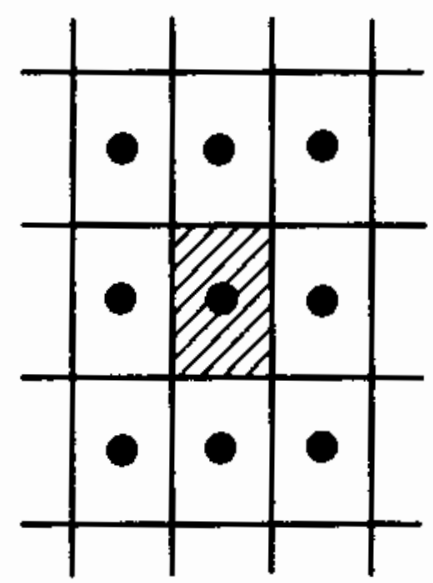

(b) FINITE DIFFERENCE

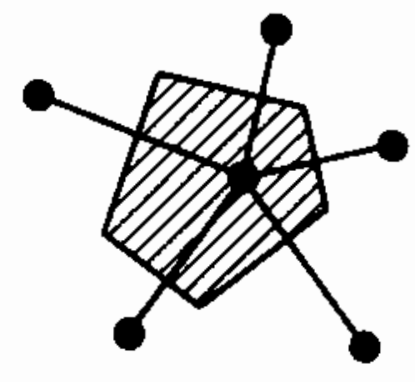

(c) INTEGRATED FINITE DIFFERENCES

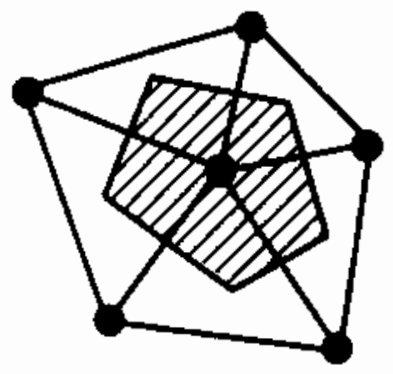

(d) FINITE ELEMENTS

FIGURE 1. Relationships Between Various Discretizations and Approximations Used in Numerical Models 
where $A$ is the area of $\Gamma$ and $\vec{n}$ is a unit vector directed to the outside of $\Gamma$ and perpendicular to the boundary of $\Gamma$.

The region $\Gamma$ in (6) is taken to be an arbitrary nodal area produced by the grid. The central idea here is to discretize the total flow domain into conveniently small subdomains or nodal areas and perform a mass balance on each small area as required.

The nodal locations are chosen such that the lines joining adjacent nodes are perpendicular to the intervening boundary interface. See Figure $1(c)$. Thus, the normal gradient at the boundary interface may be replaced with finite differences and the line integral in (6) evaluated. Replacing the time derivative with a finite difference produces a difference equation similar to that obtained by the FDM, relating the node to each of its neighbors.

The IFDM enables one to treat problems with complicated boundaries. The main drawback of the method is that, since it is designed around the normal gradients, it does not directly allow for the evaluation of tangential gradients at the interfaces.

Like the IFDM, the finite element method (FEM) utilizes an arbitrary grid, and is applied to an integral equation rather than a differential equation. The FEM equations are sometimes developed from variational principles but we shall confine the discussion here to the method of weighted residuals in general and more specifically to the Galerkin method using triangular elements where a linear approximations is used.

In the Galerkin method, the partial differential equation is first multiplied by an appropriate weighting function and then integrated over the specified region. The weighting functions are also used to approximate the dependent variables in that they are interpolation functions, i.e., basis functions.

The region of interest is discretized into a system of triangles as shown in Figure 1(d). More general shapes may be used but for this discussion we consider only triangles. The triangles are called elements, the vertices of the elements are called nodes. The nodes are then numbered in some order. We approximate the dependent variable, the hydraulic head in our example, by an interpolation function

$$
h(x, t) \simeq \sum_{m} \xi_{m}(x) h\left(x_{m}, t\right)
$$

where the sum is over a 11 nodes $m$. The variable $x$ represents a two componented vector. The functions $h\left(x_{m}, t\right)$ represent the as yet undetermined head values at node $m$ which are dependent on time $t$. The interpolation functions $\xi_{m}\left(x_{m}\right)$ $=1$ and $\xi_{m}\left(x_{n}\right)=0$ for $n \neq m$. The basis function $\xi_{m}$ varies linearly over the 
elements which have node $m$ as a vertex. Usually $\xi_{m}(x)$ is defined as zero for any point $x$ which is not in an element having the node $m$ as a vertex.

Substituting (7) for $h$ in (5), multiplying both sides of the resulting equation by $\xi_{n}(x)$ and integrating over the entire region of interest yields one equation. This equation is further modified by mathematical transformations to yield a first-order differential equation in time, which is linear in the $h\left(x_{m}, t\right)$ where the node $m$ is a neighbor of node $n$, i.e., the elements $m$ share the node $n$ as a vertex. The coefficients of the $h\left(x_{m}, t\right)$ are evaluated either analytically or numerically. This procedure is repeated for all nodes $n$ which, when boundary conditions are included yield a system of first-order differential equations in time. The time derivations are then replaced by finite differences to produce a system of algebraic equations.

The end-product of each method, FDM, IFDM and FEM is a system of algebraic equations where the unknowns are the hydraulic head at the node points. A discussion of the pros and cons of these methods appear in Faust and Mercer (198D).

Referring back to Item 5 of the list of properties characterizing the unsaturated zone given above, the hydraulic conductivity $k$, and the water content $\theta$, are functions of the pressure head $\psi$. This means that in the unsaturated zone the flow and composition equations are non-linear. This also means that the approximating algebraic equations are non-linear. The usual method of dealing with this complication is to make further approximation by linearizing the algebraic system and/or iterating to a solution.

To complicate matters even more the functional relationships between the hydraulic conductivity $K$, and the capillary pressure $\psi$, and the moisture content $\theta$ are not uniquely defined. In fact, there is considerable evidence that $K$ is a unique result of $\theta$, but $\theta$ and $\psi$ may not be uniquely related. Empirical results show that during the wetting part of the wetting-drying cycle seen in the unsaturated zone the relationship of $\psi$ and $\theta$ is uniquely defined. Similarly, the relationship is unique for the drying part of the cycle. The usual treatment is to tabulate $\psi$ as a function of $\theta$ for each part of the cycle. The function values are then obtained by interpolation techniques.

Another source of non-7inearity is the source/sink term q of Equations (1), (2) and (3). The processes of evapotranspiration are introduced through this term. These processes include plant growth and the atmospheric-soil interface and are also sometimes included through empirical functions.

Stochastic models of ground-water systems have appeared recently (Narasimhan and Witherspoon 1977b). Two such models are included in this study. These models are based on assumptions from probability theory. In a stochastic model one begins with a partial differential equation where certain parameters and/or boundary and initial conditions are assumed to have uncertainties associated with them. The solution to such an equation is not one single solution but rather a distribution of solutions. This distribution is generally difficult to obtain and so the usual procedure is to settle for one or two moments of 
the distribution. That is one obtains the average or mean solution and, if possible, a variance which measures how closely the distribution of solutions clusters around the average solution.

The stochastic differential equation is approximated by another differentiat equation wich accounts for all such second order variations (that is the approximation is second order). This epproximate differential equation is obtained subject to the original differential equation satisfying a certain "smallness" criterion, that is "the differential operator must be small in norm" (Gibbs 1980).

The approximate differential equation is then replaced with an expectation equation that the solution must satisfy. The mean solution of the expectation equation is then found by standard numerical methods. Finite difference methods are preferred because of the simple form of the approximating algebraic equations, though this is not a requirement (Oster and Gibbs 1981). In addition, the final relationship for the mean solution may require that deviations from the mean be relatively small. See for example Gibbs (1980).

\section{DATA REQUIREMENTS}

The data required for each code depends on the assumptions upon which the model is based. In general, the input data must include some or all of the following values, functions, etc.

- Program control parameters

1. Identification data

2. Auxiliary data file options

3. Output media options

4. Print out frequency

5. Interrupt-restart options

6. Solution method selection options

- Geometry parameters for discredization grid definition

- Initial distribution values for:

1. Pressure head

2. Solute concentrations

3. Moisture content

4. Temperature/energy/enthalpy

- Boundary conditions as functions of space and time for:

1. Pressure head

2. Ground water and solute flux

3. Temperature/energy/enthalpy 
- Media properties as functions of space

1. Permeabilities

2. Hydraulic conductivity (tensor)

3. Moisture capacity

4. Porosity

5. Thermal conductivity

- Fluid properties as functions of space

1. Viscoscity

2. Density

3. Mass capacity

- Source/sink functional relationships in both space and time:

1. Plant root and leaf growth models

2. Recharging functions, e.g., rainfall, irrigation

3. Evaporation mode1s

4. Geothermal and solar sources

If the model is for the solute transport problem only, one also requires a pore velocity field description as input. The usual method is to obtain this field of data by calculating it with a code to solve Equation (1).

In addition to the data required by the deterministic codes, the stochastic models require additional data about uncertainty in any stochastic parameters. This uncertainty is usually in the form of covariance functions. Such functions may be generated by the use of kriging techniques (Devary and Doctor 1981).

\section{PRACTICALITIES}

The ground-water modeler is confronted by problems which have been well described by Bellman (1957) as "To predict quantitatively, one must have a ... mathematical model. It seems reasonable to suppose that the more realistic this mathematical model, the more accurate the prediction.

"There is, however, a point of diminishing returns. The actual world is extremely complicated... If we attempt to include too many features of reality in our mathematical model, we find ourselves engulfed by complicated equations containing unknown parameters and unknown functions. The determination of these functions leads to even more complicated equations with even more unknown parameters and functions, and so on."

At one extreme, the modeler might use the one-dimensional Richard's equation (Freeze and Cherry 1979) and at the other he might use one of the very general three-dimensional codes which have much greater data demands. The user must decide whether his available data justify the cost and effort of using a sophisticated model. One is reminded of Hamming's statement, "The purpose of computing is insight, not numbers" (Hamming 1962). 
In practice, one might use a simple model, involving little expense, to gain sufficient insight to narrow the scope of the problem to a point when a more expensive model can be used. It is entirely possible that the simple model will yield all the results required.

Another problem frequently faced is the question of reliability of the output. There are a number of ways to obtain the sensitivity of output to changes in the input parameters. One might, for example, make many computer runs varying different input parameters to obtain insight into the bounds on the output. Another alternative is to use one of the stochastic codes to produce in one calculation the mean solution and its variance. The decision of which course to follow will be made based on many input factors including avajlability of initial data.

The three popular methods FDM, IFDM and FEM are not without their problems. With conventional versions of these methods one finds solutions which show numerical dispersion and numerical oscillation. Numerical dispersion produces results which are blurred or smeared while oscillatory solutions can contain such results as large negative concentrations etc. Usually the numerical dispersion is associated with the finite difference methods while numerical oscillation is associated with the finite element method, however, depending upon the approximation used for the convection term, both methods can yieid solutions exhibiting either type of behavior.

The method of characteristics (MOC) has been used as a means of avoiding the above stated problems. This method is not without its problems as well. The MOC is usually used in conjunction with a finite difference method though this is not a requirement. In applying the MOC one replaces the transport equation with an equivalent system of ordinary differential equations. The curves in space along which this system of ordinary differential equations hold are known as the characteristic curves, hence the name, method of characteristics.

The MOC is particularly useful when hydrodynamic dispersion is negliglble as this method has minimal numerical dispersion. However the determination of points along the characteristic curves and iterating to include the dispersive parts of the transport equation can be fairly expensive (Faust and Mercer 1980).

\section{COMPILING THE LIST OF CODES}

Starting with the list of unsaturated flow and transport models given by Bachmat et al. (1980), and conducting an extensive literature search along with telephone and mail correspondence with recognized leading individuals in the field produced most of the models studied here. Finally some important items were derived from the Symposium on Unsaturated Flow and Transport Modeling held in Seattle on March 23-24, 1982. The proceedings of this symposium appear in Nelson et al. (1982).

A short summary for each code investigated is contained in Appendix $E$. These codes are listed there according to an assigned sequence number. Each 
of these codes has a name associated with it. Appendix A contains a cross index by code name to Appendix $E$. That is given a code name, one obtains the sequence number from Appendix $A$ to locate the short summary page in Appendix $E$.

\section{PREFERRED CODES}

The models 1 isted in Appendix $E$ have been ranked so as to determine which are potentially more useful than others. The ranking procedure is based on:

- Documentation

- Applications

- Code Availability.

Documentation is considered in three forms. First, there is a description of the model which includes both the physical principles used and the resulting mathematical statement of the process being modeled. The second form of documentation is one or more publications describing applications of the model to actual problems. The third form of documentation is a user's manual. Included within the user's manual are detailed instructions on data requirements and data preparation, and a listing of the code along with some sample problems with the solutions. In several cases, all three forms appear under the same cover.

Some models have been applied to laboratory experiments only. Others have been applied to field data on various occasions. In general, the more times a model has been applied the higher ranking it should receive. Unfortunately, there is no sure way of knowing how many times a code had been successfully appiied. Appendix C contains the form, Table C.l, used to rank the codes. In determining the entries in Table C.1, an $X$ was placed in the appropriate applications column if the author claimed it had been applied to experimental or field data, with no question of how many times the application may have been made. In general, a model for which a code was available either in the form of computer listings, punched cards or magnetic tape was ranked higher than those for which no code is available. Any code known to be proprietary and for which additional information is lacking was considered as though the code was not available.

By this ranking procedure, several models have been identified as candidates for further study. This further study would entai] such things as application to benchmark problerns. The codes selected here are given in Table 1. Appendix $D$ contains an extensive description for each code listed in this table.

An examination of Table 1 and Table C.l reveals the existence of models not included in Table 1 but having as many $X$ 's as those so listed. Some of these models are listed in Table 2 and are discussed in the next section. The other codes were not selected for a number of reasons. In some cases the only information available is given by Bachmat et a1. (1980). Data for the Bachmat report was collected prior to 1978. When the current information consisted of only this dated material it was assumed that the code was preliminary and hence was not included in the selected set. This was the case for Code Nos. 7 , 
TABLE 1. Codes Selected for Further Study

\begin{tabular}{|c|c|c|c|}
\hline $\begin{array}{c}\text { Code } \\
\text { Number }\end{array}$ & Code Name & Type & Principal Contact \\
\hline $\begin{array}{r}4 \\
9 \\
10 \\
11 \\
18\end{array}$ & $\begin{array}{l}\text { TRUST } \\
\text { SEGOL } \\
\text { UNSAT1D } \\
\text { SUMATRA-1 } \\
\text { TARGET }\end{array}$ & $\begin{array}{l}\text { Flow } \\
\text { Flow/Transport } \\
\text { Flow } \\
\text { Flow/Transport } \\
\text { Flow/Transport }\end{array}$ & $\begin{array}{l}\text { Narasimhan } \\
\text { Segol } \\
\text { Bond } \\
\text { van Genuchten } \\
\text { Sharma }\end{array}$ \\
\hline $\begin{array}{l}24 \\
25 \\
26 \\
45 \\
54\end{array}$ & $\begin{array}{l}\text { FEMWATER } \\
\text { FEMWASTE } \\
\text { UNSAT2 } \\
\text { VS2D } \\
\text { MLTRAN }\end{array}$ & $\begin{array}{l}\text { Flow } \\
\text { Transport } \\
\text { Flow } \\
\text { Flow } \\
\text { Transport }\end{array}$ & $\begin{array}{l}\text { Yeh } \\
\text { Yeh } \\
\text { Neuman } \\
\text { Lappala } \\
\text { Reisenauer }\end{array}$ \\
\hline
\end{tabular}

TABLE 2. Codes of Potential Interest But Which Lack Documentation

\section{Code}

Number

5

8

21

29

31

32

37

38

40

41

42

43

49

50

55
Code Name

FLUMP

VERGE

MCCANN

ALPURS

COOK

GPSIM

TS\&E

AMOCO

CMG

BETAI I

SCC

SHELL

SHAMTU

PORES

WAFE

TRACR3D
Type

Flow

Flow

Flow/Transport

Flow

Flow

Flow

Flow

Flow

Flow

Flow

Flow

flow

Flow/Transport

Flow

Flow

Flow
Principal Contact

Narasimhan, Neuman

Verge, Frind

McCann, Wiles

Bansa 1, Harper, McDonald

Cook

Exxon

Technical Software and Engineering

AMOCO

CMG

Intercorp.

SCC

Shell 0il Company

Vauclin

UKAEA

Travis

Travis

15, and 47. Though not included in the Bachmat report, Code No. 27 was not selected for similar reasons. Code No. 11 contains Code No. 28 as the flow calculation module, hence No. 28 was not included in either Table 1 or 2. 
There are several other codes which might well have been included in Table 1 but were excluded because of one or more reasons. The primary reason is lack of published information about the code. In some cases the only information available is listed by Bachmat et a1. (1980). Other codes with little published information are the proprietary codes. In all cases the proprietary nature of a code results in minimal disclosure of details to the public. Only one code listed in Table 1 claims the ability to solve the energy Equation (3). That code is TARGET. The nature of codes held by the petroleum industry may well have this capability too (Oden 1982).

Table 2 lists those codes from Tables B.1, B.2 and B.3 which might have been listed in Table 1 had more documentation been available. It is interesting that only two codes listed in Table 2 have both flow and transport capabilities. 


\section{REFERENCES}

Bachmat, Y., J. Bredehoeft, B. Andrews, D. Holtz, and S. Sebastian. 1980. Ground-Water Mangement: The Use of Numerical Models. American Geophysical Union, Water Resources Monograph 5 .

Bellman, R. 1957. Dynamic Programming. Princeton University Press, Princeton, New Jersey.

Devary, J. L., and P. G. Doctor. 1981. "Geostatistical Modeling of Pore Velocity," PNL-3789, Pacjfic Northwest Laboratory, Richland, Washington.

Faust, C. R., and J. W. Mercer. 1980. "Ground-Water Modeling: Numerica 1 Method," Ground Water 18(4):395-409.

Freeze, R. A., and J. A. Cherry. 1979. Ground Water, Prentice-Hall.

Gibbs, A. G. 1980. "A Perturbation Method for Stochastic Operator Difference Equations," submitted for publication in SIAM Journal on Scientific and Statistical Computing.

Hamming, R. W. 1962. Numerical Methods for Scientists and Engineers. McGraw-Hill Book Company, Inc., New York, New York.

deLaat, P. J. M. 1980. "Model for Unsaturated Flow Above a Shallow WaterTable, Applied to a Regional Subsurface Flow Problem," Agricultural Research Report 895, Centre for Agricultural Pub1ishing and Documentation, Wageninger, The Netherlands.

Narasimhan, T. N., and P. A. Witherspoon. 1977a. "An Integrated Finite Difference Method for Analyzing Flujd Flow in Porous Media." Water Resources Research 12(1):57-64.

Narasimhan, T. N., and P. A. Witherspoon. 1977b. "Recent Developments in Modeling Ground-Water Systems," LBL-5209, Lawrence Berkeley Laboratory, University of California/Berkeley.

Nelson, R. W., G. W. Gee and E. M. Arnold, Editors. 1982. "Proceedings of the Symposium on Unsaturated Flow and Transport Modeling," NUREG/CP-0030, PNL-SA-10325. March 23-24, Seattle, Washington.

Odeh, A. S. 1982. "An Overview of Mathematical Modeling of the Behavior of Hydrocarbon Reservoirs," SIAM Review 24(3):263-273.

Oster, C. A., and A. G. Gibbs. 1981. "A Numerical Procedure for Obtaining the Mean Solution and Variance of the Two-Dimensional Stochastic Convection Equation, PNL-SA-9878, Pacific Northwest Laboratory, Richland, Washington. (Submitted for publication in Advances in Water Resources.) 
Siefken, D. L. 1982. "Introduction Remarks," in Proceedings of the Symposium on Unsaturated Flow and Transport Modeling, March 23-24, 1982, Seattle, Washìngton. R. W. Nelson, G. W. Gee and E. M. Arnold, Editors, NUREG/CPD030, PNL-SA-10325.

Thomas, R. G. 1973. "Ground-Water Models." Irrigation and Draingage Paper 21, Food and Agriculture Organization of the United Nations, Rome. 192 pp. 

APPENDIX A

PARTIALLY SATURATED AND MULTIPHASE CODES INVENTORIED, INDEXED BY CODE NAME AND TYPE 
TABLE A.1. Index by Code Name

Code

\begin{tabular}{|c|c|c|c|}
\hline Code Name & Number & Code & Principal Contact (s) \\
\hline $\begin{array}{l}\text { ALPURS } \\
\text { AMOCO } \\
\text { BACHMAT } \\
\text { BETAI I } \\
\text { BRUTSAERTI }\end{array}$ & $\begin{array}{r}21 \\
37 \\
6 \\
40 \\
33\end{array}$ & $\begin{array}{l}\text { Flow } \\
\text { Flow } \\
\text { Transport } \\
\text { Flow } \\
\text { Flow }\end{array}$ & $\begin{array}{l}\text { Bansa 1, Harper, McDonald } \\
\text { AMOCO } \\
\text { Bachmat, Chetboun } \\
\text { Intercomp } \\
\text { Brutsaert }\end{array}$ \\
\hline $\begin{array}{l}\text { BRUTSAERT2 } \\
\text { CMG } \\
\text { COOK } \\
\text { DELAAT } \\
\text { DUGUID-REEVES }\end{array}$ & $\begin{array}{l}39 \\
38 \\
29 \\
48 \\
19\end{array}$ & $\begin{array}{l}\text { Flow } \\
\text { Flow } \\
\text { Flow } \\
\text { Flow } \\
\text { Transport }\end{array}$ & $\begin{array}{l}\text { Brutsaert } \\
\text { CMG } \\
\text { Cook, Jacoby, Ramesh } \\
\text { de Laat, van der Akker } \\
\text { Duguid, Reeves }\end{array}$ \\
\hline $\begin{array}{l}\text { FECTRA } \\
\text { FEMWASTE } \\
\text { FEMWATER } \\
\text { FLUMP } \\
\text { GANDALF }\end{array}$ & $\begin{array}{r}17 \\
25 \\
24 \\
5 \\
30\end{array}$ & $\begin{array}{l}\text { Transport } \\
\text { Transport } \\
\text { Flow } \\
\text { Flow } \\
\text { Flow }\end{array}$ & $\begin{array}{l}\text { Baca, Lu, Yee } \\
\text { Yeh, Ward } \\
\text { Yeh, Ward } \\
\text { Narasimhan, Neuman } \\
\text { Morrison }\end{array}$ \\
\hline $\begin{array}{l}\text { GPSIM } \\
\text { HANKS } \\
\text { MARINO } \\
\text { MCCANN } \\
\text { MLTRAN }\end{array}$ & $\begin{array}{r}31 \\
1 \\
53 \\
20 \\
54\end{array}$ & $\begin{array}{l}\text { Flow } \\
\text { Flow/transport } \\
\text { Flow/transport } \\
\text { Flow/transport } \\
\text { Transport }\end{array}$ & $\begin{array}{l}\text { Spillette, Hillestad, Stone } \\
\text { Hanks, Childs } \\
\text { Marino } \\
\text { McCann, Wiles } \\
\text { Reisenauer, Nelson, Newbill }\end{array}$ \\
\hline $\begin{array}{l}\text { MMT-DPRW } \\
\text { MOBIDIC } \\
\text { MOMOLS } \\
\text { NMODEL } \\
\text { PORES }\end{array}$ & $\begin{array}{l}44 \\
14 \\
52 \\
15 \\
49\end{array}$ & $\begin{array}{l}\text { Transport } \\
\text { Flow/transport } \\
\text { Flow } \\
\text { Flow/transport } \\
\text { Flow }\end{array}$ & $\begin{array}{l}\text { Foote, Serne } \\
\text { Couchat, Le Cardinal, Moutonnet } \\
\text { Rojstaczer } \\
\text { Selim, Davidson } \\
\text { UKARA }\end{array}$ \\
\hline $\begin{array}{l}\text { REEVES-DUGUID } \\
\text { SCAT1D }(a) \\
\text { SCAT2D }(a) \\
\text { SEGOL } \\
\text { STAMTU }\end{array}$ & $\begin{array}{r}22 \\
35 \\
36 \\
9 \\
43\end{array}$ & $\begin{array}{l}\text { Flow } \\
\text { Transport } \\
\text { Transport } \\
\text { Flow/transport } \\
\text { Flow/Transport }\end{array}$ & $\begin{array}{l}\text { Reeves, Duguid } \\
\text { Oster } \\
\text { Oster } \\
\text { Segol } \\
\text { Vauci in, Haverkamp, Hamon }\end{array}$ \\
\hline $\begin{array}{l}\text { SHELL } \\
\text { SCC } \\
\text { STGWT /MOGWT } \\
\text { SUM-2 } \\
\text { SUMATRA-1 }\end{array}$ & $\begin{array}{l}42 \\
41 \\
27 \\
46 \\
11\end{array}$ & $\begin{array}{l}\text { Flow } \\
\text { Flow } \\
\text { Flow } \\
\text { Flow } \\
\text { Flow/Transport }\end{array}$ & $\begin{array}{l}\text { She } 11 \text { oil Company } \\
\text { SCC } \\
\text { de Smedt, van der Beken } \\
\text { de Laat, van der Akker } \\
\text { van Genuchten }\end{array}$ \\
\hline $\begin{array}{l}\text { SUPERMOCK } \\
\text { TARGET } \\
\text { TRACR3D } \\
\text { TRANS } \\
\text { TRANSONE }\end{array}$ & $\begin{array}{l}47 \\
18 \\
55 \\
23 \\
12\end{array}$ & $\begin{array}{l}\text { Flow } \\
\text { Flow/Transport } \\
\text { Flow } \\
\text { Flow/Transport } \\
\text { Flow/Transport }\end{array}$ & $\begin{array}{l}\text { Reed, Bedinger, Terry } \\
\text { Dames \& Moore } \\
\text { Travis } \\
\text { Walker, Sabey, Hampton } \\
\text { Van Genuchten }\end{array}$ \\
\hline
\end{tabular}

(a) Stochastic code. 
TABLE A.1. (contd)

\begin{tabular}{|c|c|c|c|}
\hline Code Name & $\begin{array}{c}\text { Code } \\
\text { Number }\end{array}$ & Code & Principal Contact(s) \\
\hline $\begin{array}{l}\text { TRANSTWO } \\
\text { TRIPM } \\
\text { TRMWDL } \\
\text { TRUST } \\
\text { TS\&E }\end{array}$ & $\begin{array}{r}13 \\
51 \\
2 \\
4 \\
32\end{array}$ & $\begin{array}{l}\text { Flow/transport } \\
\text { Flow } \\
\text { Transport } \\
\text { Flow } \\
\text { Flow }\end{array}$ & $\begin{array}{l}\text { Shapiro } \\
\text { Gureghian } \\
\text { Av-Ron } \\
\text { Marasimhan } \\
\text { Technical Software and Engineering }\end{array}$ \\
\hline $\begin{array}{l}\text { UNFLW } \\
\text { UNFLOW } \\
\text { UNSAT1 } \\
\text { UNSAT2 } \\
\text { UNSATID }\end{array}$ & $\begin{array}{r}3 \\
7 \\
28 \\
26 \\
10\end{array}$ & $\begin{array}{l}\text { Flow/Transport } \\
\text { Flow } \\
\text { Flow } \\
\text { Flow } \\
\text { Flow }\end{array}$ & $\begin{array}{l}\text { Kapuler } \\
\text { Pickens } \\
\text { van Genuchten } \\
\text { Neuman, Feddes, Bresler } \\
\text { Bond, Gupta }\end{array}$ \\
\hline $\begin{array}{l}\text { VERGE } \\
\text { VS2D } \\
\text { WAFE } \\
\text { WATSOL } \\
\text { WHC }\end{array}$ & $\begin{array}{r}8 \\
45 \\
50 \\
16 \\
34\end{array}$ & $\begin{array}{l}\text { Flow } \\
\text { Flow } \\
\text { Flow } \\
\text { Flow/transport } \\
\text { Flow/transport }\end{array}$ & $\begin{array}{l}\text { Verge, Frind } \\
\text { Lappala } \\
\text { Travis } \\
\text { Gaudet, Haverkemp } \\
\text { Crooks, Yeh }\end{array}$ \\
\hline
\end{tabular}


TABLE A.2. Flow Codes Indexed By Code Name

\begin{tabular}{|c|c|c|}
\hline Code Name & $\begin{array}{c}\text { Code } \\
\text { Number }\end{array}$ & Principal Contact \\
\hline $\begin{array}{l}\text { ALPURS } \\
\text { AMOCO } \\
\text { BETAI I } \\
\text { BRUTSAERT1 } \\
\text { BRUTSAERT2 }\end{array}$ & $\begin{array}{l}21 \\
37 \\
40 \\
33 \\
39\end{array}$ & $\begin{array}{l}\text { Bansal, Harper, McDonald } \\
\text { AMOCO } \\
\text { Intercomp } \\
\text { Brutsaert } \\
\text { Brutsaert }\end{array}$ \\
\hline $\begin{array}{l}\text { CMG } \\
\text { COOK } \\
\text { DELATT } \\
\text { FEMWATER } \\
\text { FLUWP }\end{array}$ & $\begin{array}{r}38 \\
29 \\
48 \\
24 \\
5\end{array}$ & $\begin{array}{l}\text { CMG } \\
\text { COOK, Jacoby, Ramesh } \\
\text { de Laat, van der Akker } \\
\text { Yeh, Ward } \\
\text { Narashimhan, Neuman }\end{array}$ \\
\hline $\begin{array}{l}\text { GANDALF } \\
\text { GPSIM } \\
\text { MOMOLS } \\
\text { PORES } \\
\text { REEVES-DUGUID }\end{array}$ & $\begin{array}{l}30 \\
31 \\
52 \\
49 \\
22\end{array}$ & $\begin{array}{l}\text { Morrison } \\
\text { Spillette, Hillestad, Store } \\
\text { Rojstoczer } \\
\text { UKARA } \\
\text { Reeves, Duguid }\end{array}$ \\
\hline $\begin{array}{l}\text { SHELL } \\
\text { SSC } \\
\text { STGWT/MOGWT } \\
\text { SUM2 } \\
\text { SUPERMOCK }\end{array}$ & $\begin{array}{l}42 \\
41 \\
27 \\
46 \\
47\end{array}$ & $\begin{array}{l}\text { Shell oil Company } \\
\text { SSC } \\
\text { de Smedt, van der Beken } \\
\text { de Laat, van der Akker } \\
\text { Reed, Bedinger, Terry }\end{array}$ \\
\hline $\begin{array}{l}\text { TRACR3D } \\
\text { TRIPM } \\
\text { TRUST } \\
\text { TS\&E } \\
\text { UNFLOW }\end{array}$ & $\begin{array}{r}55 \\
51 \\
4 \\
32 \\
7\end{array}$ & $\begin{array}{l}\text { Travis } \\
\text { Gureghian } \\
\text { Narasimhan } \\
\text { Technical Software and Engineering } \\
\text { Pickens }\end{array}$ \\
\hline $\begin{array}{l}\text { UNSAT1 } \\
\text { UNSAT2 } \\
\text { UNSAT1D } \\
\text { VERGE } \\
\text { VS2D } \\
\text { WAFE }\end{array}$ & $\begin{array}{r}28 \\
26 \\
10 \\
8 \\
45 \\
50\end{array}$ & $\begin{array}{l}\text { van Genuchten } \\
\text { Neuman, Feddes, Bresler } \\
\text { Bond, Gupta } \\
\text { Verge, Frind } \\
\text { Lappala } \\
\text { Travis }\end{array}$ \\
\hline
\end{tabular}


TABLE A.3. Transport Codes Indexed by Code Name Code

\begin{tabular}{|c|c|c|}
\hline Code Name & Number & Principal Contact \\
\hline $\begin{array}{l}\text { BACHMAT } \\
\text { DUGUID-REVEES } \\
\text { FECTRA } \\
\text { FEMWASTE } \\
\text { MLTRAN }\end{array}$ & $\begin{array}{r}6 \\
19 \\
17 \\
25 \\
54\end{array}$ & $\begin{array}{l}\text { Bachmat, Chetboun } \\
\text { Duguid, Reeves } \\
\text { Baca, Lu, Yee } \\
\text { Yeh, Ward } \\
\text { Reisenauer, Nelson, Newbill }\end{array}$ \\
\hline $\begin{array}{l}\text { MMT-DPPW } \\
\text { SCAT1D }(a) \\
\text { SCAT2D } \\
\text { TRNMDL }\end{array}$ & $\begin{array}{r}44 \\
35 \\
36 \\
2\end{array}$ & $\begin{array}{l}\text { Foote, Serne } \\
\text { Oster } \\
\text { Oster } \\
\text { AV-Ron }\end{array}$ \\
\hline
\end{tabular}

(a) Stochastic code.

TABLE A.4. Flow/Transport Codes Indexed by Code Name

\begin{tabular}{|c|c|c|}
\hline Code Name & $\begin{array}{c}\text { Code } \\
\text { Number }\end{array}$ & Principal Contact \\
\hline $\begin{array}{l}\text { HANKS } \\
\text { MARINO } \\
\text { MCCANN } \\
\text { MOBIDIC } \\
\text { NMODEL }\end{array}$ & $\begin{array}{l}1 \\
53 \\
20 \\
14 \\
15\end{array}$ & $\begin{array}{l}\text { Hanks, Childs } \\
\text { Marino } \\
\text { McCann, Wiles } \\
\text { Couchat, Le Cardinal, Moutonnet } \\
\text { Selim, Davidson }\end{array}$ \\
\hline $\begin{array}{l}\text { SEGOL } \\
\text { SHAMTU } \\
\text { SUMATRA-1 } \\
\text { TARGET } \\
\text { TRANS }\end{array}$ & $\begin{array}{l}9 \\
43 \\
11 \\
18 \\
23\end{array}$ & $\begin{array}{l}\text { Segol } \\
\text { Vauclin, Haverkamp, Hamon } \\
\text { vari Genuchten } \\
\text { Dames \& Moore } \\
\text { Walker, Sabey, Hampton }\end{array}$ \\
\hline $\begin{array}{l}\text { TRANSONE } \\
\text { TRANSTWO } \\
\text { UNFLW } \\
\text { WATSOL } \\
\text { WHC }\end{array}$ & $\begin{array}{r}12 \\
13 \\
3 \\
6 \\
34\end{array}$ & $\begin{array}{l}\text { van Genuchten } \\
\text { Shapiro } \\
\text { Kapuler } \\
\text { Gaudet, Haverkemp } \\
\text { Crooks, Yeh }\end{array}$ \\
\hline
\end{tabular}


APPENDIX B

SUMMARY CHARTS OF INVENTORIED CODES 


\section{TABLE B.1. Flow Code Summary}

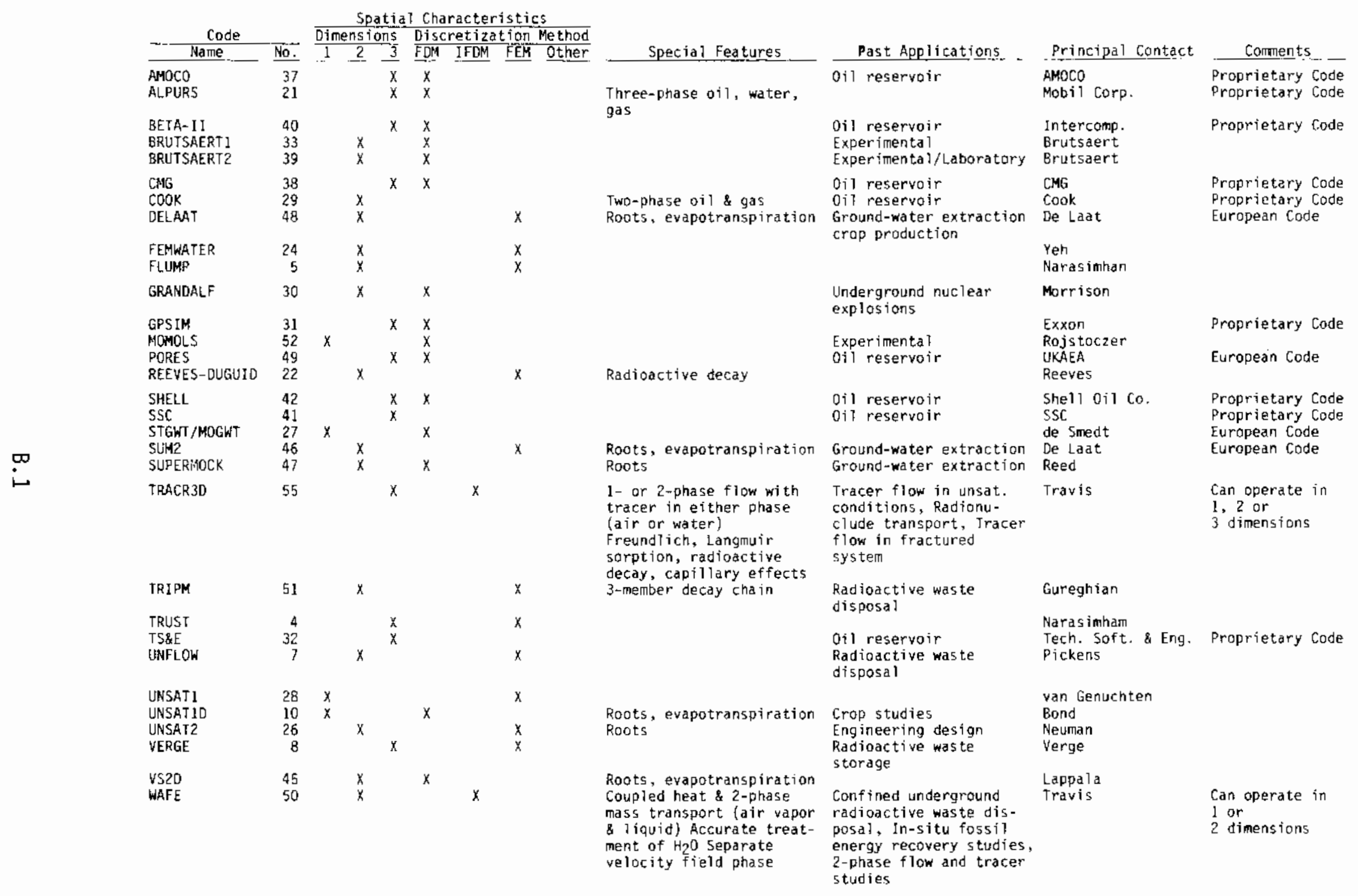

KEY: $\quad$ FOM $=$ finite difference method.

IFDM = integrated finite difference method FEM = fintte element method. 
TABLE B.2. Transport Code Summary

\begin{tabular}{|c|c|c|c|c|c|c|c|c|c|}
\hline Code & №. & $\frac{0 \text { imensions }}{1} \frac{2}{3}$ & $\begin{array}{l}\text { Discretiva } \\
\text { FoM IFDM }\end{array}$ & $\begin{array}{l}\text { then } \\
\text { ation } \\
\text { FEM }\end{array}$ & $\begin{array}{l}\text { Method } \\
\text { Mther }\end{array}$ & _...Special Feztures & Past Applications & Principal contact & Corments \\
\hline $\begin{array}{l}\text { BACHMAT } \\
\text { DUGUID-REEVES }\end{array}$ & $\begin{array}{r}6 \\
19\end{array}$ & $x$ & $x$ & $x$ & & $\begin{array}{l}\text { Surface/ground water } \\
\text { Absorption \& decay }\end{array}$ & & $\begin{array}{l}\text { Backnat } \\
\text { Duguid }\end{array}$ & $\begin{array}{l}\text { Middle-east Code } \\
\text { Compatible with } \\
\text { Code No. } 22\end{array}$ \\
\hline $\begin{array}{l}\text { FECTRA } \\
\text { FEMKASTE }\end{array}$ & $\begin{array}{l}17 \\
25\end{array}$ & $\begin{array}{l}x \\
x\end{array}$ & & $\begin{array}{l}x \\
x\end{array}$ & & 1st-order decay, sorption & & $\begin{array}{l}\text { Baca } \\
\text { Yeh }\end{array}$ & $\begin{array}{l}\text { Compatible with } \\
\text { Code No. } 22\end{array}$ \\
\hline MLTRAN & 54 & $x$ & & $x$ & & & & Reisenauer & $\begin{array}{l}\text { Compatible with } \\
\text { Code No. } 44\end{array}$ \\
\hline MMT-DPRW & 44 & $x$ & & & $x$ & & Ground-water studies & sirmons & $\begin{array}{l}\text { Discrete Parcel } \\
\text { Random Walk }\end{array}$ \\
\hline $\begin{array}{l}\text { SCATID } \\
\text { SCAT2D } \\
\text { TRNMDL }\end{array}$ & $\begin{array}{r}35 \\
36 \\
2\end{array}$ & $\begin{array}{l}x \\
x\end{array}$ & $\begin{array}{l}x \\
x \\
x \\
x\end{array}$ & & & $\begin{array}{l}\text { Stochastic velocity field } \\
\text { stochastic velocity field }\end{array}$ & & $\begin{array}{l}\text { Oster } \\
\text { Oster } \\
\text { Av-Ron }\end{array}$ & $\begin{array}{l}\text { Stochastic Code } \\
\text { Stochastic Code } \\
\text { Middle-east Code }\end{array}$ \\
\hline
\end{tabular}

KEY: FDM = finite difference method.

IFDM = integrated finite difference method.

$F E M=$ finite element method. 
TABLE B.3. Flow-Transport Code Summary

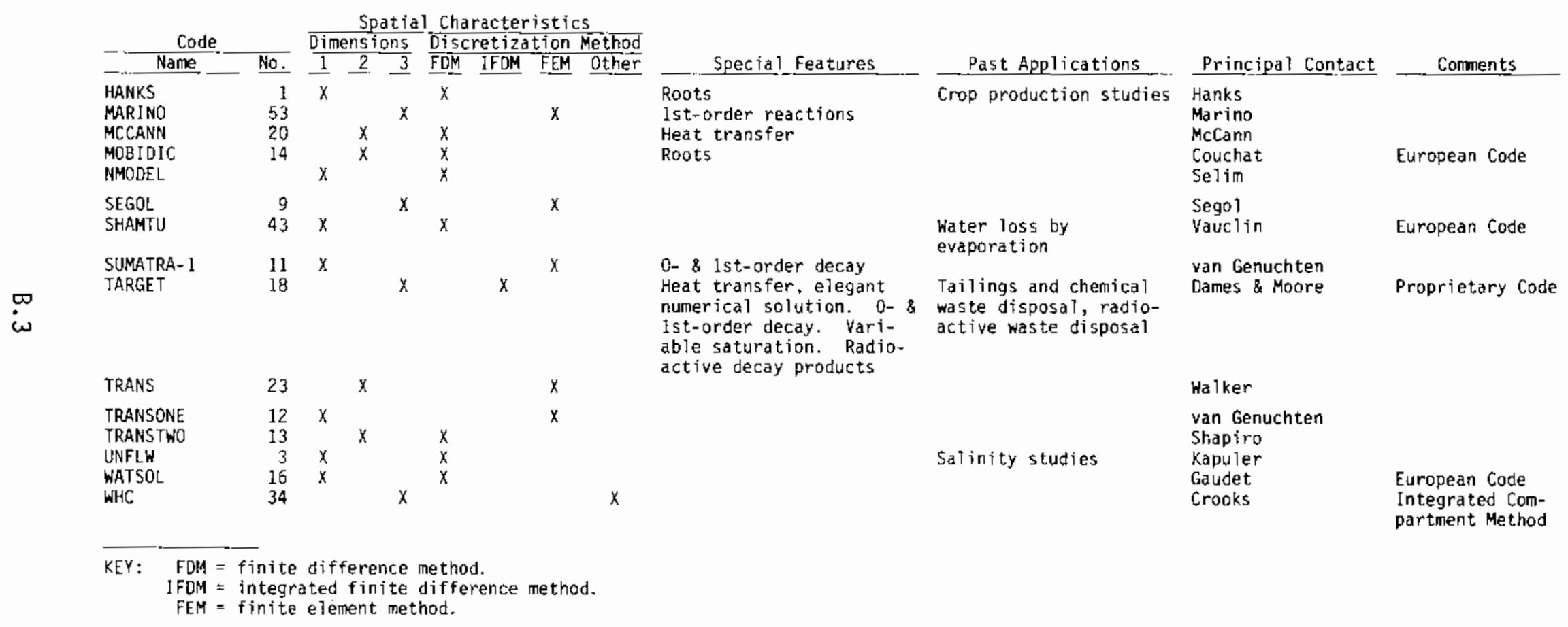



APPENDIX C

COOE EVALUATIONS 


\section{TABLE C.1. Code Evaluations}

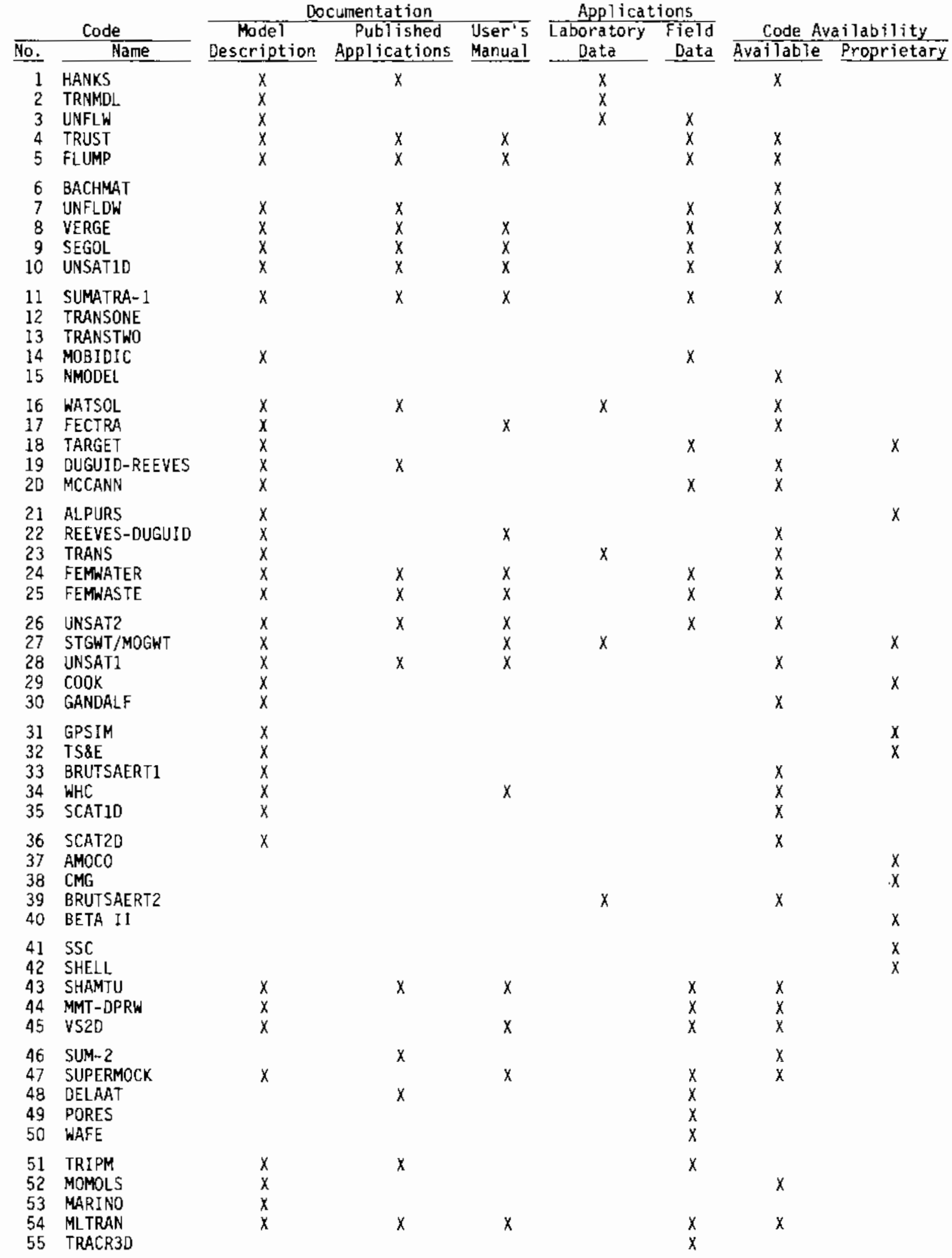

C.1 

APPENDIX D

SUMMARY OF SELECTED CODES 


\section{Summary of Code}

Purpose and Scope--TRUST was developed to study fluid flow problems arising in variably saturated porous media with complicated geometry. The fluid mass conservation equations used are based on elemental volumes that have a constant volume of solid. Nonelastic deformation of the skeleton is permitted, permeability and compressibility coefficients may be nonlinearly related to effective stress, relationships between permeability and saturation with pore water pressure in the unsaturated zone may include hysteresis. is:

Author--TRUST was developed by Dr. T. N. Narasimhan. His current address

Dr. T. N. Narasimhan

Research Geological Engineer

Lawrence Berkeley Laboratory

University of California

Berkeley, CA 94720

Telephone: (415) 486-5655

Code Functions--TRUST provides a versatile tool to solve a wide spectrum of fluid flow problems arising in variably saturated deformable porous media. The governing equations express the conservation of fluid mass in an elemental volume that has a constant volume of solid. Deformation of the skeleton may be nonelastic. Permeability and compressibility coefficients may be nonlinearly related to effective stress. Relationships between permeability and saturation with pore water pressure in the unsaturated zone may include hysteresis.

The code grew out of the original TRUMP code written by Edwards (1968). The code uses an integrated finite difference algorithm for numerically solving the governing equation. Marching in time is performed by a mixed explicit-implicit numerical procedure in which the time step is internally controlled. The time step control and related feature in the TRUST code provide an effective control of the potential numerical instabilities that can arise in the course of solving this difficult class of nonlinear boundary value problem.

Potential Usage--TRUST has the capabilities for treating the wettingdrying front problem which appears in arid regions where many potential low level waste repository sites occur. In addition, the following list enumerates some of the problems which have been solved in the past using TRUST: settlement and consolidation in soft-clay systems under constant or variable loads; deformation of organic soils undergoing drainage and desaturation; simulation of drainage and infiltration in variably saturated columns, ditches and sand boxes; slug tests, constant rate or constant drawdown well-tests in porous media with single or multiple-fractures; internal drainage into mines expanding with time; response of an aquifer-well system of earthquakes or earth tides. 
Relation to NRC Issues--Not applicable as no list of issues currently exists for low level radioactive waste treatment.

Restrictions on Use--TRUST is in the public domain and is listed in Reisenauer, et a1. (1982).

Compatibility with Other NRC Codes--TRUST is written in FORTRAN IV, using no special equipment. The code does use some statements which are specific for some but not all computers. These are identified in Reisenauer, et al. (1982) so that conversion should be readily accomplished.

\section{Surunary of Findings}

General Critique--The TRUST code grew out of the original TRUMP code for therna] modeling. The TRUMP model was written by Edwards (1968) of the Lawrence Livermore Laboratory.

The basic motivation in developing the original TRUST algorithm was to have a fairly general computational tool to implement the mass conservation equation over complex, multidimensional flow regions occupied by porous materials under conditions of variable saturation and deformation. The simple, one-dimensional deformation assumption of Terzaghi has helped dispense with the need to solve an additional set of stress-strain equation, while still enabling the consideration of matrix deformation in so far as it affects fluid flow. Viewed in this phenomenological context, the TRUST approach provides a powerful, versatile tool to solve a wide spectrum of fluid flow problems arising in disciplines such as hydrogeology, soil mechanics, soil physics, rockmechanics, and related subjects.

In order that the versatility of the tool be preserved, it is necessary that the data-input structure be kept flexible and general. For this reason, it is important to make special note of the following two special features of IRUST: a) the computational model considers pressure-dependent density variations of water and conserves the mass of water, and b) the physical parameters in the governing equation are used in their primitive forms. Although options are available to employ familiar forms rather than primitive forms of the parameters, it is felt that a greater inter-disciplinary flexibility is afforded by the latter. Thus, intrinsic permeability, fluid viscosity, fluid density and gravitational constants are separately input rather than hydraulic conductivity; so also, fluid mass capacity, assembled from deformation and desaturation parameters is physically more realistic than the traditional concept of specific storage. In addition, the organization of the input of the geometric data in the TRUST approach is such that the algorithm does not intrinsically differentiate between a one-, two-, or three-dimensional problem. In a sense this enables one to have the invariant physics in focus while using TRUST.

Applicability to Medium--TRUST is designed to simulate fluid flow in variably saturated porous deformable media. The simulation can be carried out in one-, two- or three-dimensions. 
Sensitivity Analysis--No sensitivity analysis has been published.

Code Validation and Field Verification--TRUST has been used in many applications. See Potential Usage above. A particularly good field study is given by Nelson, et aT. (1980). This study involved using TRUST to analyse seepage from a buried uranium mill tailings site. The analysis involved the combined partially saturated and saturated modeling of four tailings management alternatives. The site being in the arid west involved severely desiccated soils with sharp advancing wetting fronts.

\section{General Description}

Operating Characteristics--TRUST as listed in Reisenauer, et al. (1982) has been made operational on UNIVAC and VAX-II computers. It is also available on the CDC $6400 / 6600 / 7000$ system at LBL. The UNIVAC and CDC versions of TRUST are card oriented, the VAX version is not. Also, there are single and double precision variants on the VAX system.

Inputs--Inputs for TRUST include:

Grid geometry

Initial heads

Prescribed head and flux boundary conditions

Intrinsic permeabilities

Fluid viscosity

Fluid density

Gravitational constant

Fluid mass capacity

Outputs--The TRUST code output can be controlled by a print frequency input parameter. The input data are printed always and at specified points in time the following variables are printed for each node:

Pressure heads

Fluid potential

Change in pressure head

Volumetric fluid generation rate

Quantity of fluid

Fluid mass added up to print time

Total mass flow into node up to print time

Fluid properties

Available Documentation--TRUST is documented in Reisenauer, et al. (1982) which contains the equations, theory, user's manual, sample input and sample output. 


\section{Review of Theory}

Equations-- The fundamental equation of transient groundwater motion is an equation of mass conservation and can be expressed as

$$
G+\int_{\Gamma} \rho_{W} \frac{k \rho_{W} g}{\mu} \nabla(z+\psi) \cdot \vec{n} d \Gamma=\frac{d}{d \psi}\left(\rho_{W} V n S\right) \frac{D \psi}{D t} .
$$

where

$$
\begin{aligned}
G & =\text { source term } \\
\Gamma & =\text { closed surface of the domain of interest in the flow region } \\
P_{W} & =\text { mass density of water } \\
k & =\text { permeability } \\
g & =\text { gravitational constant } \\
\mu & =\text { coefficient of viscosity } \\
z & =\text { elevation } \\
\psi & =\text { pressure head } \\
\vec{n} & =\text { unit outer normal to d } \Gamma \\
V & =\text { bulk volume } \\
S & =\text { saturation } \\
\frac{D}{D t} & =\text { total derivative }
\end{aligned}
$$

Equation (1) is derived from the mass conservation equation in an integral form for a flow region which deforms with time. Assuniptions were made that $\mathrm{Dz} / \mathrm{Dt}=0$, implying that $z$ is fixed during the time interval and that if $\rho_{W}, v, n$ and $S$ are functions only of $\psi$, then $\theta=n S$.

The right-hand side of (1) can be expressed as

$$
\begin{aligned}
M_{C} & =\frac{d}{d \psi}\left(\rho_{w} V_{n} S\right) \\
& =V_{s} \rho_{w o}\left(\operatorname{Se}_{w_{0}} \beta g+\frac{S \gamma_{w^{\prime}} X^{\prime} C_{C}}{2.303 \sigma^{\prime}}+e \frac{d S}{d \psi}\right)
\end{aligned}
$$


where

$$
\begin{aligned}
V_{S} & =\text { volume of solids } \\
P_{w_{0}} & =\text { density of water at atmospheric pressure } \\
e & =\text { void ratio } \\
\beta & =\text { coefficient of compressibility of water } \\
Y_{W} & =\text { specific weight of water } \\
X^{\prime} & =\text { parameter correlating change in effective stress and change in } \\
C_{C} & =\text { compression index } \\
\sigma^{\prime} & =\text { effective stress }
\end{aligned}
$$

The parameter $M_{C}$ in Equation (2) represents the mass of fluid which the volume $V$ can absorb due to a unit change in the average value of $\psi$ over $V$. The three terms on the right-hand side represents the compressibility of water, deformability of soil skeleton and desaturability of pores. The derivation of (2) is given in Reisenauer et a1. (1982).

Note that in (2) the quantities $\rho_{w}, S$, and e are all functions of $\psi$ and change continuously with time. The parameter $x^{\prime}$ is also a function of $\psi$, since $S$ is related to $\psi$.

Numerical Approximations--Equations (1) and (2) are solved by an integrated finite difference method (IFDM) in which physical quantities such as potential, density, void ratio and saturation, are properly defined averages over defined subdomains. In addition to this integral basis, the IFDM employs finite difference gradients for implementing Darcy's Law.

Finally, TRUST uses a mixed explicit-implicit approach, in setting up the final matrix equations. The mixed explicit-implicit approach recognizes the fact that in a flow region with volume elements having widely varying time constants (stable time steps), isolation groups of elements with relatively small time constants are only weakly coupled to each other through other elements with larger time constants. A practical consequence of this recognition is, that over a time step of a given $\Delta t$, it is necessary to solve simultaneous equations only for the isolated groups of elements with time constants less than $\Delta t$. In other words, the large matrix of the entire flow region is partitioned into one or more submatrices for purposes of matrix solution, leading to efficiency of computation. Currently, TRUST uses a Point-Jacobi type iterative scheme with an acceleration factor for solving the implicit equations.

Consider an appropriately small subregion of the flow region (Figure 1) over which the variation of $\psi$ is not rapid, and let the average properties of this volume element be associated with a representative nodal point $\ell$. Furthermore, let the volume element be so chosen that the lines joining the nodal point \& to its neighbors be normal to the interfaces between the respective elements. It is assumed that the average properties, such as the $\psi$ associated with each 
nodal point, are functions only of time, while the spatial variation of these average properties between adjacent nodal points can be represented by a simple linear relation which is independent of time. Then, applying (1) to the element in Figure 1, we can write

$$
G_{\ell}+\sum_{m} \rho_{w} \frac{k \rho_{w} g}{\mu}\left[\frac{\left(z_{m}+\psi_{m}\right)-\left(z_{\ell}+\psi_{\ell}\right)}{d_{\ell, m}+d_{m, \ell}} r_{\ell, m}\right]=M_{c, \ell} \frac{\Delta \psi_{\ell}}{\Delta t}
$$

Note that the quantity within the summation sign in (3) represents the flux across the interface between elements $\ell$ and $m$. The quantities $k$ and $\rho_{w}$ in (3) are evaluated at the interface $\Gamma_{\ell, m}$ between the elements. When there is materia1 heterogeneity and elements $\ell$ and $m$ are composed of different materials, a harmonic mean permeability is used in order to preserve continuity of flux at the interface.

Let $V_{\ell, m}$ denote the $f l u x$ across the interface $\ell$, m due to a unit difference between $\left(z_{m}+\psi_{m}\right)$ and $\left(z_{l}+\psi_{l}\right)$. It is shown in Reisenauer et al. (1982) that (3) can be solved explicitly for $\Delta \psi_{\ell}$. For an element \& whose boundary surface

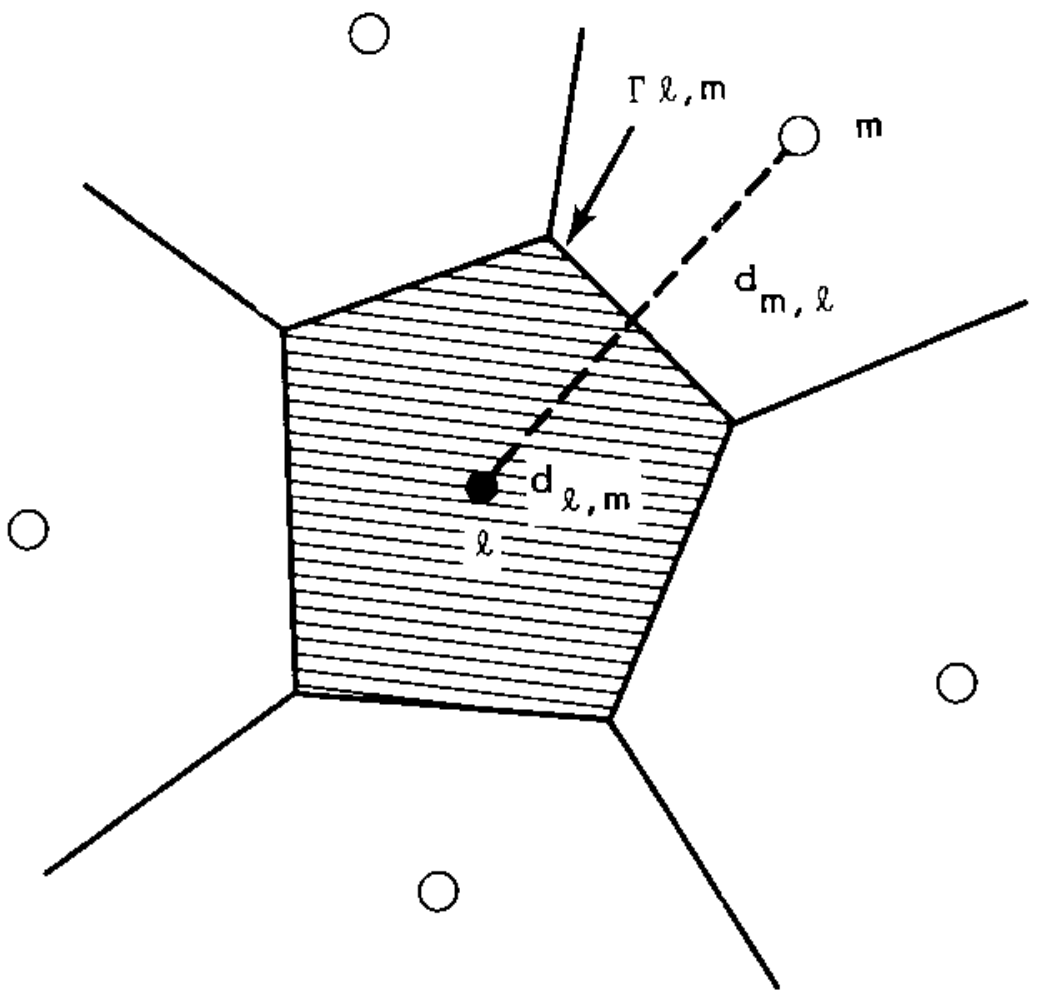

FIGURE 1. Volume Element Associated with Nodal Point \& 
may partly coincide with portions of the boundary of the overall flow region, the equation for $\Delta \psi_{\ell}$ is

$$
\begin{aligned}
\Delta \psi_{\ell, \exp }= & \frac{\Delta t}{M_{c, \ell}}\left\{G_{\ell}+\sum_{b} U_{\ell, b}\left[\left(z_{b}+\bar{\psi}_{b}\right)-\left(z_{\ell}+\psi_{\ell}^{0}\right)\right]\right. \\
& +\sum_{i=1} U_{\ell, m}\left[\left(z_{m}+\psi_{m}^{0}\right)-\left(z_{\ell}+\psi_{\ell}^{0}\right)\right]
\end{aligned}
$$

where the subscript exp denotes explicit nature of the equation and where the subscript $b$ denotes boundary values.

To permit reasonably large time steps to be used in the numerical solution the interpolation (stability) parameter $\lambda$ is introduced, which permits one to write $\Delta \psi_{l}$ as the sum of an explicit component and an implicit component

$$
\Delta \psi_{\ell}=\Delta \psi_{\ell, \exp }+\frac{\lambda \Delta t}{M_{c, l}}\left\{-\sum_{b} U_{\ell, b} \Delta \phi_{\ell}+\sum_{m} U_{\ell, m}\left(\Delta \psi_{m}-\Delta \psi_{\ell}\right)\right\}
$$

Note that for $\lambda=0,(5)$ reduces to (4). The three cases, $\lambda=0, \lambda=0.5$, and $\lambda=1.0$, are known as forward differencing, central differencing, and backward differencing procedures, respectively.

The local nature of stability and the form of (5) suggest that in order to carry out the solution process over the whole flow domain, one could first compute $\Delta \psi_{\ell}$,exp for all the nodal points in the flow region and compute the implicit correction only for those elements whose stability limit is exceeded by $\Delta t$.

\section{Probabilistic or Statistical Aspects--None.}

Assumptions and Simplifications--The main assumptions are:

Darcy's Law is valid and hydrautic-head gradients are the only significant driving mechanisms for fluid flow.

Structure and Level of Detail--TRUST provides the user with a method using discretization cells which are quite general. Where detail is required the user simply defines smaller cells, where the detail is not needed larger cells may be used. Similarly the treatment of one-, two- or three-spatial dimensions is readily accomplished. 
Applicability, Limitations, Validity and Completeness--This code is applicable to both saturated and unsaturated flow in porous, deformable media. The code has been successfully used on a wide variety of problems, many related to the earth sciences.

\section{References--}

Edwards, A. L. 1968. "TRUMP: A Computer Program for Transient and SteadyState Temperature Distributios in Muldidimensional Systems, "Rep. UCRL-14754, Nat. Tech. Inform. Serv., Springfield, Virginia, (Third Revision 1972).

Nelson, R. W., A. E. Reisenauer and G. W. Gee. 1980. "Model Assessment of Alternatives for Reducing Seepage of Contaminants from Buried Uranium Mi11 Tailings at the Morton Ranch Site in Central Wyoming." NUREG/CR-1495 PNL-3378, prepared for U.S. Nuclear Regulatory Cormission by Pacific Northwest Laboratory, Richland, Washington.

Reisenauer, A. E., K. T. Key, T. N. Narasimhan, and R. W. Nelson. 1982.

"TRUST: A Computer Program for Variably Saturated Flow in Multidimensional, Deformable Media," NUREG/CR-2360, PNL-3975, prepared for Division of Health, Siting and Waste Management, Office of Nuclear Regulatory Research, U.S. Nuclear Regulatory Commission by Pacific Northwest Laboratory, Richland, Washington.

Acceptance and Adequacy--TRUST is based on state-of-the-art research and is generally accepted by the research community as being as good as is possible at the current level of understanding. 
Model Name: SEGOL

Code No. 9

Type: Flow/Transport

I. Summary of Code

Purpose and Scope--SEGOL was developed to simulate in two- or threedimensions, mass transport in variably saturated flow systems. is:

Author--SEGOL was developed by Dr. Genevieve Segol. Her current address

Bechtel Civil and Minerals, Inc.

P.0. Box 3965

San Francisco, CA 94119

Telephone: (415) 768-7159

The primary contact for SEGOL is:

Dr. E. O. Frind

Department of Earth Sciences

University of Water 100

Waterloo, Ontario

N2L 3G1

Code Functions--SEGOL is a three-dimensional model for the analys is of mass tranpsort in variably saturated flow systems. The Galerkin-finite element method is used to obtain the approximate sets of governing equations. Advantage is taken of the banded nature of the arrays in using out-of-core equation solvers to reduce the computer storage requirements. A two-dimensional model is also available, which is identical in all respects to the threedimensional one except that the third dimension is discarded and that the solution is performed entirely in core.

Potential Usage--SEGOL can be used to investigate three-dimensional mass transport problems. The flow region may have any complex shape and may consist of different soil types arranged in arbitrary patterns. The following boundary conditions can be imposed; prescribed pressure head, prescribed flux normal to the boundary and seepage faces. The two-dimensional model may be used to check, if necessary, the results obtained with the three-dimensional code on a case where the third dimension may be irrelevant; it also provides the user with a means to quantify the importance of the three-dimensional nature of a particular problem and to decide whether or not the more expensive three-dimensional analysis is justified.

Relation to NRC Issues--Not applicable as no list of issues currently exists for low level radioactive waste treatment.

Restrictions on Use--This code is in the public domain and is listed in Segol (1976a). 
Compatibility with 0ther NRC Codes--SEGOL is written in FORTRAN IV using no special equipment, hence it is compatable with other FORTRAN codes.

\section{Summary of Findings}

General Critique--The SEGOL code may be useful to the NRC for the analys is of contaminant concentration distributions in a three-dimensional saturated or unsaturated aquifer system. The two-dimensional version of the code, being more efficient computationally, may be used to quantify the importance of the threedimensional nature of a particular problem and hence determine whether or not a more expensive three-dimensional analysis is justified. Hysteresis has not been included in the code, thus restricting its usage to either a single wetting or drying cycle.

Sensitivity Analysis--No sensitivity analyses have been published.

Code Validation and Field Verification--Simulation of a one-dimensional infiltration experiment reported by Warrick, et al. (1971) was used to check the accuracy of the three- and two-dimensional models. The comparison of this simulation is briefly given in Segol (1976a) and more fully in Segol (1976b). Good agreement was obtained in this check.

\section{General Description}

Operating Characteristics--SEGOL is written in FORTRAN IV and is operational on an IBM 360/75. It consists of 19 subprograms. Nine scratch files are used by the three-dimensional code and four scratch files are used by the two-dimensional program.

Inputs--Input quantities for SEGOL include:

Basic program control parameters

Grid geometry (node coordinates and incidences)

Source and sink fluid and mass fluxes

Initial pressure and concentration data

Elemental parameters:

Hydraulic conductivity (anisotropic)

Longitudina 1 and transverse dispersivity

Porosity, elastic constants

Retardation coefficients and decay constants

Dirichlet boundary conditions for flow and concentration

Neumann boundary nodes for flow and concentration

initial position of seepage faces

Unsaturated flow properties

Outputs--All output is to a line printer. This output includes the input information and the pressure head and concentration in both space and time. 
Available Documentation--Segol (1976a) is a user's manual and includes a code listing for both the three-dimensional and the two-dimensional programs.

IV. Review of Theory

Equations--The equation governing water movement in a saturated-unsaturated zone has the form

$$
L_{\psi}=\left(k+\frac{\theta}{\varepsilon} s_{s}\right) \frac{\partial \Psi}{\partial t}-\sum_{\alpha=1}^{3} \sum_{\beta=1}^{3} \frac{\partial}{\partial x_{\alpha}}\left(K_{r} K_{\alpha \beta}^{s} \frac{\partial \Psi}{\partial x_{\beta}}+K_{r} K_{\alpha \beta}^{s}\right)-Q=0
$$

with

$$
\begin{aligned}
K=\frac{\partial \theta}{\partial \Psi} & , \text { moisture capacity }\left(L^{-1}\right) \\
K_{r} & , \text { relative hydraulic conductivity } \\
\mathrm{K}_{\alpha \beta}^{5} & , \text { hydraulic conductivity at saturation }\left(\mathrm{LT}^{-1}\right) \\
Q=A_{W}\left(x_{W \alpha}\right) \delta\left(x_{\alpha}-x_{W_{\alpha}}\right) & , \text { strength of source or sink function }\left(T^{-1}\right) \\
Q_{W} & , \text { well discharge }\left(\mathrm{L}^{3} \mathrm{~T}^{-1}\right) \\
\mathrm{S}_{S} & , \text { specific storage }\left(\mathrm{L}^{-1}\right) \\
\mathrm{x}_{W \alpha} & , \text { coordinate of discharge or recharge point }(\mathrm{L}) \\
E & , \text { porosity } \\
\theta & , \text { moisture } \\
\Psi & , \text { pressure head }(\mathrm{L})
\end{aligned}
$$

In the unsaturated zone Equation (1) is nonlinear since moisture content and hydraulic conductivity are functions of the pressure head. Hysteresis is not considered in the present analysis and consequently the relationships $K(\Psi)$ and $\Phi(\Psi)$ are uniquely defined.

The initial and boundary conditions of the problem take the form

$$
\begin{aligned}
& \Psi\left(x_{\alpha}, 0\right)=\Psi_{0} \text { in } \Omega \\
& \Psi\left(x_{\alpha}, t\right)=\bar{\Psi} \text { on } \Gamma_{1}
\end{aligned}
$$




$$
k_{r} \sum_{\alpha=1}^{3}\left[k_{\alpha 3}^{s}+\sum_{\beta=1}^{3} k_{\alpha \beta}^{s} \frac{\partial \Psi}{\partial x_{\beta}}\right]=-V \text { on } \Gamma_{2}
$$

where $\Omega$ is a three-dimensional domain bounded by a surface $\Gamma=\Gamma_{1}+\Gamma_{2}$.

Along those boundaries where infiltration or evaporation take place, the exact boundary conditions cannot in general be predicted a priori. A solution is sought by maximizing the absolute value of the flux subject to the requirements.

$$
\begin{aligned}
& \left|k_{r} \sum_{\alpha=1}^{3}\left[k_{\alpha 3}^{s}+\sum_{\beta=1}^{3} k_{\alpha \beta}^{s} \frac{\partial \Psi}{\partial x_{\beta}}\right]\right| \leq\left|E_{s}\right| \\
& \Psi_{L} \leq \Psi \leq 0 \quad \text { for infiltration } \\
& \Psi \geq \Psi_{L} \quad \text { for evaporation }
\end{aligned}
$$

where $E_{S}$ in the maximum possible surface flux and where $\psi_{L}$ is the minimum allowed pressure head at the soil surface.

The equation describing the solute transport is taken in the form

$$
L_{c}=\frac{\partial \theta c}{\partial t}-\sum_{\alpha=1}^{3} \sum_{\beta=1}^{3} \frac{\partial}{\partial x_{\alpha}}\left(\theta D_{\alpha \beta} \frac{\partial c}{\partial x_{\beta}}\right)-\sum_{\alpha=1}^{3} \frac{\partial q_{\alpha} c}{\partial x_{\alpha}}+Q c^{\prime}=0
$$

with $\mathrm{C}$, solute concentration $\left(\mathrm{ML}^{-3}\right)$

$\mathrm{C}^{\prime}$, concentration of the considered ion in the source of sink fluid fluid $(M L-3)$

$D_{\alpha \beta}$, dispersion tensor $\left(\mathrm{L}^{2} \mathrm{~T}^{-1}\right)$

$q_{\alpha}$, volumetric flux of water $\left(\mathrm{LT}^{-1}\right)$

The moisture content $\theta$ appearing in (7) is a unique function of $\Psi$ and can therefore be evaluated from the solution of (1). The mass-transport equation is also coupled to the flow equation through the mass-average velocity $q_{\alpha}$ which is obtained from Darcy's Law as 


$$
q_{\alpha}=-k_{r}\left[k_{\alpha 3}^{s}+\sum_{\beta=1}^{3} k_{\alpha \beta}^{s} \frac{\partial \Psi}{\partial x_{\beta}}\right] .
$$

The coefficients $D_{\alpha \beta}$ include the effects of mechanical dispersion and molecular diffusion, and are taken in the form

$$
D_{\alpha \beta}=D_{\alpha \beta}^{M}(V, t)+D_{p}(\theta, t) \delta_{\alpha \beta}
$$

where

$$
D_{\alpha \beta}^{M}=a_{L}|V| \delta_{\alpha \beta}+\left(a_{L}-a_{T}\right) \frac{V_{B} V_{\alpha}}{T_{V} \mid}
$$

$a_{1}$ and a being the longitudinal and transverse dispersivities, respectively; $v_{\alpha}=q_{\alpha} / \theta$ is the component of velocity in the direction $x_{\alpha}$. The soil diffusion coefficient $D_{p}(\theta, t)$ is assumed to be an exponential function of moisture content. Thus,

$$
D_{p}(\theta, t)=D_{0} a e^{b \theta}
$$

$a$ and being empirical constants characteristic of the soil, and $D_{0}$ being the equivalent diffusion coefficient in a free-water system.

The initial conditions required to soive (7) are expressed in a manner analogous to (2) in the form

$$
c\left(x_{\alpha}, 0\right)=c_{0} \text { in } \Omega
$$

Dirichlet, Neumann or mixed boundary conditions are specified in the form

$$
\begin{aligned}
& c\left(x_{\alpha}, t\right)=\bar{c} \text { on } \Gamma_{1}^{\prime} \\
& n_{\alpha} \frac{\partial c}{\partial x_{B}}=0 \text { on } \Gamma_{2}^{\prime}
\end{aligned}
$$




$$
\left(-D_{\alpha \beta} \frac{\partial c}{\partial x_{\beta}}+q_{\beta} c\right) n_{\alpha}=q_{\beta} n_{\alpha} C_{0}(t) \text { on } \Gamma_{3}^{\prime}
$$

where $r=\Gamma_{1}^{\prime}+r_{2}^{\prime}+\Gamma_{3}^{\prime}$

where $C_{0}(t)$ is the concentration of solute in the influx water, and $n_{\alpha}$ is a component of the outward normal unit vector.

In many practical problems, the flow can be assumed to be two-dimensional and only a vertical cross-section of the three-dimensional space need to be considered. The flow and solute movements referred to the $x_{1}-x_{2}$ plane are still described by Equations (1) and (7), respectively, where the indices $\alpha$ and $\beta$ take on values equal to 1 and 2 .

Numerical Approximations--The noniinear set of Equations (1) and (7) are solved by using the Galerkin finite element method. In this approach, one seeks the solution of a partial differential equation

$$
L(\phi)=0
$$

by assuming that the unknown variable $\phi\left(x_{\alpha}, t\right)$ can be represented by a series expansion of the form

$$
\phi\left(x_{\alpha}, t\right) \simeq \hat{\phi}\left(x_{\alpha}, t\right)=\sum_{i=1}^{N} \gamma_{i}(t) w_{i}\left(x_{\alpha}\right)
$$

where $w_{j}\left(x_{\alpha}\right)$ are known functions of space, or basis functions. The functions $w_{j}\left(x_{\alpha}\right)$ are ${ }^{\alpha}$ linearly independent, satisfy the boundary conditions imposed on (16) and Constitute a complete set. The $Y_{j}(t)$ are unknown time-dependent coefficients which correspond to the approximate solution of (16) at specified points within the domain of interest.

Since only a finite number $n<N$ of the basis functions can be taken into account, $L[\hat{\phi}(x, t)]$ is equal to a certain non-zero residual. This residual is minimized by requiring that $L\left[\hat{\phi}\left(x_{\alpha}, t\right)\right]$ be orthogonal to each basis function, that is

$$
\begin{aligned}
\int_{\Omega} L\left[\hat{\phi}\left(x_{\alpha}, t\right)\right] w_{i}\left(x_{\alpha}\right) d \Omega & =\int_{\Omega} L\left[\sum_{j=1}^{n} y_{j}(t) w_{j}\left(x_{\alpha}\right)\right] w_{j}\left(x_{\alpha}\right) d \Omega=0 \\
i & =1,1, \ldots n
\end{aligned}
$$


Equation (18) represents a set of $n$ equations which will be solved for the $n$ unknown coefficients $Y_{f}(t)$. Such a system can be conveniently expressed in the matrix form

$$
[A]\{Y\}=\{B\}
$$

where the arrays [A] and $\{B$ ] are functions of the space coordinates and can be evaluated by performing the relevant integrations, and where $\{Y\}$ is a vector containing the unknown, time-dependent coefficients.

The region of interest is subdivided into a network of isoparametric hexahedral elements. A number is assigned to each element and to each node of the discretized doamin. The choice of a node numbering scheme is important because it affects the bandwidth of the final system of algebraic equations and, consequently, the size of the coefficient matrices.

Let the variables $\Psi$ and $c$ be approximated by series expansions of the form:

$$
\begin{aligned}
& \Psi\left(x_{\alpha}, t\right) \simeq \hat{\Psi}\left(x_{\alpha}, t\right)=\sum_{j=1}^{n} P_{j}(t) \omega_{j}\left(x_{\alpha}\right) \\
& c\left(x_{\alpha}, t\right) \simeq \hat{c}\left(x_{\alpha}, t\right)=\sum_{j=1}^{n} c_{j}(t) \gamma_{j}\left(x_{\alpha}\right)
\end{aligned}
$$

Upon substituting (20) and (21) into (1) and (7) and applying the orthogonality theorem (18) one obtains

$$
\begin{aligned}
& {[S] \frac{d\{P\}}{d t}+[H]\{P\}+\{F\}=0} \\
& {[M] \frac{d\{C\}}{d t}+[N]\{C\}+\{R\}=0}
\end{aligned}
$$

where the coefficient matrices are given by Equations (28) and (29), pages 12 to 13 of Segol (1976a).

The time derivatives appearing in (22) and (23) are treated using a finite difference scheme such that 


$$
\begin{aligned}
& \left.\frac{d\{P\}}{d t}\right|_{t+e \Delta t}=\frac{1}{\Delta t}\left(\{P\}_{t+\Delta t}-\{P\} t\right) \\
& \left.\frac{d\{C\}}{d t}\right|_{t+E \Delta t}=\frac{1}{\Delta t}(\{C\} t+\Delta t-\{C\} t)
\end{aligned}
$$

where $\Delta t$ is the time step. The parameter $\varepsilon$ is equal to 1 if an implicit scheme is used and to $1 / 2$ in a time-centered scheme. The value of $\{P\}$ and $\{C\}$ at $t+\Delta t$ are obtained from the relation

$$
\begin{aligned}
& \{P\}_{t+\varepsilon \Delta t}=\varepsilon\{P\}_{t+\Delta t}+(1-\varepsilon)\{P\}_{t} \\
& \{C\}_{t+\varepsilon \Delta t}=\varepsilon\{C\}_{t+\Delta t}+(1-\varepsilon)\{C\}_{t}
\end{aligned}
$$

The solution of the mass-transport equation was found to be more stable when the backward difference algorithm is used. The present model does not a]low one to use different values of $\varepsilon$ in the flow and mass-transport equations. Substitution of (24) and (25) in (22) and (23), respectively, yields for $E=1$.

$$
\begin{aligned}
& \left(\frac{1}{\Delta t}[S]+[H]\right)\{P\}_{t+\Delta t}=-\{F\}+\frac{1}{\Delta t}[S]\{P\}_{t} \\
& \left(\frac{1}{\Delta t}[M]+[N]\right)\{C\}_{t+\Delta t}=-\{R\}+\frac{1}{\Delta t}[M]\{C\}_{t}
\end{aligned}
$$

When a Dirichlet condition is specified along a boundary, the value of the variable is kept constant at the nodes located along that boundary. As a consequence no equation in the system (28) is generated for a node where a constant pressure is specified. Similarly, no equation in the system (29) is generated for a node of constant concentration.

When a Neumann condition is specified along a boundary the normal derivative of the variable is known along that boundary. In the flow equation this, condition is incorporated through the surface integral term.

$$
\int_{\Gamma} k_{r}\left(k_{\alpha \beta}^{s} \sum_{m=1}^{n} \frac{\partial \omega_{m}}{\partial x_{\beta}} p_{m}+k_{\alpha \beta}^{s}\right) n_{\alpha} \omega_{i} d \Gamma=-\int_{\Gamma} v_{n} \omega_{i} d \Gamma
$$


where $V_{n}$ is the flux normal to the bounding surface. For a node located on a no-flow boundary $V_{n}=0$ and (3) is not generated.

Similarly, Neumann boundary conditions can be specified for the masstransport equation through the term

$$
\int_{\Gamma} D_{\alpha \beta} \sum_{m=1}^{n} \frac{\partial \gamma_{m}}{\partial x_{\beta}} C_{m} \gamma_{i} d \Gamma=\int_{\Gamma} D_{\alpha \beta} \frac{\partial c}{\partial n} \Gamma_{i} d \Gamma
$$

where $\partial c / a n$ represents the normal concentration gradient at the boundary. In. the present documentation it is assumed that wherever $\partial \mathrm{c} / \partial \mathrm{n}$ is specified its value is zero and (31) is not generated.

Mixed boundary conditions are specified for the mass-transport equation along those parts of the boundary where infiltration or evaporation take place. Using (15) one writes, for infiltration,

$$
\left(-D_{\alpha \beta} \frac{\partial c}{\partial x_{\beta}}+q_{\beta} c\right) n_{\alpha}=q_{\beta} n_{\alpha} C_{0}(t)
$$

while for evaporation

$$
\left(-D_{\alpha \beta} \frac{\partial C}{\partial x_{\beta}}+q_{\beta} c\right) n_{\alpha}=0
$$

Atmospheric boundary conditions cannot be fixed a priori but depend on the current moisture conditions of the soil. Iteration is thus used to determine whether a Dirichlet or a Neumann condition should be applied at a node located on such a boundary. During the first iteration in each time step, the surface nodes may be treated as Neumann nodes and are then assigned an arbitrary fraction of the maximum flux. If the computed values of pressure head satisfy (6), the absolute value of the flux at each node is increased by $\left|\Psi_{L}\right| /|\Psi|$ in the case of evaporation, or by $\left|\Psi_{L}\right| /\left|\Psi_{L}-\psi\right|$ in the case of infittration. If a value of $\Psi$ does not satisfy $(6)$ then during the subsequent iteration a Dirichlet boundary condition is specified at that node with $\Psi=0$ for infiltration and $\psi=\Psi_{L}$ for evaporation. This situation is maintained as long as Equation (5) is satisfied. Otherwise, a Neumann type boundary condition is assigned again.

A similar iterative procedure is used along a seepage face, since under transient conditions its exact extent is unknown. 
It follows that for those nodes located on atmospheric boundaries or seepage faces the equations corresponding to Dirichlet nodes must nevertheless be included in the global matrix which is then modified appropriately.

For unsaturated flow, the values of permeability and moisture content must be evaluated at the beginning of each time step from an estimate of the pressure in the next time interval. Thus, before solving for the $(k+1)$ th time increment the value of $\Psi$ at $t^{k+1 / 2}$ is predicted by linear interpolation of the previous results from

$$
\Psi^{k+1 / 2}=\Psi^{k}+\frac{\Delta t^{k}}{2 \Delta t^{k-1}}\left(\psi^{k}-\psi^{k-1}\right)
$$

Consequently the coefficient matrices are evaluated at half the time step, $k+1 / 2$, which has a dampening effect on possible numerical oscillations.

Due to the nonlinear nature of (1) the initial estimate of pressure must be improved by an iterative procedure. Thus if $\psi k+1$ is the most recent value of pressure head at time $k+1$, the pressure estimate during the next iteration is computed from

$$
\psi^{k+1 / 2}=\frac{1}{2}\left(\psi^{k}+\psi^{k+1}\right)
$$

The relations between permeability, moisture content and pressure head are provided in the form of tables and cubic splines are used to interpolate between the data points. It was found that the accuracy of the process can be improved by performing the spline fit on the logarithmic expressions of $K$ and $\Psi$. Similarly, the moisture capacity $k=\partial \theta / \partial \Psi$ is evaluated from

$$
k=\frac{1}{\Psi} \frac{\partial \theta}{\partial \operatorname{Tog} \Psi} \log \mathrm{e}
$$

where the expression $2 \theta / \partial \log \Psi$ is a quadratic polynomial corresponding to the first derivatives of the cubic spline.

The coefficient matrices appearing in (22) and (23) are evaluated for each element and are assembled using the wel1-known direct stiffness method. When the system of equations (22) is being processed, the coefficient matrices [M] and $[\mathrm{N}]$, are placed into secondary storage. Conversely, the arrays [S] and $[\mathrm{H}]$ are saved on scratch storage during assembiy and solution of the masstransport equation. Therefore, only two matrices need to be in high-speed core storage at the same time: the upper triangular parts of [S] and [H] when 
dealing the the flow equation, or the upper triangular part of [M] and the banded portion of $[\mathrm{N}]$ when the mass-transport equation is being processed. For practical purposes, the stiffness matrices [H] and [N] are assembled in their transposed form. Finally, the left-hand sides of (28) and (29) are evaluated and stored in $[S]$ and $[N]^{\top}$, respectively.

The Cholesky algorithm is used to solve the symmetric system of equations for flow. The Gauss elimination procedure with a partial pivoting intended to reduce round-off errors is applied to the mass-transport equation in which the coefficient matrix is nonsymmetrical.

In the three-dimensional transport model, out-of-core equation solvers are used in order to decrease the storage space requirements. In this approach the matrices are assembled by blocks where a block is defined as a square submatrix of dimension equal to the semi-bandwidth for a symmetric matrix or to the bandwidth for a nonsymmetric matrix. When a block has been processed, it is transferred to secondary storage so that only two blocks need to be in memory at the same time. The present three-dimensional model is therefore mainly intended for systems in which the bandwidth is small compared to the total number of equations, as is often the case. The drawback of this technique is of course an increased number of $1 / 0$ operations and a longer solution time.

Probabilistic or Statistical Aspects--None.

As sumptions and Simplifications--The main assumptions are:

- Darcy's Law is valid and hydraulic-head gradients are the on ly significant driving mechanisms for fluid flow.

- The maximum rate of transpiration is determined by atmospheric conditions alone.

- The hydraulic conductivity at each point is exposed as a symmetric tensor $K_{j j}=K^{r}(\theta) K_{i j}^{5}$, where $K_{i j}^{5}$ is the conductivity at saturation and $\mathrm{k}^{r}(\theta)$ is the relative conductivity $\left(0 \leq k^{r}(\theta) \leq 1\right)$ as a function of volumetric moisture content.

Structure and Level of Detail--SEGOL models a flow system in a complete three-dimensional coordinate system. In cases where one-dimensions can be ignored, there is a two-dimensional form of the code.

Major Variables--Aside from the input parameter, the major dependent variables are pressure head and solute concentration.

Applicability, Limitations, Validity and Completeness--This code is applicable to both saturated and unsaturated flow in porous media. There is no provision for hysteresis is included, thus the code's usage is restricted to ejther a single wetting or drying cycle. 


\section{References--}

Segol, Genevieve. 1976a. "A Three-Dimensional Galerkin Finite Element Model for the Analysis of Contaminant Transport in Variably Saturated Porous Media, User's Guide," Department of Earth Sciences, University of Waterloo, Waterloo, Ontario, Canada.

Segol, Genevieve. 1976b. "A Three-Dimensional Galererkin Finite Element Model for the Analysis of Contaminant Transport in Saturated-Unsaturated Porous Media," International Conference on Finite Element in Water Resources, Princeton University, Princeton, New Jersey.

Warrick, A. W., T. W. Biggar and D. R. Nielsen. 1971. "Simultaneous Solute and Water Transfer for an Unsaturated Soil," Water Resources Research, $7(5): 1216-1225$.

Acceptance and Adequacy--SEGOL is based on state-of-the-art research and is generally accepted by the research community both in the United States and abroad, as being as good as is possible given the present level of understanding. 


\section{Summary of code}

Purpose and Scope--UNSATID was developed to simulate one-dimensional flow chrough a partially-saturated flow system. UNSATID simulates infiltration, vertical seepage, and plant uptake by roots as a function of the hydraulic properties of a soil, soil layering, root growth characteristics, evapotranspiration rates, and frequency, rate and amount of precipitation and/or irrigation.

Authors--UNSAT1D was developed at Battelle's Pacific Northwest Laboratories by S. K. Gupta and C. S. Simmons. The primary contact for UNSATID is

F. W. Bond

Battelle-Northwest

P.O. Box $9 g 9$

Richland, WA 99352

Phone: (5D9) 376-8339

Code Functions--UNSATID is a fully implicit finite difference model of a one-dimensional flow through a partially saturated flow system. UNSAT1D simulates infiltration, vertical seepage, and plant uptake by roots as a function of the hydraulic properties of a soil, soil layering, root growth characteristics, evapotranspiration rates, and frequency, rate and amount of precipitation and/or irrigation.

Potential Usage--UNSAT1D can be used to estimate ground-water recharge; irrigation and consumptive use of water, irrigation return flows and other related areas dealing with partially-saturated and saturated soils. Other applications of interest to the NRC include aiding in the design of low-level radioactive waste repositories at shallow depths.

Relation to NRC Issues--Not applicable as no list of issues currently exists for low level radioactive waste treatment. to the NRC.

Restrictions--The code is in the public domain and is therefore available

Compatibility with Other NRC Codes--UNSAT1D is written in FLECS (Beyer 1975) which is compatible with FORTRAN. Some subroutines are written in FORTRAN IV. The code utilizes PNL graphics software and relies on graphical hardware for use in the interactive mode. 


\section{Summary of Findings}

General Critique--The UNSAT1D model is a one-dimensional finite difference, fully implicit approach to simulating ground-water flow in the unsaturated zone. UNSAT1D simulates infiltration, vertical seepage, and plant uptake by roots as a function of the hydraulic properties of a soil, soil layering, the root growth characteristics of a given crop in a given soil profile, evapotranspiration rates, and frequency, rate, and amount of rainfall and/or irrigation. It can be used for estimation of ground-water recharge, irrigation and consumptive use or water, irrigation return flows, and other related areas dealing with unsaturated and saturated soils.

UNSATID is designed for use under varied field conditions. The application of water can be in the form of rain, sprinkler, or flooding. Actual evapotranspiration can be estimated as a function of moisture content and potential evapotranspiration using on-off, linear decrease, logrithmic decrease, or combination methods. The soil profile can be homogeneous, heterogeneous, or layered. Th hydraulic properties can be defined as polynomials or other empirical equations. The root growth uptake has built-in options for the root suction, root-distribution or user defined mathematical model. The lower boundary conditions can be water table, dynamic, quasi-dynamic, or unit gradient.

UNSAT1D may be useful to the NRC for the analysis of infiltration with various plant populations and deep percolation in a saturated-unsaturated flow system. The capability of treating irrigation and/or rainfall and plant root uptake are often essential for analysis of shallow waste repositories.

Applicability to Medium--UNSAT1D is designed to simulate water movement in saturated or unsaturated or a combination of saturated and unsaturated flow systems which can adequately be represented by a one-dimensional model.

Sensitivity Analysis--No sensitivity studies have been published.

Code Validation and Field Verification--Bond et al. (1982) contains a detailed example based on hypothetical, but realistic, input parameters.

\section{General Description}

Operating Characteristics--The UNSATID model consists of a single computer code that makes the unsaturated flow predictions and several support codes used for preparation of input data, and for evaluating and displaying model results. The complete series of codes which formulate the unsaturated flow modeling package is known in the documentation, as the UNSATID Model Sequence.

The UNSATID code itself is written in FLECS (Beyer 1975), a structured programming language akin to FORTRAN. (The FLECS compiler acts as a preprocessor to FORTRAN producing a FORTRAN code as output). Other supporting programs in the UNSAT1D Mode1 Sequence are written in either FORTRAN IV or FLECS. The UNSAT1D Model Sequence is operational on the DEC family of computers. The 
UNSATID system operates in the interactive mode and requires graphical output devices for full utilization of its capabilities.

Inputs-- The amount of input data required by UNSAT1D is dependent on the given problem. In general, the input data includes soil profile description, (homogeneous, heterogeneous, or layered), hydraulic properties of each layer (package includes estimation of hydraulic conductivity for the unsaturated zone on the basis of moisture retention curve), plant characteristics (rooting depth constant or function of growth, root distribution, leaf area index, wilting point), water application (precipitation, irrigation, ponding), and potential evaporation/transpiration (package includes estimation from climatic data by $\mathrm{B}$ laney Criddle, radiation, Penman, or ETPAN method).

Outputs--The output from the UNSAT10 model includes soil water potential (suction), moisture content, and soil water flux rate at each node (depth increment) for each time interval. The results can be in the form of lineprinter listings, binary files, or Calcomp plots.

Available Documentation--The analytical documentation is contajned in Gupta et al. (1978). Bond et a1. (1982) is a user's manual describing not only the UNSAT1D code but the several supporting codes. The described codes are all listed in an appendix.

IV. Review of Theory

Equations--The basic differential equation solved by UNSAT1D is

$$
C(\theta) \frac{\partial h}{\partial t}=\frac{\partial}{\partial z}\left[K(\theta) \frac{\partial H}{\partial z}\right]-S
$$

where

$$
\begin{aligned}
C(\theta) & =\text { soil water differential capacity } \\
\theta= & \text { volumetric water content of the soil } \\
h= & \text { pressure head } \\
t= & \text { time } \\
z= & \text { vertical coordinate with origin at the soil surface and positive } \\
& \text { downward } \\
K(\theta)= & \text { hydraulic conductivity of soil } \\
H= & \text { total head } \\
= & h-z \\
S= & \text { source/sink term representating rainfall and irrigation influx or } \\
& \text { water uptake by plants }
\end{aligned}
$$


The above equation is obtained from Darcy's Law, continuity principles and Richard's transformation.

To solve the governing partial differential equations with the appropriate sink term, the following initial and boundary conditions must be determined. The initial conditions are $h_{S}(z, 0)=h_{0}(z)\left[\operatorname{or} \theta(z, 0)=\theta_{0}(z)\right]$ at $0 \leq z \leq z$ and $t=0$, where $Z$ is the depth of the semi-infinite depth, or the static quasidynamic or dynamic water table at $t=0$, and subscript 0 denotes initial condition.

Boundary conditions are of two kinds, the upper-boundary or soit surface conditions and the lower-boundary or sub-surface conditions. At the soil surface, $z=0$ and $t>0,|q(0, t)| \leq\left|Q_{0}(t)\right|$, $h_{d} \leq h_{s}(0, t) \leq 0$ or $\theta_{g} \leq \theta(0, t) \leq \theta_{s}$, where $Q_{0}(t)$ is the prescribed maximum possib7e flux $\left(\mathrm{cm}^{3} \cdot \mathrm{cm}^{-2} \cdot \mathrm{s}^{-1}\right)$ as governed by meteorological conditions, plant growth, and irrigation; and subscripts $d$ and $s$ respectively denote dry and saturated conditions. If irrigation is by ponding, the upper-boundary condition is $h(0, t)=P(t)$, where $P$ is the depth of ponding $(\mathrm{cm})$ at the surface.

Lower-boundary conditions considered are:

1. semi-infinite depth; under the assumption of unit gradient at base, $q Z, t)=k[\theta(Z, t)]$

2. with static or quasi-dynamic water table, $h_{0}(z, t)=0$

3. with dynamic water table, $g(z, t)=Q_{z}(t)$ where $Q_{z}(t)$ is the prescribed flux at depth $Z\left(\mathrm{~cm}^{3} \cdot \mathrm{cm}^{-2} \cdot \mathrm{s}^{-1}\right)$.

Additional conditions are imposed on the source term $\mathrm{S}$. There are pressure limits in the plant root $x y 1$ em. At the soil surface, $h_{x 0}$ (water potential root $x y l e m$ at the soil surface) can take values between zero (maximum) and the "wilting point" $h_{x w i l t}$ so that $h_{x w i j t} \leq h_{x 0} \leq 0$.

The actual rate of transpiration $(T)$ is maximized subject to the constraints $T \leq$ (PET - surface evaporation) and $h_{X 0} \geq h_{X w i l t}$. PET is the potential evapotransporation.

Numerical Approximations--It is assumed that $\theta$ and $h$ are related by a soil water characteristic curve. The UNSAT10 Model Sequence provide approximations to this relationship by interpolation or fitting low order polynomials.

The basic differential equation is replaced by the following system of finite difference equations. In the following description, $h$ stands for $h_{s}$, omitting subscript so to simplify notation. The working numerical equation then becomes: 


$$
\begin{aligned}
& {\left[\frac{h_{i}^{j} c_{i}^{j}-h_{i}^{j-1} c_{i}^{j-1}}{\Delta t}\right]=\frac{1}{\left(z_{i+1}-z_{i-1}\right)}\left[\left(\left(\frac{h_{i}^{j-1}-h_{j-1}^{j-1}+2 z_{i}}{2 \Delta z_{1}}\right) k_{i-\frac{1}{2}}^{j-1}\right.\right.} \\
& -\left(\frac{h_{i+1}^{j-1}-h_{j}^{j-1}+2 z_{j}}{2 \Delta z_{2}}\right){ }_{\substack{i+\frac{1}{2} \\
k^{j-1}}}^{j}+\left(\frac{h_{i}^{j}-h_{j-1}^{j}+2 z_{i}}{2 \Delta z_{1}}\right) k_{i-\frac{1}{2}}^{j} \\
& \left.\left.-\left(\frac{h_{i+1}^{j}-h_{j}^{j}+2 z_{i}}{2 \Delta z_{2}}\right) k_{i+\frac{1}{2}}^{j}\right)\right]-\operatorname{sink}
\end{aligned}
$$

where

$$
\begin{aligned}
i & =\text { subscript representing the depth of a node } \\
j & =\text { subscript representing time } \\
\Delta z_{1} & =z_{i}-z_{i-1} \\
\Delta z_{2} & =z_{i+1}-z_{i}
\end{aligned}
$$

Each nonboundary node has a finite difference Equation (2) associated with it. This collection of equations can be written as a matrix equation where the coefficient matrix is tri-diagonal. Such systems of linear equations are readily solved using Gaussian elimination. The elements of this matrix depend on $C$ and $K$ which depend on $\theta$. At each time step, $c^{j}$ and $K^{j}$ are initially taken as $\mathrm{Cj}^{j-1}$ and $\mathrm{KJ}^{\mathrm{j}-1}$. The total moisture content in a given soil profile is estimated from the values of $\mathrm{hj}^{\mathrm{j}}$ and also by mass balance (initial outflow + inflow). If option for iteration is chosen, then the iterations are carried out with estimated $C^{j+1}$ and $k^{j+1}$ from $h^{j+1}$ of last iterative solution at that time step. If convergence is not achieved within 10 iterations the $\Delta t$ is reduced by half and the process is repeated until convergence is satisfactory. If $\Delta t$ is less than the lower limit provided by the user, the program prints a message and proceeds without further iterations, to provide some data for review by the user.

\section{Probabilistic or Statistical Aspects--None.}

Assumptions and Simplifications--The primary assumptions are:

1. Richard's equation holds

2. Sufficient symmetry exists so that a one-dimensional model is adequate. 
Structure and Level of Detail--UNSAT1D is a one-dimensional model for simulating ground-water flow in the unsaturated zone. UNSATID simulates infiltration, vertical seepage, and plant uptake by roots as a function of the hydraulic properties of a soil, soil layering, the root growth characteristics of given crop in a given soil profile, evapotranspiration rates, and frequency, rate, and amount of rainfall and/or irrigation. UNSATID is designed for use under varied field conditions. The application of water can be in the form of rain, sprinkler, or flooding. Actual evapotranspiration can be estimated as a function of moisture content and potential evapotranspiration using on-off, linear decrease, logrithmic decrease, or combination methods. The soil profile can be homogeneous, heterogeneous, or layered. The hydraulic properties can be defined as polynomials or user mathematical equations. The root growth uptake has built-in options for the root suction, root-distribution or user defined mathematical model. The lower boundary conditions can be water table, dynamic, quasi-dynamic, or unit gradient.

Major Variables--Aside from the input variables, the major variables are the soil water potential (head or suction), moisture content, and flux at each node in the one-dimensional column.

Applicability, Limitations, Validity and Completeness--This code can be used in situations where a one-dimensional model is adequate. It is useful to predict the amount and rate of water entering and moving through a partiallysaturated flow system.

\section{References--}

Beyer, T. 1975. "Flecs User's Manual." Department of Computer Science, University of Oregon, Eugene, Oregon.

Bond, F. W., C. R. Cole and P. J. Gutknecht. 1982. "Unsaturated Flow Model (UNSAT1D) Computer Code Manual." To be published by EPRI. Research Project 1406-1.

Gupta, S. S., K. Tanju, D. Nie]sen, J. Biggar, C. Simmons, and J. MacIntyre. 1978. "Field Simulation of Soil-Water Movement with Crop Water Extraction." Water Science and Engineering Paper No. 4013. Department of Land, Air and Water Resources, University of California, Davis, California.

Acceptance and Adequacy--UNSAT1D is based on state-of-the-art research and is generally accepted by the research community both in the United States and abroad, as being as good as is possible given the present level of understanding. 


\section{Summary of Code}

Purpose and Scope--SUMATRA-1 was written to simulate the simultaneous flow of water and solutes transport in a one-dimensional (vertical) soil profile under transient saturated-unsaturated conditions.

Author--SUMATRA-1 was written by

Dr. M. Th. van Genuchten

U.S. Salinity Laboratory

4500 Glenwood Drive

Riverside, CA 92501

Code Functions-- SUMATRA-1 is based upon a Hermitian (cubic) finite element solution of the governing transport equations. The model includes such processes as linear equilibrium adsorption and zero- and first-order decay.

Potential Usage--This model is capable of performing a one-dimensional (vertical) simulation of a subsurface flow region. This flow system may have regions of saturated or unsaturated porous media. Hysteresis is not considered which restricts the usage to only one side of the wetting-drying front cycle.

Relation to NRC Issues--Not applicable as no list of issues currentiy exists for low-level radioactive waste treatment.

Restrictions--The code is in the public domain and is therefore available to the NRC.

Compatibility with Other NRC Codes--SUMATRA-1 is written in FORTRAN IV, using no speciat equipment, and is compatible with other FORTRAN codes.

\section{Summary of Findings}

General Critique--SUMATRA-1 is a one-dimensional code based on Hermitian (cubic) finite elements. van Genuchten (1978a) shows that this scheme produced excellent solutions though sometimes requiring more computing time than other methods.

SUMATRA- I may be used to study water and solute movement in onedimensional variably saturated non-homogeneous soil profile. The model considers both abrupt layering and smoothly changing soil properties.

Applicability to Medium--SUMATRA-1 is designed to simulate the simultaneous flow of water and solutes in a one-dimensional (vertical) soil profile 
under transient saturated-unsaturated conditions. The model is based upon a Hermitian (cubic) finite element solution of the governing transport equations, and includes such processes as linear equilibrium adsorption and zero- and first-order decay. Since hysteresis is not considered the usage of the model is restricted to only one side of the wetting-drying front cycle.

Sensitivity Analysis--SUMATRA-1 is based on Hermitian (cubic) finite elements (HFE). van Genuchten (1978a) contains a comparison obtained by solving the same problem using (HFE), finite differences (FD) linear finite elements with mass-lumping (MFE) and iinear finite elements without mass-lumping (LFE).

The HFE-scheme always generated the most accurate solutions of both the moisture and solute fronts when simulating the infiltration of water and chloride in a $125-\mathrm{cm}$ deep soil profile, but this occurred at the expense of somewhat more computation time. It is concluded that the FD- and MFE-schemes are preferred when infiltration in extremely dry soil needs to be simulated. The HFE-scheme seems more attractive for less extreme cases.

Code Verification--An example problem compares results obtained with the Hermitian finite element scheme with those generated with a newly developed analytical solution for solute movement under steady-state flow conditions. The example was used to check the programining accuracy of the various decay terms in the transport equation.

\section{Field Verification--None.}

\section{II1. General Description}

Operating Characteristics--SUMATRA-1 is written in FORTRAN IV. It consists of the main program and nine subprograms. The program listings are contained in van Genuchten (1978a).

Inputs--Input includes possibly making changes to one or more of the function subprograms $8 C$, SPR and SPS. BC supplies the transient data for the boundary conditions at the soil surface. SPR defines the hydraulic functions

$$
\begin{aligned}
& \theta(h)=\text { moisture content } \\
& K(h)=\text { hydraulic conductivity } \\
& C(h)=\text { moisture capacity } \\
& h(\theta)=\text { pressure head }
\end{aligned}
$$

for each soil type. The function SPS specifies the soil physical and chemical parameters.

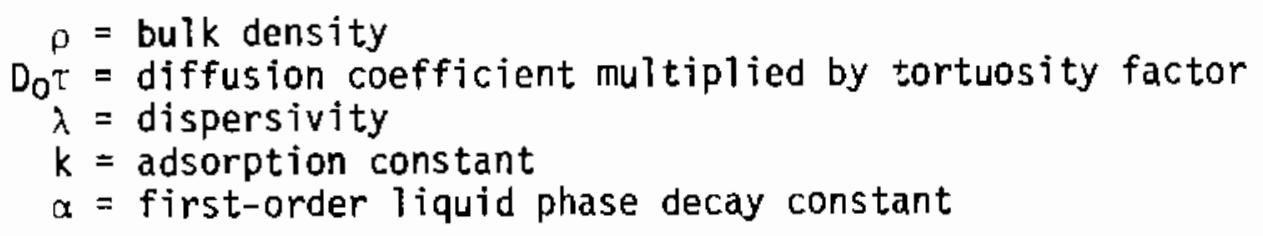


$\beta=$ first-order solid phase decay constant

$\gamma=$ zero-order liquid phase decay constant

for each soil type.

In addition, the following data is required:

Program control parameters

Grid definition

Soil type specifications

Initial pressure head or moisture content

Initial pressure gradients or moisture gradient

Initial concentration

Initial concentration gradient

Outputs--SUMATRA-1 output is entirety to the line printer and consists of the initial input data and for specified points in time the pressure head, moisture content and solute concentrations are printed for every node.

Available Documentation--SUMATRA-1 is documented in van Genuchten (1978a). van Genuchten (1978b) reports the solution of the flow equation and van Genuchten (1978a) discusses primarily solution of the transport equation. SUMATRA-1 is listed in van Genuchten (1978a) which also contains input preparation instructions.

IV. Review of Theory

Equations--The partial differential equation governing the one-dimensional vertical flow of water in a saturated-unsaturated medium is given by:

$$
L_{w}(h) \equiv \frac{\partial}{\partial x}\left(k \frac{\partial h}{\partial x}-k\right)-c^{*} \frac{\partial h}{\partial t}=0
$$

where

$\mathrm{C}^{*}$ is the specific soil moisture capacity $\left(\mathrm{L}^{-1}\right)$,

$h$ is the pressure head $(L)$,

$K$ is the hydraulic conductivity $\left(L T^{-1}\right)$,

$x$ is the vertical distance (positive down) (L), and

$t$ is the time $(T)$.

The initial condition of the system is given by

$$
h(x, 0)=h_{i}(x)
$$


One of the following two boundary conditions may be specified at the soil surface $(x=0)$

$$
\begin{aligned}
& h(0, t)=h_{0}(t) \\
& \left.\left(-k \frac{\partial h}{\partial x}+k\right)\right|_{x=0}=q_{0}(t)
\end{aligned}
$$

where $q_{0}(t)$ represents the actual (net) flux at the soil surface (precipitation + irrigation - evaporation). Similar boundary conditions may also be applied to the lower boundary of the soil profile $(x=\ell)$, i.e.,

$$
h(l, t)=h_{\ell}(t)
$$

or

$$
\left.\left(-K \frac{\partial h}{\partial x}+K\right)\right|_{x=\ell}=q_{\ell}(t)
$$

where $q_{\ell}(t)$ represents the imposed drainage flux. For a free draining profile $q_{l}(t)$ equals $k$ at $x=l$, and $(6)$ reduces to

$$
\left.\frac{\partial h}{\partial x}\right|_{x=\ell}=0
$$

The solution of the chemical transport equation requires an expression relating the adsorbed concentration (S) with the solution concentration (c). Assuming only single-ion equilibrium transport and the general adsorption isotherm to be of the form

$$
S=k c
$$

where

$k$ is an empirical constant $\left(M^{-1} L^{3}\right)$ gives 


$$
L_{s}(c)=\frac{\partial}{\partial x}\left(\theta D \frac{\partial c}{\partial x}-q c\right)-\frac{\partial}{\partial t}(\theta R c)+(\alpha \theta+\beta \rho k) c+\gamma \theta
$$

where the retardation factor $R$ is defined as

$$
R=1+\frac{p k}{\theta} .
$$

and where

$C$ is the solution concentration $\left(\mathrm{ML}^{-3}\right)$,

$D$ is the dispersion coefficient $\left(L^{2} T^{-1}\right)$,

$S$ is the adsorbed concentration,

$q$ is the volumetric flux $\left(\mathrm{LT}^{-1}\right)$,

$\alpha$ is a first-order rate constant (liquid phase) $\left(T^{-1}\right)$,

3 is a first-order rate constant (solid phase) $\left(T^{-1}\right)$,

$\gamma$ is a zero-order rate constant (liquid phase) $\left(\mathrm{ML}^{-3} \mathrm{~T}^{-1}\right.$ ),

$O$ is the volumetric moisture content $\left(L^{\circ}\right)$,

$\rho$ is the bulk density $\left(\mathrm{ML}^{-3}\right)$.

Equation (8) is the chemical transport equation solved in SUMATRA-1.

The initial condition for the concentration is given by

$$
c(x, 0)=c_{j}(x) .
$$

The following mixed (or third-type) boundary condition may be specified at the soil surface

$$
\left.\left(-\theta D \frac{\partial c}{\partial x}+q c\right)\right|_{x=0}= \begin{cases}q_{0}(t) c_{0}(t) & \text { if } q_{0}(t)>0 \\ 0 & \text { if } q_{0}(t) \leq 0\end{cases}
$$

where $q_{0}(t)$ is the same as in (4), and where $c_{0}(t)$ is the concentration of the infiltrating water. Note that the solute flux becomes zero during periods of evaporation $\left(q_{0}<0\right)$ and redistribution $\left(q_{0}=0\right)$. In some cases it may be necessary to specify a first-type boundary condition at the soil surface. In that case (11) should be replaced by 


$$
c(0, t)=c_{0}(t) .
$$

The following boundary condition at $x=\ell$ may be used when a free draining profile is considered

$$
\left.\frac{\partial c}{\partial x}\right|_{x=\ell}=0 .
$$

In some cases it may be necessary to specify a first-type boundary condition at the lower boundary of the soil profile; for example when, during periods of excessive evaporation, the profile is in contact with saline ground water. In that case one has

$$
c(l, t)=c_{\ell}(t)
$$

where $c_{\ell}(t)$ is the concentration of the ground water. Equation (14) holds only for upward flow of water at $x=\ell$, i.e., for $q_{l}(t)<0$.

Numerical Approximations--Galerkin-finite element techniques are used to solve the governing flow and transport equations. Only the solution procedure for the transport equation will be given here, the treatment of the flow equation is quite parallel.

In the finite element approach the dependent variable, $c$, is approximated by a finite series of the form

$$
c(x, t) \simeq \hat{c}(x, t)=\sum_{j=1}^{n} \phi_{j}(x) a_{j}(t)
$$

where the $\phi_{j}(x)$ are the selected basis (or shape) functions, and the $a_{j}(t)$ unknown, time dependent coefficients which represent solutions of (8) at specified points ("nodes") within the solution domain. Beçause only a finite number of basis functions are used in (15), the residual $L_{S}(\hat{C})$, obtained by substituting (15) into (8), will not become zero but attain a certain non-zero value. The residual is minimized by making $L_{s}(\hat{c})$ orthogonal to the set of basis functions $\phi_{j}(x)$ in (15), resulting in the following set of $n$ equations in $n$ unknowns

$$
\int_{0}^{\ell} L_{s}\left[\sum_{j=1}^{n} \phi_{j}(x) a_{j}(t)\right] \phi_{i}(x) d x=0 \quad j=1,1, \ldots, n
$$


Substitution of (8) into (16) and further simplification will load to a set of $r$ ordinary differential equations of the form

$$
[A]\{X\}+[B]\left\{\frac{d X}{d t}\right\}=\{F\}
$$

where the coefficients $[A],[B]$ and $[F\}$ represent arrays which are functions of the spatial coordinate, and where $\{X\}$ is a vector containing the unknown, time dependent coefficients aj $(t)$.

The treatment of the time derivatives proceeds along a different route than is usually seen in the literature. Equation ( 8 ) is replaced by a similar equation where the time derivatives have been replaced with finite differences and where the dispersion coefficients aitered. The new equation is

$$
\begin{aligned}
L_{s}(c) \equiv & \frac{(\theta R c)^{t+\Delta t}-(\theta R c)^{t}}{\Delta t} \\
& -\frac{1}{2}\left[\frac{\partial}{\partial x}\left(\theta D^{-} \frac{\partial c}{\partial x}-q c\right)+(\alpha \theta+\beta \rho k) c+\gamma \theta\right] t+\Delta t \\
& -\frac{1}{2}\left[\frac{\partial}{\partial x}\left(\theta D^{+} \frac{\partial c}{\partial x}-q c\right)+(\alpha \theta+\beta \rho k) c+\gamma \theta\right] t=0
\end{aligned}
$$

where

$$
\begin{aligned}
& D^{-}=D-\frac{q^{2} \Delta t}{6 \theta^{2} R} \\
& D^{+}=D+\frac{q^{2} \Delta t}{6 \theta^{2} R}
\end{aligned}
$$

Equation (18) is essentially a centered-in-time, Crank-Nicolson type scheme with correction factors applied to the dispersion coefficients. Note that the correction factors are different for the old and new time levels. 
The finite element analysis, starting with (18) instead of (9), proceeds along familiar lines. Substitution of (18) into (16) and integrating by parts the spatial derivatives yields the following matrix equation

$$
[P]^{t+\Delta t}\{X\}^{t+\Delta t}=[Q]^{t}\{X\}^{t}+\{S\} .
$$

The coefficient matrices [P], [Q] and the vector $\{\mathrm{S}\}$ are given on pages 12 and 13 of van Genuchten (1978a). The unknown vector $\{x\} t$ has $a_{j}(t)$ for the $i$ th component. Once $\{x\}^{t+\Delta t}$ is obtained by solving (21) the approximate solution $\hat{c}(x, t+\Delta t)$ is obtained by substitution of $\{x\} t+\Delta t$ into (15).

The flow equation is approximately solved by applying the above method to (1) to yield $\hat{h}(x, t+\Delta t)$.

The basis functions used in SUMATRA-1 are based on Hermitian polynomials and permit the user to not only solve for the values of the function but also solve for the values of the spatial derivatives. A discussion of these basis functions appear in van Genuchten (1978a).

\section{Probabilistic or Statistical Aspects--None.}

Assumptions and Simplifications--The main assumptions are:

Darcy's Law is valid

Only single-ion equilibrium transport occurs

The general adsorption isotherm is linear

The one-dimensional geometry is adequate

Structure and Level of Detail--SUMATRA-1 models the flow system as a soil column in one-dimension.

Major Variables--Aside from the input parameter, the major variables are the hydrautic heads, moisture contents, and solute concentrations.

Applicability, Limitations, Validity and Completeness--This code is applicable to both saturated and unsaturated flow and solute transport in a porous medium. The application must be restricted to those problems where a one-dimensional model is adequate. For those problems where SUMATRA-1 can be applied, it shoutd be economical to use.

\section{References--}

van Genuchten, M. Th. 1978a. "Mass Transport in Saturated-Unsaturated Media: One-Dimensional Solutions" Research Report 78-WR-11, Water Resources Program, Department of Civil Engineering, Princeton University, Princeton, New Jersey. 
van Genuchten, M. Th. 1978b. "Numerical Soltuions of the One-Dimensional Saturated-Unsaturated Flow Equation" Research Report 78-WR-9, Water Resources Program, Department of Civil Engineering, Princeton University, Princeton, New Jersey.

Acceptance and Adequacy--SUMATRA-1 is based on state-of-the-art research and is generality accepted by the research community as being about as good as is possible given the present level of understanding. 



\section{Summary of Code}

Purpose and Scope--TARGET was developed at Dames \& Moore for prediction of coupled hydrodynamics, heat transfer and chemical-species transport in saturated and unsaturated porous media.

Authors--TARGET was developed at Dames \& Moore by

Dr. Devraj Sharma

Manager, Advanced Technology Center

Dames \& Moore

1626 Cole Boulevard

Golden, CO 80401

Code Functions--TARGET is an integrated finite difference model of groundwater flow and effluent transport under transient conditions. The model permits zero and first order decay of reacting chemical species being transported by the ground water. Provisions are also made for heat transfer, a useful feature for radioactive waste studies. The numerical procedure used to solve the differential equations is computationally economical.

Potential Usage--TARGET should be of interest to the NRC because of its heat transfer and chemical species transport features. The model is capable of performing three-dimensional simulations of transient ground-water flow through variably saturated multilayered soils.

Relation to NRC Issues--Not applicable as no list of issues currently exists for low-level radioactive waste treatment.

Restrictions--This code is propriatory, owned by Dames \& Moore.

Compatibility with Other NRC Codes--TARGET is written in FORTRAN IV, using no special equipment and is compatible with other NRC codes.

\section{Summary of Findings}

General Critique--The code is not available directly for use by the NRC since it is owned by Dames \& Moore. This propriatory nature results in few open literature publications about the code. The code is quite flexible permitting its application to many different types of problems. The code has the capability to treat heat transfer problems.

Applicability to Medium--TARGET was designed to simulate transient groundwater flow through variably saturated soils. It has the capability to deal 
with both chemical species transport and heat transfer. These later two features are not available in many models. The simulation can also be carried out in one-, two- or three-dimensions.

Sensitivity Analysis--No extensive data have been published. Dames \& Moore (1980) contains results of some one-dimensional tests comparing TARGET results with results obtained by using another model and laboratory experiments. The comparison shows good agreement.

Code Verification--The code was verified by using a one-dimensional experiment of steady infiltration into a uniform sand column assumed to be uniformly unsaturated initially. Similarly the sand column was assumed to be uniformly saturated initially, the top surface maintained as impermeable while the column was drained.

Field Valjdation--None reported.

III. General Description

Operating Characteristics--TARGET is written in FORTRAN IV and is operational on a CDC 6600 computer.

Inputs--Input to TARGET includes:

Grid geometry

Initial pressure heads

Initial moisture contents

Initial concentrations of any chemical species being transported

Initial temperatures

Boundary specifications

Boundary flow specifications

Soil properties

Outputs--Output includes

All input data initialiy

Pressure heads

Velocities

Concentrations of chemical species

Temperature

Available Documentation--Since TARGET is a propriatory code the documentation is quite limited. Dames \& Moore (1980) contains some sketchy information.

IV. Review of Theory

Equations--The partial differential equation governing the distribution of "pressure head" in unsaturated-saturated regions within undeformable soils is

D. 18.2 


$$
\left[\frac{\partial}{\partial \psi}^{\left(n S_{+}\right)}\right] \frac{\partial \psi}{\partial t}=\sum_{i=1}^{3} \sum_{j=1}^{3} \frac{\partial}{\partial x_{i}}\left\{k_{+} k_{i j}\left(\frac{\partial \psi}{\partial x_{j}}+\frac{\partial z}{\partial x_{j}}\right)\right\}+s^{\psi}
$$

where

$$
\begin{aligned}
& \psi \text { is pressure head } \\
& n \text { is porosity } \\
& S_{+} \text {is saturation } \\
& t \text { is time }
\end{aligned}
$$

$x_{i}$ is spatial coordinate

$K_{.}$is relative hydraulic conductivity of unsaturated media

$k_{i j}$ is tensorial form of saturated hydraulic conductivity

$z$ is vertical spatial coordinate

$S^{\phi}$ is source (and/or sink) term for $\phi$.

Implicit in Equation (1) is the definition of Darcy velocity for unsaturated flows:

$$
U_{i}=-\sum_{j=1}^{3} k_{T} k_{i j}\left(\frac{\partial \Psi}{\partial x_{j}}+\frac{\partial z}{\partial x_{j}}\right)
$$

The equation governing the concentration of the $l^{\text {th }}$ chemical species of concern is expressed as:

$$
\begin{aligned}
& \frac{\partial}{\partial t}\left\{n S_{+} c_{\ell}\left[1+\left(\frac{i-n}{n}\right)\left(\begin{array}{cc}
\rho_{s} & \frac{k_{d \ell}}{\rho} \\
S_{+}
\end{array}\right) c_{\ell}^{m-1}\right]\right\}+\sum_{i=1}^{3} \frac{\partial}{\partial x_{j}}\left(U_{i} C_{\ell}\right) \\
= & \sum_{i=1}^{3} \sum_{j=1}^{3} \frac{\partial}{\partial x_{i}}\left\{D \ell_{i, j} \frac{\partial C_{\ell}}{\partial x_{j}}\right\}+s^{C_{l}}
\end{aligned}
$$

where

$C_{\ell}$ is concentration of $\ell^{\text {th }}$ chemical species

$\rho_{s}$ is dry density of soil matrix

$\rho$ is density of water 
$K_{d \ell}$ is distribution coefficient for species $\ell$ in the Freundlich equation

$m$ is exponent in chemical kinetic term $D \ell_{i, j}$ is dispersion coefficient of species $\ell$ as a variable in coordinate
directions $i$ and $j$.

The equation governing conservation of themal energy may be expressed as:

$$
\frac{\partial}{\partial t}\left(\bar{C}_{v} T\right)+\sum_{i=1}^{3} \frac{\partial}{\partial x_{i}}\left(U_{i} \bar{C}_{p} T\right)=\sum_{i=1}^{3} \frac{\partial}{\partial x_{i}}\left(\Gamma_{x_{i}}^{\top} \frac{\partial T}{\partial x_{i}}\right)+s^{\top}
$$

where

$\bar{C}_{v}$ is average specific heat capacity at constant volume

$\bar{C}_{p}$ is average specific heat capacity at constant pressure

$T$ is temperature

$\Gamma_{\mathrm{x}_{i}}^{\phi}$ is effective hydraulic conductivity or dispersion coefficient for

The relationship between unsaturated permeability and suction pressure, as well as that between moisture content and suction pressure, are usually obtained empirically for each soil type. One set of such relationships is:

$$
\begin{aligned}
& K_{+}=\left\{1+\left[a_{0 K}(-\psi)\right]^{a_{1 K}}\right\}^{-a_{2 K}}, \\
& \left.\left.S_{+}=\frac{\theta_{R}}{\theta_{S}}+\left(1-\frac{\theta_{R}}{\theta_{S}}\right)\right\}_{1}+\left[a_{O S}(-\psi)\right]{ }^{a_{1 S}}\right\}^{-a_{2 S}, \quad(-\infty<\psi \leq 0) .}
\end{aligned}
$$

The pressure head is defined by:

$$
\psi \equiv \frac{p}{\rho\left(g / g_{C}\right)}
$$


The dispersion coefficient $D \ell_{j}, j$ is obtained empirically, usually with reference to laboratory-scale experiments. The adsorbed/desorbed concentration of solute in the solid matrix is usually expressed on the assumption of a simple equilibrium reaction, thus:

$$
c_{S_{\ell}}=K_{d \ell} c_{\ell}^{m}
$$

This expression is called the Freundlich equation and $K_{d l}$ is the familiar distribution coefficient.

In order to complete the mathematical specification of a given problem, both initial and boundary conditions are required to be specified. Initial conditions, supplied over the entire domain selected for solution, must include values of:

- moisture content, $\theta$; and when appropriate

- concentration of species, $\ell, C_{l}$.

Boundary conditions on the boundaries of the domain must be specified with respect to:

- type of flow boundary and related flow quantities;

- nature of boundary in respect of chemical species, if appropriate; and

- sources (and/or sinks) of mass on the boundaries of or within the doma in.

Numerical Approximations--The numerical algorithm adopted for the set of Equations (1) to (4) is based upon an integrated finite-difference technique designed to solve efficiently, partial differential equations of the general form:

$$
A \frac{\partial Q}{\partial t}+\frac{\partial(B Q)}{\partial x_{1}}=\frac{\partial}{\partial x_{1}}\left(C \frac{\partial Q}{\partial x_{1}}\right)+D
$$

Details of the technique are provided in Sharma (1979). It is emphasized here however, that the technique is particularly suited to nonlinear forms of the above equation. Specifically, coefficients A, B, C and D can be strong functions of $Q$ itself. Hence, the twin requirements that the technique satisfies the finite-difference form of the above equation at a grid node P, i.e., 


$$
\left\{\sum_{p} A-S N_{p}\right\} Q_{p}=\sum_{k} A_{k} Q_{k}+S O_{p}
$$

exactly and be iterative in order to account for the dependence of the coefficients upon the dependent variable itself, are both met. In (10) the following notation is used:

$$
\begin{aligned}
& S N_{P} \text { is component of linearized source term at node } P \\
& S \mathrm{O}_{\mathrm{P}} \text { is component of linearized source terms at node } P \\
& k \text { is the index ranging over the neighboring grid lines in space } \\
& \text { about the grid node } P
\end{aligned}
$$

The sets of simultaneous algebraic equations noted above are solved by the efficient application of an alternating-direction, heavily-implicit, lineby-line solution algorithm coupled to a plane-by-plane block correction procedure. Details are provided in Sharma (1979). This algorithm applied iteratively leads to relatively monotonic solutions for most problems with commonly-encountered boundary conditions.

\section{Probabilistic or Statistical Aspects--None.}

Assumptions and Simplifications--The assumptions imposed include:

- Darcy's law holds and pressure head gradients are the only significant driving mechanisms for fluid flow

- The source term in the describing equation may be dependent on the temperature

- The hydraulic conductivity at each point is experienced as a symmetric tensor $K_{+} K_{k j}$ where $K_{+}$is the relative hydraulic conductivity of the unsaturated media and $K_{i j}$ is the saturated hydraulic conductivity. $K+$ ranges from 0 to 1 .

- Vapor diffusion in the unsaturated zone is not considered.

Structure and Level of Detail--The integrated finite difference technique allows the user to define the discretization grid to yield much detail in some regions of interest and use large cells where details are not important.

Major Variables--The major variables used in TARGET are

Pressure head

Flow rates

Chemical species concentrations

Temperature. 
Applicability, Limitations, Validity and Completeness--This model is applicable to both saturated and unsaturated flow systems where thermal energy transfer and chemical transport are of interest. The integrated finite difference method allows one to apply the same model in one-, two- or threedimensional situations.

\section{References--}

Dames \& Moore. 1980. "Detailed Seepage Investigation of Mi11 Waste Disposal Alternatives, West Gas Hills, Wyoming, for Federal American Partners" Volume II, Dames \& Moore Job 10500-004-06, Sa1t Lake City, Utah.

Sharma, D. 1979. "A Comprehensive Mathematical Model Capable of Predicting Flow, Heat Transfer as Well as Chemical-Species Transport in Porous Media," Dames \& Moore, Advanced Technology Group, Rep. TN-DN-42.

Acceptance and Adequacy--This model is based on state-of-the-art research and is generality accepted by the research community as being about as good as is possible given the present level of understanding. 



\title{
I. Summary of Code
}

Purpose and Scope--FEMWATER (A Finite-Element Model of water Flow through Saturated-Unsaturated Porous Medial was developed to simulate ground-water dynamics in saturated-unsaturated subsurface systems.

Authors--FEMWATER was developed at Oak Ridge National Laboratory by G. T. Yeh and D. S. Ward. It is an extension of work done by Reeves and Dugid (1976). Prime contact is:

\author{
Dr. G. T. Yeh \\ Room 203, Bldg. 1505 \\ Oak Ridge National Laboratory \\ P.0. Box X \\ Oak Ridge, TN 37830 \\ Phone: (615) 574-7285
}

Code Functions--FEMWATER is a finite-element model of water flow through porous media to simulate the ground-water dynamics in saturated-unsaturated subsurface systems. The response of the ground-water basin to the rainfall, artificial withdrawal, and other recharge or discharge sources (such as lakes, reservoirs, and streams) may be included in the simulation.

The aquifer to be modeled may be given an areal description or may be cross sectional. Aquifer parameters may be distributed or zoned and the system may be anisotropic. The model considers nonlinearities by allowing the storage term and the hydraulic conductivity to be a function of the pressure head. Three types of boundary conditions are considered; they all may be functions of time. Additionally, the flow field is computed in a manner consistent with the finite element approach, thus obtaining continuity of the velocities at the nodes of the finite element mesh.

Potential Usage--This model is capable of performing a two-dimensional simulation of an aquifer system. This system may have regions of unsaturated or saturated porous media. FEMWATER produces not only a continuous pressure distribution, but also a continuous velocity field. This continuous velocity field is used as input to the companion code, FEMWASTE, which simulates the contaminant transport in such a medium.

Relation to NRC Issues--Not applicable as no list of issues currently exists for low-level radiation waste treatment. to the NRC.

Restrictions--The code is in the public domain and is therefore available 
Compatibility with Other NRC Codes--FEMWATER is written in FORTRAN IV using no special equipment, hence it is compatible with other NRC codes.

\section{Summary of Findings}

General Critique--The code may be useful to the NRC for the analys is of the flow patterns and pressure distributions in a saturated or unsaturated aquifer system. Boundary conditions consist of specified head, specified flux or a mixture of the two (seasonal variation). The model analyzes an aquifer from a plane cross-sectional or areal viewpoint. However, radial coordinates have not been implemented; this would be a major disadvantage in the analysis of radial we1l flow problems.

FEMWATER is an extension of the work performed by Duguid and Reeves (1976) in which the continuity equation of water mass governing the distribution of pressure head is solved by the Galerkin finite-element method subject to appropriate boundary and initial conditions. The flow field is then computed with Darcy's Law by taking the derivatives of the calculated pressure field. Inherent in that approach, however, is the resulting discontinuity in the velocity at element boundaries and nodal points, which unfortunately leads to a violation of the conservation of mass in a local sense. When the spatial distribution of the velocity is significant in the region, inputting this discontinuous flow field to the contaminant transport computation could conceivably produce a large error. FEMWATER incorporates a technique to overcome this problem by solving Darcy's law for the velocity field at nodal points by the finiteelement method rather than by taking the derivatives of the pressure field. This approach is consistent with the spirit of finite-element methods, and yields a continuous velocity over the whole region of interest, including element boundaries and nodal points.

Applicability to Medium--FEMHATER is designed to simulate saturated or unsaturated water flow subject to variable boundary or initial conditions. The code is applicable to most porous media as long as vertical or horizontal averaging is valid and a two-dimensional simulation is performed.

Sensitivity Analysis--A comparison of velocity components simulated by the original code by Duguid and Reeves (1976) to FEMHATER was performed. Unique velocity fields are obtained by the revised model, while the discontinuous velocity fields at all nodal points appear by the old model. The discontinuity ranges from several hundred percent to negligible. The overall mass loss through boundaries for the transient problem is much reduced from $23.8 \%$ to $2.2 \%$ for one case and from $29.7 \%$ to $3.6 \%$ for another case.

Code Verification--Two sample problems to which solutions had previously been obtained by other validated numerical models, namely, 1) the seepage pond problem, and 2) the Freeze transient problem, were solved. In addition, results by all six alternative numerical schemes were compared in both examples, and reported in Yeh and Ward (1979). 
Field Validation--None.

\section{General Description}

Operating Characteristics--FEMWATER is written in FORTRAN for use on an IBM 360 machîne.

Inputs--Inputs for FEMWATER include:

Grid geometry

Initial heads

Prescribed head and flux boundary conditions

Hydraulic conductivity tensor

Modified storage coefficient

Material properties

Outputs--Output for FEMWATER consists of the pressure distribution and velocity field at each time step.

Available Documentation--FEMWATER is documented in Yeh and Ward (1979) and in Yeh (1982).

IV. Review of Theory

Equations--The governing equations to describe the pressure field in a two-dimensional subsurface system are obtained from the principle of conservation of mass and Darcy's law. This can be written in the form

$$
F \frac{\partial h}{\partial t}-\left[\frac{\partial}{\partial x}\left(K_{x x} \frac{\partial H}{\partial x}+K_{x z} \frac{\partial H}{\partial z}\right)+\frac{\partial}{\partial z}\left(K_{z x} \frac{\partial H}{\partial x}+K_{z z} \frac{\partial H}{\partial z}\right)\right]-Q=0
$$

where

$$
F=\frac{\theta}{\phi} \alpha^{\prime}+\beta^{\prime} \theta+\frac{d \theta}{d h},
$$

and

$$
H=h+2 \text {, }
$$

in which $\mathrm{h}$ is the pressure head; $\theta$ is the moisture content; $\phi$ is the effective porosity; $\alpha^{\prime}$ and $\beta^{\prime}$ are the modified coefficients of compressibility of the 
medium and water, respectively; $K_{x x}, K_{x z}, K_{z x}$, and $K_{z z}$ are the hydraulic conductivity tensor components; $x$ and $z$ are the horizontal and vertical coordinates, respectively; $t$ is the time; $Q$ is the artificial recharge or withdrawal.

Equation (1) is defined over a region $R$ in the $x-z$ plane. $R$ is bounded by the curve $B(x, z)$ which is composed of four parts, one which is denoted as $B_{1}$, the impervious part of the boundary. Three types of boundary conditions are considered in the program. These boundary conditions partition the remaining parts of $B$ into $B_{1}, B_{2}$ and $B_{3}$.

In the first type (Dirichlet) boundary the pressure head is prescribed as a known function of time and $(x, z)$ on $B_{1}$. In the second type (Neumann) boundary the flux is prescribed as a known function of time and $(x, t)$ on the $B_{2}$ portion of the curve $B$. The third type is variable in the sense that either Dirichlet or the Neumann conditions may prevail as known functions of time, and $(x, z)$ on the $B_{3}$ portion of $B$.

Thus the boundary condition equations are

$$
h=h_{1}(x, z, t)
$$

on $\mathrm{B}_{1}$,

$$
-\left[\left(k_{x x} \frac{\partial h}{\partial x}+k_{x z} \frac{\partial h}{\partial z}+k_{x z}\right) \cdot n_{x}+\left(k_{z x} \frac{\partial h}{\partial x}+k_{z z} \frac{\partial h}{\partial z}+k_{z z}\right) \cdot n_{z}\right]=q z
$$

on $B_{2}$, and

$$
h=h_{3}(x, z, t)
$$

or

$$
-\left[\left(k_{x x} \frac{\partial h}{\partial x}+k_{x z} \frac{\partial h}{\partial z}+k_{x z}\right) \cdot n_{x}+\left(k_{z x} \frac{\partial h}{\partial x}+k_{z z} \frac{\partial h}{\partial z}+k_{z z}\right) \cdot n_{z}\right]=q_{3}
$$

on $B_{3}$. In Equations (3) and (5) $n_{x}$ and $n_{z}$ are the directional cosines of the outward unit vector normal to the boundary at the point of application.

Initially, Equation (5) is applied to the boundary $B_{3}$ when the exact boundary conditions cannot in general be predicted a priori. Such a case 
would arise at the ground surface where either ponding (Dirichlet) or infiltration (Neumann) conditions could prevait. This can only be determined in the cyclic process of solving Equation (1).

In general, Equation (1) is nonlinear as both the soil properties, $F$, and hydraulic conductivity, $K$, are functions of the pressure head.

The initial condition of Equation (1) is assumed to be known as:

$$
h=h_{0}(x, z) \text { in } R \text {, }
$$

where $h_{0}$ is a known function of spatial coordinates $x$ and $z$. The function $h_{0}$ may be obtained by simulating the steady-state verion of (1) with timeinvariant boundary conditions.

After ( 1 ) is solved for the pressure head, $h$ [subject to initial and boundary conditions, (2) through (6)], the velocity components are then obtained from

$$
v_{x}=-\left(k_{x x} \frac{\partial h}{\partial x}+k_{x z} \frac{\partial h}{\partial z}+k_{x z}\right)
$$

and

$$
v_{z}=-\left(k_{z x} \frac{\partial h}{\partial x}+k_{z z} \frac{\partial h}{\partial z}+k_{z z}\right)
$$

Numerical Approximations--Equations (1) through (6) are solved by the Galerkin finite-element method. The region of interest is subdivided into an assemblage of smaller subdomains called elements. The quadrilateral bilinear element is used. Following the standard procedure of the Galerkin finiteelement method, an approximate formulation of the pressure head $h$ is obtained.

The variable $h$ is approximated in an element e by

$$
h \approx h=\sum_{j=1}^{4} h_{j}(t) N_{j}
$$

where $N_{j}$ and $h_{j}$ are the basis function of element $e$ and the amplitude of $h$, respectively, at nodal point $f$. 
Using the Galerkin weighted residual procedure over the domain $R$, one obtains the following element matrix equation for element $e$ :

$$
\left[M_{i j}\right]\left\{\dot{h}_{j}\right\}+\left[s_{i j}\right]\left\{h_{j}\right\}+\left\{D_{i}\right\}+\left\{Q_{i}\right\}=0
$$

where the temporal derivative of the head, $h_{\mathfrak{i}}$ is given as:

$$
\dot{h}_{i}=\frac{d h_{i}}{d t}
$$

and where the matrix equation coefficients may be found in Yeh and Ward (1979), page 8.

Finite-difference methods are typically used in the approximation of the time derivative. Three time-marching methods are adopted in the present water flow model. In the first one, the central or Crank-Nicolson formulation $v$ is used, in which the required matrices are evaluated at $(t+\Delta t / 2)$. In the second method the backward difference formulation is used in which the required matrices are evaluated at $t+\Delta t$. In the third optional method, the values of the unknown variables assumed to vary linearly with time during the time interval $\Delta t$. In this mid-difference method, the required matrices are all evaluated at $t+\Delta t / 2$. This option has been shown superior to the central or backward-difference formulation, if the mass matrix is not lumped.

In summary, all element matrix equations presented in this section can be written as:

$$
\left[C_{i j}\right]\left\{h_{j}\right\}=\left\{R_{i}\right\}-\left\{Q_{i}\right\}
$$

where $\left[C_{j j}\right]$ is the element coefficient matrix, $\left\{h_{j}\right\}$ is the unknown vector to be found, and $\left\{R_{j}\right\}$ is the element load vector.

It is important to note that the model also applies the Galerkin technique to Darcy's law so as to produce a continuous flow field. This avoids discontinuities of the flow field at the nodes.

Probabilistic or Statistical Aspects--None.

Assumptions and Simplifications--The main assumptions are:

- Darcy's law is valid and hydraulic-head gradients are the only significant driving mechanisms for fluid flow. 
- The noniinear soil properties, $F$, and the hydraulic conductivity, $K$, are functions of the pressure head, $h$, only.

Structure and Level of Detail-FEMWATER models an aquifer either from an areal viewpoint or as a cross section. The domain is discretized using fournoded isoparametric finite elements of almost any quadrilateral shape. The time domain is discretized by finite-difference techniques.

Major Variables --Asjde from the input parameters, the major variables are the hydraulic heads.

Applicablity, Limitations, Validity and Completeness--This code is applicable to both saturated or unsaturated flow in a porous medium. This has evident advantages over codes that only model saturated flow. The code is limited to two-dimensional flow problems.

\section{References--}

Yeh, G. T., and D. 5. Ward. 1979. "FEMWATER: A finite-Element Model of Water Flow Through Saturated-Unsaturated Porous Media," Oak Ridge National Laboratory Report ORNL-5567.

Yeh, G. T. (1982). "Training Course No.1: The Implementation of FEMWATER (ORNL-5567) Computer Program--Final Report." NUREG/CR-2705.

Reeves, M., and J. O. Duguid. 1976. "Water Movemennt Through SaturatedUnsaturated Porous Media: A Finite-Element Galerkin Model," Oak Ridge Nationa] Laboratory Report ORNL-4927.

Acceptance and Adequacy--The physics of flow in the unsaturated zone is less fully understood than that for flow in the saturated zone. This code is based on state-of-the-art research and is generally accepted by the research community as being about as good as is possible given the present level of understanding. 

Mode] Name: FEMWASTE

Code No. 25

Type: Transport

\section{Summary of Code}

Purpose and Scope--FEMWASTE (A Finite-Element Model of Waste Transport Through Saturated-Unsaturated Porous Medial was developed to simulate the transport of dissolved constituents by ground water through saturatedunsaturated subsurface sytems.

Authors--FEMWASTE was developed at Oak Ridge National Laboratory by G. T. Yeh and D. S. Ward. It is an extension of work done by Duguid and Reeves (1976). Prime contact is:

Dr. G. T. Yeh

Room 203, B1dg. 1505

Oak Ridge Nationa1 Laboratory

P.O. Box X

Oak Ridge, TN 37830

Phone: (615) 574-7285

Code Functions--FEMWASTE is a finite element model for the transport of dissoTved constituents by ground water through saturated-unsaturated porous media. Transport mechanisms include: advection, hydrodynamic dispersion, chemical sorption, and first-order decay. Implementation of quadrilateral isoparametric finite elements, bilinear spatial interpolation, asymmetric weighting functions, several time-marching techniques, and Gaussian elimination are employed in the numerical formulation. The waste transport model is compatible with the water flow model FEMWATER for predicting convective Darcy velocities in partially saturated porous media. FEMWATER is documented in Yeh and Ward (1979).

Potential Usage--FEMWASTE is capable of simulating the transport of dissolved constituents in a two-dimensional ground-water sytem. This system may have regions of saturated or unsaturated porous media. The velocity field for the ground water may be obtained by using the companion code FEMWATER.

Relation to NRC Issues--Not applicable as no list of issues currently exists for low-level radioactive waste treatment.

Restrictions--The code is in the public domain and is therefore available to the NRC.

Compatibility with Other NRC Codes--FEMWASTE is written in FORTRAN IV using no special equipment, hence it is compatible with other NRC codes. 


\section{Summary of Findings}

General Critique--The code may be useful to the NRC for the analysis of contaminant concentration distributions in a saturated or unsaturated aquifer system. Boundary conditions consist of specified concentrations, specified flux or a mixture of the two (seasonal variation). The model analyzes an aquifer from a plane cross-sectional or arial viewpoint. However, radial coordinates have not been implemented; this would be a major disadvantage in the analysis of radial well flow problems.

FEMWASTE is an extension of the work performed by Duguid and Reeves (1976) in which the distribution of the pollutant constituent is obtained from mass balance equations.

Applicability to Medium--FEMWATER is designed to simulate the transport of dissolved constituents by ground water through saturated or unsaturated flow sytems subject to variabie boundary or initial conditions. The code is applicable to most porous media as long as vertical or horizontal averaging is valid and a two-dimensional simulation is performed.

Sensitivity Analysis--A comparison is made with results obtained by the original code (Duguid and Reeves 1976; Reeves and Duguid 1976) using the original water movement model (Reeves and Duguid 1976) and the flow field produced by the companion code FEMWATER (Yeh and Ward 1979). The mass-balance error was reduced from $17 \%$ (old mode1) to $1 \%$ to $2 \%$ (new model), depending on the numerical scheme used.

Code Verification--A sample problem to which solutions had previously been obtained by other validated numerical mode1s is studied in Yeh and Ward (1981). This problem is the seepage pond problem given in Duguid and Reeves (1976). In addition, results by all twelve alternative numerical schemes were compared with this example.

Field Validation--None.

\section{General Description}

Operating Characteristics--FEMWASTE is written in FORTRAN for use on an IBM 360 machine.

Inputs--Inputs for FEMWASTE include:

Grid geometry

Initial concentrations

Prescribed concentration and flux boundary conditions

Material properties

Flow field velocity components 
Outputs--Output for FEMWASTE consists of the pressure distribution and velocity field at each time step.

Available Documentation--FEMWASTE is documented in Yeh and Ward (1981) and in Yeh (1982).

\section{Review of Theory}

Equations--The equation governing the distribution of a pollutant constituent in a two-dimensional subsurface porous system is obtained from the law of mass balance. It can be written in the form

$$
\begin{aligned}
& L(c)=\frac{\partial}{\partial t}(\theta c+\rho s)+(\theta c+\rho s) \alpha^{\prime} \frac{\partial h}{\partial t}+\left(\frac{\partial V_{x} c}{\partial x}+\frac{\partial V_{z} c}{\partial z}\right) \\
& -\left[\frac{\partial}{\partial x}\left(\theta D_{x x} \frac{\partial c}{\partial x}+\theta D_{x z} \frac{\partial c}{\partial z}\right)+\frac{\partial}{\partial z}\left(\theta D_{z x} \frac{\partial c}{\partial x}+\theta D_{z z} \frac{\partial c}{\partial z}\right)\right] \\
& +\lambda(\theta c+\rho s)-M=0
\end{aligned}
$$

where $\theta$ is the moisture content; $c$ is the concentration of dissolved constituent in the water; $\rho$ is the bulk density of the solid; $s$ is the concentration of the constituent that is adsorbed on the solid; $\alpha^{\prime}$ is the modified coefficient of compressibility of the medium; $h$ is pressure head of the water; $D_{x x}, D_{x z}, D_{z x}$, and $D_{z z}$ are the dispersion coefficient tensor components; $V_{x}$ and $V_{z}$ are the Darcian velocity components in the $x$ - and $z$-directions, respectiveiy; $\lambda$ is the decay constant; $M$ is the artificial source; $x$ and $z$ are the horizontal and vertical coordinates, respectively; $t$ is the time; and $L$ is an operator.

Equation (1) expresses the mass balance in an initially small bulk volume. The first term represents the rate of change of total mass (including dissolved and adsorbed) in the element volume. The second term is the mass change due to the change of the bulk volume under pressure. The third and fourth terms represent the mass fluxes out and into the volume by advection and dispersion, respectively. The fifth term is the mass change due to the decay while the last term is the artificial input or withdrawal. Variables, $\theta, h, v_{x}$, and $v_{z}$, in Equation (1) are obtained from the hydrodynamics of the subsurface flow system. The dispersion coefficient tensor is related to flow field and media properties as

$$
\begin{aligned}
& \theta D_{x x}=a_{T} V+\left(a_{L}-a_{T}\right) V_{x}^{2} / V+D_{m} T, \\
& \theta D_{x z}=\theta D_{z x}=\left(a_{L}-a_{T}\right) V_{x} V_{z} / V,
\end{aligned}
$$


and

$$
\theta D_{z z}=a_{T} V+\left(a_{L}-a_{T}\right) V_{z}^{2} / V+D_{m} T
$$

where $V=\sqrt{V_{x}^{2}+V_{z}^{2}}$; a and a are the transverse and longitudinal dispersivities, respectively; $T$ is the tortuosity; and $D_{m}$ is the molecular diffusion coefficient. The decay constant, $\lambda$, is a property of the constituent and $\rho$ and $\alpha^{\prime}$ are the properties of the porous media under consideration. The independent variables include: $x, z$, and $t$. Thus, there are two dependent unknowns, $c$ and $s$, in Equation (1) to be determined. An additional equation is required to completely define the system. It is assumed that the adsorption of the constituent by the solid is to occur at a rapid rate (i.e., a fast exchange reaction) such that the dissolved material is in equilibrium with the material adsorbed by the solid. This is expressed by the linear equation:

$$
s=K_{d^{c}}
$$

where $K_{d}$ is the distribution coefficient. Substituting (5) into (1), yields

$$
\begin{gathered}
L(c)=\theta R_{d} \frac{\partial c}{\partial t}+\left(\frac{\partial V_{x} c}{\partial x}+\frac{\partial V_{z} c}{\partial z}\right)-\left[\frac{\partial}{\partial x}\left(\theta D_{x x} \frac{\partial c}{\partial x}+\theta D_{x z} \frac{\partial c}{\partial z}\right)\right. \\
\left.+\frac{\partial}{\partial z}\left(\theta D_{z x} \frac{\partial c}{\partial x}+\theta D_{z z} \frac{\partial c}{\partial z}\right)\right]+\left(\frac{\partial \theta}{\partial t}+\alpha^{\prime} \theta R_{d} \frac{\partial h}{\partial t}+\lambda \theta R_{d}\right) c-M=0,
\end{gathered}
$$

where

$$
R_{d}=1+\frac{\rho K_{d}}{\theta}
$$

is the retardation factor, which is a measure of the delay of the breakthrough of the dissolved constituent.

Equation (6) is defined over a region $R$ in the $x-z$ plane. $R$ is bounded by the curve $B(x, z)$ which is composed of four parts, one which is denoted as $B_{1}$ is the impervious part of the boundary. Three types of boundary conditions are considered in the program. These boundary conditions partition the remaining parts of $B$ into $B_{1}, B_{2}$ and $B_{3}$. 
The first type of boundary conditions occurs on the Dirichlet boundaries where the concentration is prescribed by

$$
c=c_{1}(x, z, t) \text { on } B_{1} \text {, }
$$

where $c_{1}$ is a given function of time and $(x, z)$ on $B_{1}$. The second type occurs on the Aeumann boundaries where the normal gradient of the concentration is prescribed by

$$
\begin{aligned}
& -\left(\theta D_{x x} \frac{\partial c}{\partial x}+\theta D_{x z} \frac{\partial c}{\partial z}-V_{x} c\right) n_{x}-\left(\theta D_{z x} \frac{\partial c}{\partial x}+\theta D_{z z} \frac{\partial c}{\partial z}-v_{z} c\right) n_{z} \\
= & q_{2}(x, z, t)+\left(v_{x} n_{x}+v_{z} n_{z}\right) c \text { on } B_{2},
\end{aligned}
$$

where $n_{x}$ and $n_{z}$ are the directional cosines of the outward unit vector normal to the $B_{2}$ portion of the curve $B ; q_{2}(x, z, t)$ is the given function of time, $t$, and $(x, z)$ on $B_{2}$. The right-hand side of $(9)$ is zero when it is applied to impervious boundaries on which both $q_{2}(x, z, t)$ and the normal velocity, $\left(v_{x} n_{x}+v_{z} n_{z}\right)$, are equal to zero. If it is applied to the flow-through boundaries with outflows from the region, it becomes a concentration-dependent boundary condition and $q_{2}(x, z, t)$ is normally set to zero. When it is applied to the flow-through boundaries with inflows into the region, it degenerates into a third type (Cauchy) boundary condition

$$
\begin{aligned}
& -\left(D_{x x} \theta \frac{\partial c}{\partial x}+D_{x z} \theta \frac{\partial c}{\partial z}-v_{x} c\right) n_{x}-\left(D_{z x} \theta \frac{\partial c}{\partial x}+D_{z z} \theta \frac{\partial c}{\partial z}-v_{z} c\right) n_{z} \\
= & q_{3}(x, z, t) \text { on } B_{2},
\end{aligned}
$$

where $q_{3}$ is a given function of time and points $(x, z)$ on $B_{3}$ portion of $B$.

The initial condition for (6) is assumed to be known as:

$$
c=c_{0}(x, z) \quad \text { at } t=D \text { and }(x, z) \text { in } R \text {, }
$$

where $c_{0}$ is a given function of spatial coordinates, $x$ and $z ; R$ is a region bounded by the curve, $B(x, z)=0$. 
Numerical Approximations--Equations (6) through (10) are solved by the Galerkin finite-element method. The region of interest is subdivided into an assemblage of smaller subdomains called elements. Following the procedure of finite-element weighted-residual method, and employing quadrilateral bilinear elements for spatial discretization, approximate formulation of the concentration distribution, $c$, is obtained. The variable $c$ is approximated in an element e by

$$
c \cong c=\sum_{j=1}^{4} c_{j}(t) N_{j},
$$

where $\mathrm{N}_{j}$ and $\mathrm{C}_{j}$ are the basis functions (interpolating functions) of element $\mathrm{e}$ and the magnitude of $c$, respectively, at nodal point, $j$.

Using the Galerkin weighted-residual procedure over the domain $\mathrm{R}$ one rotains the following element matrix equation for element e

$$
\left[M_{i j}\right]\left\{\dot{c}_{j\}}\right\}+\left[s_{i j}\right]\left\{c_{j\}}\right\}+\left\{D_{i j}\right\}+\left\{Q_{i}\right\}=0,
$$

where

$$
\dot{c}_{j}=\frac{d c_{j}}{d t} \text {. }
$$

The $M_{i j}, S_{i j}, D_{i}$ and $Q_{i}$ are defined in Yeh and Ward (1981), p. 13-14.

Finite-difference methods are typically used in the approximation of the time derivative. Three time-marching methods are adopted in the present water flow model. In the first one, the central or Crank-Nicolson formulation is used, in which the required matrices are evaluated at $(t+\Delta t / 2)$. In the second method the backward difference formulation is used in wich the required matrices are evaluated at $t+\Delta t$. IN the third optional method, the values of the unknown variables assumed to vary lineariy with time during the time interval $\Delta t$. In this mid-difference method, the required matrices are all evaluated at $t+\Delta t / 2$. This option has been shown superior to the central or backwarddifference formulation, if the mass matrix is not lumped.

In summary, all element matrix equations presented in this section can be written as:

$$
\left.\left[C_{i j}\right] ; C_{j}\right\}=\left\{R_{i}|-| Q_{i} \mid\right.
$$


where $\left[C_{i j}\right]$ is the element coefficient matrix, $\left\{c_{j}\right\}$ is the unknown vector to be found, and $\left\{R_{j}\right\}$ is the element load vector.

Probabilistic or Statistical Aspects--None.

Assumptions and Simplifications--The main assumptions are:

Darcy's law holds

The system being studied is effectively two dimensional.

Structure and Level of Detail--FEMWASTE models an aquifer either from an areal viewpoint or as a cross section. The domain is discretized using fournoded isoparametric finite elements of almost any quadrilateral shape. The time domain is discretized by finite-difference techniques.

Major Variables--Aside from the input parameters, the major variables are the contaminant concentration.

Applicability, Limitations, Validity and Completeness--The code is limited to plane two-dimensional flow.

\section{References--}

Yeh, G. T., and D. S. Ward. 1981. "FEMWASTE: A Finite-Element Model of Waste Transport Through Saturated-Unsaturated Porous Medja," Oak Ridge National Laboratory, Report ORNL-5601, April.

Yeh, G. T. 1982. "Training Course No. 2: The Implementation of FEMWATER (ORNL-5601) Computer Program--Final Report." NUREG/CR-2706.

Duguid, J. 0., and M. Reeves. 1976. "Material Transport in Porous Media: A Finite-Element Galerkin Mode1," Oak Ridge National Laboratory, Report ORNL-4928.

Yeh, G. T., and 0. S. Ward. 1979. "FEMWATER: A Finite-Element Model of Water Flow Through Saturated-Unsaturated Porous Media," Dak Ridge National Laboratory, Report ORNL-5567.

Reeves, M., and J. 0. Duguid. 1976. "Water Movement Through SaturatedUnsaturated Porous Media: A Finite-Element Galerkin Model," Oak Ridge Nationa 1 Laboratory, Report ORNL-4927.

Acceptance and Adequacy--This code is based on state-of-the-art research and is generally accepted by the research community as being about as good as is possible given the present level of understanding. 



\section{Summary of Code}

Purpose and Scope--UNSAT2 was developed to simulate nonsteady flow of water in saturated-unsaturated media.

Authors--UNSAT2 was developed by S. P. Neuman, R. A. Feddes and E. Bresler. The primary contact in the U.S. is

Dr. Shlomo P. Neuman

Department of Hydrology and Water Resources

University of Arizona

Tucson, AZ 85717

Phone: (602)884-4434

FTS: $\quad(602) 626-4434$

\section{features.}

Code functions--UNSAT2 was designed to include the following list of

- Capability to treat nonuniform flow regions having irregular boundaries and arbitrary degrees of local amisotropy;

- Flow can occur in a vertical plane, a horizontal plane, or a threedimensional system with radial symmetry;

- Atmospheric boundaries can be simulated;

- Water uptake by plant roots can be simulated;

- Flow to a fully- or partially-penetrating well of finite radius can be simulated.

Potential Usage--UNSAT2 can be used to investigate problems involving two spatial dimensions in the horizontal or vertical plane. Three-dimensional problems can be treated provided the flow pattern retains an axial symmetry about the vertical coordinate. The two-dimensional flow region may have any complex shape and it may consist of different soil materials arranged in arbitrary patterns. Each soil material may exhibit an arbitrary degree of local anisotropy, with the principal hydraulic conductivities oriented at any desired angle with respect to the coordinates.

A wide range of time-dependent boundary conditions can be treated; prescribed pressure head; prescribed flux normal to the boundary; seepage faces; and evaporation and infiltration boundaries where the maximum rate of flux is prescribed by atmospheric or other external conditions, whereas the actual rate is initially unknown. In addition, the program can handle water uptake by plants assuming that the maximum rate of transpiration is determined by 
atmospheric conditions, whereas the actual rate of uptake depends on atmospheric as well as soil and plant conditions. Internal volumetric sinks or sources of prescribed strength can be included in the flow system at any stage of the computation. Finally, a special provision has been made for the analysis of axisymmetric flow to a well of finite radius jartially penetrating an unconfined aquifer system and discharging at a prescribed time-dependent rate. The well may be partially cased and its capacity for storing water is taken into account. Several layers can be tapped by the well at the same time.

Restrictions on Use--This code is in the public domain and is Jisted in Neuman et a]. (1974).

Compatibility with Other NRC Codes--UNSAT2 is written in FORTRAN IV using no special equipment, hence it is compatible with other FORTRAN codes.

\section{Summary of Findings}

General Critique--UNSAT2 has evolved over several years. Earlier versions have been sucessfully used in field studies abroad. The UNSAT2 code may be useful to the NRC for the analysis of pressure distributions in a saturatedunsaturated flow system. The capability of treating atmospheric boundaries as well as water loss by plant roots is essential for shallow waste repositories. It should be noted however that hysteresis is not included in the code and hence will restrict the code usage to a single cycle of the wetting-drying front problem.

Provisions are included to restart a previousiy interrupted run.

Sensitivity Analysis--No sensitivity analyses have been published.

Code Validation and Field Verification--Feddes et al. (1975) reports on comparison studies made using UNSAT2 simulations with field measurements for two problems. One of these problems is one-dimensional and has been simulated using finite-difference methods (Feddes et al. 1974). In this exampie the authors report,

"In general, there is excellent agreement between field transpiration data and the results obtained by both methods."

The second example is two-dimensional and reported by Feddes et a1. (1973). Again quoting from Feddes et a1. (1975)

"This example clearly demonstrates the flexibility of the finite element approach and its capability in treating complex situations which one often encounters in the field." 


\section{General Description}

Operating Characteristics--UNSAT2 is written in FORTRAN IV and is operational on an IBM 370/165. It consists of some 13 subprograms.

Inputs--Input quantities for UNSAT2 include:

Grid geometry and program options

Initial heads and moisture conditions

Well description

Root zone description

Root behavioral data

Material properties.

Outputs--Virtually all output is to a line printer. It consists of a listing of all input information, a complete description of the finite element network, the boundary codes of all nodes, and the properties of each material. During each time step the program prints a listing of total head values, pressure head values, moisture content values, and discharge into or out of the system (not flow through the system) at all nodes. The rate of convergence of the iterative procedure is printed during each time step together with additional information pertaining to the particular problem at hand.

Available Documentation--The document by Neuman et al. (1974) is a User's Manuat and includes a code listing.

IV. Review of Therory

Equations--The flow of water in an incompressible variably-saturated soil can be described by

$$
L(\psi)=\sum_{i=1}^{3} \sum_{j=1}^{3} \frac{\partial}{\partial x_{i}}\left[K^{r}(\psi) K_{i j}^{s} \frac{\partial \psi}{\partial x_{j}}\right]+\sum_{i=1}^{3} \frac{\partial}{\partial x_{i}} k^{r}(\psi) K_{i 3}^{s}+s-c(\psi) \frac{\partial \psi}{\partial t}=0
$$

where $L$ is a quasilinear differentiai operator defined in the flow region; $x_{i}(i=1,2,3)$ are spatial coordinates ( $x_{3}$ the vertical, $k^{r}$ is relative hydraulic conductivity $\left(0 \leq \mathrm{K}^{r} \leq 1\right)$, $\mathrm{K}_{i j}^{\mathrm{s}}$ is conductivity tensor at saturation (the separation of $\mathrm{K}^{r}(\psi)$ and $\mathrm{K}_{i j}^{S}$ is a somewhat arbitrary assumption), $\psi$ is pressure head, $\varepsilon$ is specific molsture capacity (defined as $d \theta / d \psi$ ), $\theta$ is volumetric moisture content, $t$ is time, and $S$ is a positive sink term (or, equivalently, a negative source term). In this case, $S$ represents the volume of water taken up by the roots per unit bulk volume of the soil in unit time. 
The sink term may be expressed as

$$
S=k^{r} k_{11}^{S}\left(\psi-\psi_{r}\right) b^{\prime}
$$

where $\psi_{r}$ is pressure head in the roots and $x_{1}^{S}$ is principal conductivity parallel to the horizontal $\left(x_{1}\right)$ axis (all diagona $f$ components of $K_{i j}^{\$}$ are implicitly assumed to be zero in the root zone). The term $b^{*}$ is an empirical quantity, referred to herein as the root effectiveness function, $b^{\prime}$ represents the ratio between the specific surface area of the roots and the impedance (thickness divided by conductivity) of the soil-root interface.

Equation (1) must be supplemented by appropriate initial and boundary conditions. Hysteresis is not considered in the present case as $\psi$ is a singlevalued function of $\theta$ and therefore, the initial conditions are simply

$$
\psi\left(x_{i}, 0\right)=\Psi_{0}\left(x_{j}\right)
$$

where $\Psi_{0}$ is a prescribed function of $x_{i}$. In addition to this, one must specify either the pressure head or the normal flux at each point along the boundary. If $\Gamma_{1}$ is the segment of the boundary, $\Gamma$, along which pressure heads are prescribed, and $\Gamma_{2}$ is the complementary segment of $\Gamma$ along which normal fluxes are prescribed, then the boundary conditions become:

$$
\begin{aligned}
\psi\left(x_{i}, t\right) & =\psi\left(x_{i}, t\right) \text { on } \Gamma_{1} \\
& \sum_{i=1}^{3} \sum_{j=1}^{3}\left(k^{r} x_{i j}^{s} \frac{\partial \psi}{\partial x_{j}}\right)+\sum_{i=1}^{3} k^{r} k_{i 3}^{s}=-v\left(x_{i}, t\right) \text { on } \Gamma_{2}
\end{aligned}
$$

Here $\Psi$ and $V$ are prescribed functions of $x_{j}$ and $t$.

Along soil-air interfaces (in the absence of ponding) the soil can lose water to the atmosphere by evaporation or gain water by infiltration. While the potential (i.e., maximum possible) rate of evaporation from a given soil depends only on atmospheric conditions, the actual flux across the soil surface is limited by the ability of the porous medium to transmit water from below. Similarly, if the potential rate of infiltration (e.g., the rain intensity) exceeds the infiltration capacity of the soil, part of the water may be lost by surface runoff. Here, again, the potential rate of infiltration is controlled by atmospheric (or other) external conditions, whereas the actual flux depends on antecedent moisture conditions in the soil. 
Thus, the exact boundary conditions to be assigned at the soil surface cannot be predicted a priori, and a solution must be sought by maximizing the absolute value of the flux (while maintaining the correct sign) subject to the requirements.

$$
\begin{gathered}
\left|\sum_{i=1}^{3} \sum_{j=1}^{3}\left(k^{r} k_{i j}^{s} \frac{\partial \psi}{\partial x_{j}}\right)+\sum_{i=1}^{3} k^{r} k_{i 3}^{s}\right| \leq\left|E_{s}^{\star}\right| \\
\psi_{L} \leq \psi \leq 0
\end{gathered}
$$

Where $E_{S}^{\star}$ is the prescribed potential surface flux and $\psi_{L}$ is the minimum allowed pressure head at the soil surface. Both $E_{S}^{\star}$ and $\psi_{L}$ may vary with time.

$E_{S}^{*}$ and $\psi_{L}$ are calculated by methods based on atmospheric data. The total potential evapotranspiration from both soil and crop, $E^{\star}$, is calculated according to

$$
E^{\star}=\frac{\delta\left(R_{n}-G\right)+\rho_{a} C_{p}\left(e_{z}^{\star}-e_{z}\right) / r_{a}}{(\delta+\gamma) L}
$$

where $\delta$ is slope of saturation vapor pressure curve, $R_{n}$ is net radiation flux, $G$ is heat flux into soil, $\rho_{a}$ is density of moist air, $C_{p}$ is specific heat of air at constant pressure, $\mathrm{e}_{2}^{\frac{\alpha}{2}}$ is saturated vapor pressure and $\mathrm{e}_{2}$ is unsaturated vapor pressure at elevation $z$ and ambient temperature $r_{a}$ is resistance to vapor diffusion through air layer around leaves, $\gamma$ is psychrometric constant, and $L$ is latent heat of water vaporization. The potential evaporation, Es, is calculated from a simplified form of $(8)$ by neglecting the aerodynamic term and taking into account only that fraction of $R_{n}$ which reaches the soil surface.

$$
E_{S}^{\star}=[\delta /(\delta+\gamma) L] R_{n} \exp -0.39(L A I)
$$

where LAI is the leaf-area index.

The value of $\psi_{\mathrm{L}}$ in (7) is determined from equilibrium conditions between soil water and atmospheric vapor using the formula

$$
\psi_{L}=(R T / M g) \ln (f)
$$


where $R$ is universal gas constant, $T$ is absolute temperature, $M$ is molecular weight of water, $g$ is acceleration due to gravity, and $f$ is relative humidity of air.

The potential rate of transpiration by plants, E⿱艹 1 , which we assume is equal to the maximum possible rate of water extraction by roots per unit horizontal area of the soil, is also dependent on atmospheric conditions. This quantity can be calculated directly from (8) and (9) according to

$$
E_{p 1}^{*}=E^{*}-E_{S}^{*}
$$

This quantity will be required later in the text.

A seepage face is another kind of atmospheric boundary at which water seeps out from the saturated portion of a porous medium. The length of the seepage face varies with time in a manner that can never be predicted a priori. On the other hand, pressure head along the seepage face must be uniformly zero (if atmospheric pressure is also taken to be zero).

Numerical Approximations--Equation (1), together with appropriate initial and boundary conditions, is solved by the Galerkin finite-element method. Here the flow region is subdivided into a network of triangular elements. Let the corners of these elements be designated as nodal points and let $x_{1}^{p}(i=1,2,3)$ represent the space coordinates of the $n^{t h}$ node. Also, let each element, e, be associated with a set of so-called local coordinate functions, $\xi_{n}^{e}\left(x_{i}\right)$, which may vary linearly inside the element, vanish outside the element, and satisfy the requirement $\xi_{n}^{e}\left(x_{i}^{m}\right)=\delta_{n m}$ where $\delta_{n m}$ is kronecker delta. Then an approximate solution to the problem at any given time, $t$, is obtained as

$$
\psi^{N}\left(x_{i}, t\right)=\sum_{i=1}^{N} \psi_{n}(t) \stackrel{u}{e} \xi_{n}^{e}\left(x_{i}\right)
$$

where $N$ is the total number of nodes, $\psi_{n}(t)$ is the value of $\psi$ at node $n$, and the union sign is taken over all elements. The values of $\psi_{n}$ must be determined so as to satisfy the initial and boundary conditions of the problem together with the orthogonality requirement

$$
\sum_{e} \int_{\Omega} L\left(\psi^{N}\right) \xi_{n}^{e} d \Omega=0 ; \quad n=1,2, \ldots, N
$$

where $\Omega$ is the interior of $\mathrm{e}$. 
Since the Galerkin method applies only at a given instant of time, the time derivative $\partial \psi / a t$ appearing in $L(\psi)[$ (see (1)] must be determined independently of the orthogonalization process. The nodal values of the time derivatives as defined as weighted averages over the entire flow region according to

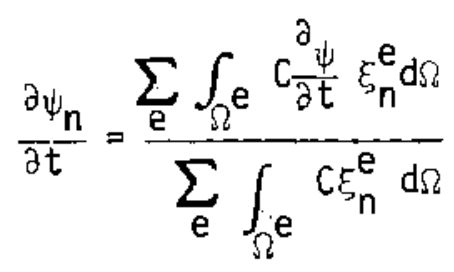

$K_{1}^{\S} j$ is assumed constant in each element while $K^{r}$ and $C$ vary linearly according to

$$
\begin{aligned}
k^{r} & =\sum_{\ell} k_{\ell}^{r} \xi_{\ell}^{e} \\
c & =\sum_{\ell} c_{\ell} \xi_{\ell}^{e}
\end{aligned}
$$

where $\ell$ stands for the corners of the triangle. By combining (12), (13), (14), and (15) and using Green's first identity, one obtains a set of quasilinear first-order differential equations

$$
A_{n m} \psi_{m}+F_{n m} \frac{d \psi_{m}}{d t}=Q_{n}-B_{n}-D_{n} n, m=1,2, \ldots, N
$$

where the quantities $A_{n m}, F_{n m}, Q_{n}, B_{n}$ and $D_{n}$ are defined in Neuman et al. (1974).

The matrix with elements $A_{n m}$ is sparse and symmetric. The matrix with elements $F_{n m}$ is diagonal as a direct consequence of the averaging process implied by (14). The quantity $Q_{n}$ is zero at all internal nodal points which do not act as sinks or sources. $D_{n}$ represents the effects of water withdrawal by $p l a n t$ roots and $B_{n}$ accounts for all other boundary values not accounted for in $\mathrm{Q}_{\mathrm{n}}$ and $\mathrm{B}_{\mathrm{n}}$.

To integrate (16) the time domain is descretized into a sequence of finite intervals, $\Delta t$, and the time derivatives of $\psi_{n}$ are replaced by finite differences. If the entire flow system remains unsaturated at all times, good results can be obtained by employing the time-centered scheme 


$$
\begin{aligned}
& \left(A_{n m}^{k+\frac{1}{2}}+\frac{2}{\Delta t^{k}} F_{n m}^{k+1 / 2}\right) \psi_{m}^{k+1}=2 Q_{n}^{k+\frac{1}{2}}-2 B_{n}^{k+\frac{1}{2}}-2 D_{n}^{k+\frac{1}{2}} \\
& -\left(A_{n m}^{k+\frac{1}{2}}-\frac{2}{\Delta t^{k}} F_{n m}^{k+\frac{1}{2}}\right) \psi_{m}^{k} n, m=1,2, \ldots N
\end{aligned}
$$

where $k$ represents the time $t=t^{k}$ and $\Delta t^{k}=t^{k+1}-t^{k}$. In order to evaluate the coefficients in (17), one must know the values of $\psi k^{+\frac{1}{2}}$ at $t^{k+\frac{1}{2}}=t^{k}+\Delta t^{k} / 2$. At the beginning of each time step, these are predicted by linear extrapolation from previously calculated values according to

$$
\psi_{n}^{k+\frac{1}{2}}=\psi_{n}^{k}+\frac{\Delta t^{k}}{2 \Delta t^{k-1}}\left(\psi_{n}^{k}-\psi_{n}^{k-1}\right) .
$$

The resulting set of simultaneous linear algebraic equations is then solved by a Gauss elimination algorithm (which takes account of the sparse and symmetric nature of $A_{n m}$ and $F_{n m}$ ) for the values of $\psi_{n}^{k+1}$ at all nodes.

Due to the nonlinear nature of (17), these results must be improved by an iterative process. At each iteration, the most recent values of $\psi_{h}^{k+1}$ are used to obtain an improved estimate of $\psi_{n}^{k+\frac{p}{2}}$ from

$$
\psi_{n}^{k+3 / 2}=1 / 2\left(\psi_{n}^{k}+\psi_{n}^{k+1}\right)
$$

After having re-evaluated the coefficients, the equations are again solved by Gauss elimination for improved values of $\psi_{n}^{k+1}$. The iterative procedure continues as long as it is necessary to achieve a satisfactory degree of convergence.

If part of the system is saturated, the values of $F_{n m}$ corresponding to nodal points in the saturated zone vanish because $C$ is zero, and the governing equations there become elliptic. This means that sudden changes in boundary conditions around the saturated zone have an instantaneous effect on the values of $\psi$ everywhere in this zone, and $\psi$ is no longer a continuous function of time. For example, by imposing a certain boundary condition at time $t=t^{k}$, all values of $\psi_{n}^{k}$ at the start of the time step, $\Delta t^{k}$, becomes unknown. Thus, the right-hand side of (17) is unknown, and the equations cannot be solved.

To overcome this problem, a fully implicit backward difference scheme in terms of $\psi$ is used 


$$
\left(A_{n m}^{k+\frac{1}{2}}+\frac{1}{\Delta t_{k}} F_{n m}^{k+\frac{1}{2}}\right) \psi_{m}^{k+1}=Q_{n}^{k+1 / 2}-B_{n}^{k+1 / 2}-D_{n}^{k+\frac{1}{2}}+\frac{1}{\Delta t^{k}} F_{n m}^{k+1 / 2} \psi_{m}^{k} .
$$

Here the coefficients are all evaluated at half the time step, $k+\frac{1}{2}$, this is done in order to dampen the tendency of $\psi$ to oscillate around its limit.

With this scheme a solution can be obtained without knowing the values of w $\mathrm{k}_{\mathrm{n}}$ at the start of the time step in the saturated zone. The only exception to this rule occurs at nodes that pass from a state of saturation to a state of incomplete saturation during a time step. The values of $\mathrm{F}_{\mathrm{nm}}^{\mathrm{k}+\mathrm{s}}$ corresponding to such nodes may differ from zero and (20) can no longer be solved wi thout knowing the values of $\psi_{n}^{k}$. However, $\mathrm{F}_{\mathrm{nm}^{2}}^{\mathrm{k}}$ represents only storage due to changes in the moisture content, $\theta$. Such changes occur only within the negative range of $\psi$ values whereas when $\psi$ is positive, $\mathrm{C}=\partial \theta / \partial \psi$ is zero. Thus, whenever a value of $\psi k$ in the saturated zone becomes unknown due to a sudden change in the boundary conditions, one is justified in replacing this value by zero in (20).

As the numerical solution is developed the boundary conditions are imposed as needed. Neuman et a1. (1974) describes the exact procedure used to treat multiple plant species root growth and atmospheric condition changes as a function of time.

\section{Probabilistic or Statistical Aspects--None.}

Assumptions and Simplifications--The main assumptions are:

- Darcy's law is valid and hydraulic-head gradients are the only significant driving mechanisms for fluid flow.

- The maximum rate of transpiration is determined by atmospheric conditions alone.

- The hydraulic conductivity at each point is expressed as a symmetric tensor $K_{j j}=k r(\theta) K_{k j}$, where $K \oint_{j}$ is the conductivity at saturation and $k^{r}(\theta)$ is the relative conductivity $\left(0 \leq k^{r}(\theta) \leq 1\right)$ as a function of volumetric moisture content.

Structure and Level of Detai1--UNSAT2 models a flow region either from an areal viewpoint, as a vertical cross section or as a radially symmetric (vertical) cylinder. The spatial domain is discretized using triangular isoparametric-finite elements. The time domain is descretized by finite difference methods.

Major Variables--Aside from the input parameters, the major variables are the hydraulic heads.

Applicability, Limitations, Validjty and Completeness--This code is applicable to both saturated and unsaturated flow in porous media. The code is limited to two dimensons or three dimensions with axial symmetry. 


\section{References--}

Neuman, S. 0., R. A. Feddes and E. Bresler. 1974. "Finite Element Simulation of Flow in Saturated-Unsaturated Soils Considering Water Uptake by Plants," Third Annual Report, Project AL0-SWC-77, Hydrodynamics and Hydraulic Engineering Laboratory Technion, Haifa, Israel.

Feddes, R. A., S. 0. Neuman and E. Bresler. 1975. "Finite Element Analysis of Two-Dimensional Flow in Soils Considering Water Uptake by Roots: II. Field Applications," Soil Science Society of Amerjca Proceedings 39(3):231-237, March-Aprî1.

Feddes, R. A., E. Bresler and S. 0. Neuman. 1974. "Field Test of a Modified Numerical Model for Water Uptake by Root Systems," Water Resources Research 1D(6): 1199-1206 (December).

Feddes, R. A., and M. G. vanSteenbergen. 1973. "Subirrigation Field 'de Groeve'," Nota 735. Inst. for Land and Water Management Res. Wageningen, the Netherlands (in Dutch).

Acceptance and Adequacy--UNSAT2 is based on state-of-the-art research and is generally accepted by the research community both in the U.S. and abroad as being as good as is possible given the present level of understanding. 


\title{
1. Summary of Code
}

Purpose and Scope--VS2D was developed to simulate multidimensional movement of liquid water in variably saturated porous media.

Author and Contacts--VS2D was developed at U.S. Geological Survey by E. G. Lappala. Prime contact for additional infomation is

\author{
Project Chief \\ U.S. Geological Survey \\ Box 25046, Mail Stop 420 \\ Denver Federal Center \\ Lakewood, C0 80225
}

Lappala (1981) may be purchased by contacting

$$
\begin{aligned}
& \text { Open File Services Section } \\
& \text { U.S. Geological Survey } \\
& \text { Box } 25425 \\
& \text { Denver Federal Center } \\
& \text { Denver, C0 80225 } \\
& \text { Phone: (303)235-5888 } \\
& \text { FTS: (303)234-5888 }
\end{aligned}
$$

\section{features.}

Code Functions--VS2D was designed to include the following list of

- Capability to handle problems in which part of the solution domain is saturated and part is unsaturated.

- Capability to handle "difficult" nonlinear problems, such as those caused by infiltration into dry soils, anisotropy, and discontinuities in permeabilities and porosities.

- Inclusion of general nonlinear source-sink terms to account for stresses such as evapotranspiration.

- Capability to analyze problems in one and two dimensions with planar, and cylindrical geometries.

Potential Usage--Recharge to aquifer systems generally occurs through overlying materials that are variably saturated. Land-use activities may alter both quantity and quality of recharge. Prediction of the fate of pollutants applied to the land surface or buried above the zne of permanent saturation often can be most readily accomplished with numerical models of variably saturated flow. VS2D provides a user-oriented tool for examining these types of 
problems. Although an attempt has been made to make VS2D general enough to handle most field situations, its use should be accompanied by a thorough understanding of the theoretical and practical limitations described herein. Field applications exist for which this model is not adequate; an example would be evapotranspiration in which significant anisothermal movement of water vapor as well as liquid water occurs. However, these types of problems can be analyzed using modified versions of the basic isothermal model. This version of the model does not include solution of the equations for movement of solutes.

Restrictions on Use--This code is in the public domain and is available from USGGS.

Compatibility with Other NRC Codes--Since VS2D is written in FORTRAN the output files are directTy usable by other FORTRAN codes.

\section{Summary of Findings}

General Critique--The VS2D code may be useful to the NRC for the analysis of the pressure distributions in a saturated-unsaturated flow system. Boundary conditions consist of specified head, specifjed flux or a mixture of the two (seasonal variation). The model analyzes flow sytems from a plane crosssectional or areal viewpoint. Cylindrical coordinates have been included in the code.

Understanding the occurrence and movement of water in variably saturated systems is important in developing predictive tools for managing both quantity and quality of ground-water sytems. Recharge to aquifer systems generally occurs through overlying materials that are variably saturated. Land-use activities may alter both quantity and quality of recharge. Prediction of the fate of pollutants applied to the land surface or buried above the zone of permanent saturation often can be most readily accomplished with numberical models of variably saturated flow. The VS2D model provides a user-oriented tool for examining these types of problems. An attempt has been made to make the model general enough to handle most field situations. Field applications exist for which this model is not adequate; an example would be evapotranspiration in which significant anisothermal movement of water vapor as well as liquid water occurs. However, these types of problems can be analyzed using modified versions of the basic isothermal model. The current version of the code does not include solution of the equations for movement of solutes.

VS2D was designed to handle the "difficult" nonlinear problems caused by infiltration into dry soils, anisotropy, and discontinuities in permeabilities and porosities. This capability is met by using finite differences to discretize spatial and temporal domains. Adequate solutions of nonlinear equations using finite elements discretization in space require such numerical tricks as lumping the capacity (storage) term over each element. The upstream weighting of relative hydraulic conductivities that may be required to prevent numerical oscillations is more difficult with finite elements than with finite differences. Finally, algebraic equations resulting from a finite-element 
spatial discretization scheme generally require more computer core storage and time to solve than those resulting form a finite difference scheme. General nonlinear source-sink tems are included to account for stresses, such as evapotranspiration.

Sensitivity Analysis--No sensitivity analyses were reported.

Code Validation--The computer code VS2D was verified on several test problems. Owing to the nonlinearity of the descriptive flow equation closedform analytic solutions are not available for all possible problems to which the code might be applied. However, a few analytic solutions are available for one-dimensional geometries and specific nonlinearities. Tests of the numerical solutions against a few of these solutions are described by Lappala (1981). Also described are two tests of linear forms of the flow equation to verify the code for rectanguiar and radial coordinates.

Field Verification--None.

III. General Description

Operating Characteristics--VS2D is written in FORTRAN and consits of 24 subprograms.

Inputs--Inputs for VS2D include:

Grid geometry and program options

Initial heads or moisture content conditions

Source/Sink strengths

Material properties

Outputs--Output may be obtained on six files. The files used and their contents depend on input specifications. In general these files and their contents are:

File 2--Total head and saturation at selected observation points for every time step.

File 6--Printer file--echo of all input data, initial conditions, boundary conditions; mass balance summary heads and saturations and maximum $\Delta H / i$ teration for every $\mathrm{KTH}$ time step.

File 7--Cumulative and evapotranspiration--elapsed time for each time step.

File 8--Total head and saturation at all nodes at selected times.

File 9--Mass balance summary as a function of elapsed time.

File 10--Number of iterations/time step as a function of time. 
Available Documentation--VS2D is documented in Lappala (1981).

IV. Review of Theory

Equations--The equation that describes the transient movement of liquid water under isothermal and isohaline conditions is developed by combining the equation for continuity of mass for waster with auxiliary equations for fluid flux and storage. These relationships are developed for elementary volume elements or cells obtained by the spatial discretization procedure applied to the solution domain. The resulting equation for each volume element, or cell, of the solution domain is

$$
v\left[\rho\left(\phi c_{m}+s \beta+s \phi \rho \alpha\right)\right] \frac{\partial H}{\partial t}-\sum_{k=1}^{m} \frac{A_{k} \rho^{2}}{\mu} g \overline{\bar{K}} K_{r} \frac{\partial H}{\partial n_{k}}+\rho W=0 .
$$

where

$$
\begin{aligned}
& v=\text { volume of the cell, } L^{3} \\
& \rho=\text { liquid density, } \mathrm{ML}^{-3} \text {; } \\
& \phi=\text { porosity, } L^{\circ} \text {; } \\
& S=1 i q u i d \text { saturation, } L^{\circ} \text {; } \\
& c_{m}=\left(\frac{\partial S}{\partial h}\right)_{\rho \phi}=\begin{array}{l}
\text { specific moisture capacity, which is the slope of the mois- } \\
\text { ture retention or pressure-saturation curve, } L-1 ;
\end{array} \\
& \beta=\left(\frac{\partial \phi}{\partial h}\right)_{\rho S}=\text { matrix compressibility, } L^{-1} \text {; } \\
& \alpha=\frac{1}{\rho}\left(\frac{\partial \rho}{\partial h}\right)_{\phi S}=\text { fluid compressibility, } L^{-1} ; \\
& h=\text { pressure potential, L; } \\
& H=\text { total potential of the fluid, expressed as the height of a column } \\
& \text { of the liquid, L; } \\
& t=\text { time, } T \text {; } \\
& \mathrm{m}=\text { number of faces on the cell; } \\
& A_{k}=\text { area of } k^{\text {th }} \text { face on the cell, } L^{2} \text {; } \\
& \mu=\text { dynamic viscosity of the riquid, } M^{-1} T^{-1} \text {; } \\
& \mathrm{g}=\text { gravitational acceleration, } \mathrm{LT}^{-2} \text {; } \\
& \overline{\mathrm{R}}=\text { intrinsic permeability of the medium, } L^{2} \text {; }
\end{aligned}
$$



$\begin{aligned} K_{r}(s)= & \text { relative hydraulic conductivity to liquid as a function of } \\ & \text { liquid saturation (s) } L^{\circ} ;\end{aligned}$

$n_{k}=$ direction orthogonal to face $A_{k}$ of the cell;

$W=$ volumetric source/sink term for the cell, $L^{3} T^{-1}$.

Retention of the volume and area factors in (1) facilitates the use of either rectangular or cylindrical coordinate systems. variable.

The program solves for the total potential, $H$, as the principal dependant

The solution to (1) requires that initial values of $H$ be specified everywhere in the solution domain. These initial conditions usually represent some type of steady state or equilibrium. However, this need not be the case. If initial conditions are used that do not represent steady state, any simulation results will include transient effects from the difference between specified initial conditions and equilibrium conditions. Since (13) is nonlinear, it is not permissible to use the principle of superposition to subtract out the effects of transient initial conditions, as is often done in simulating fully saturated ground-water systems.

Solutions to (13) require boundary conditions that specify either the flux or liquid across the boundary, or the total potential along the boundaries. Boundary conditions of the first type are defined as:

$$
\rho \vec{u}_{k}=f_{1}\left(x_{k}, t, \nabla H_{k}\right)
$$

where $u_{k}$ is the liquid flux normal to boundary face $k, L^{3} T^{-1} ; f_{1}\left(x_{k}, t, \nabla H_{k}\right)$ is a general function that depends upon location, time, and the gradient in total hydraulic potential across the face.

Boundary conditions of the second type are defined as:

$$
H_{k}=f_{2}(x, t)_{k}
$$

where $f_{2}$ is a general time-dependent function.

Three phenomena exist in flow through variably saturated media that may make a priori specification of the boundary condition type impossible: infiltration, evaporation, and discharge through seepage faces.

Numerical Approximations--The spatial derivitives in (13) are approximated by finite differences. The values of the differenced variables are 
assumed to be located at the volumetric center of the cel1. For a twodimensional rectangular grid the number of faces [m in (1)] of the cell is 6 . However, two of the faces are not explicitly included because generally no liquid flow occurs across them.

The spatial derivitives of total potential, $\partial \mathrm{H} / \partial \mathrm{n}_{\mathrm{K}}$, in (1) are approximated at the cell boundaries using the sign convention that flow into the cell as positive and flow out of the cell as negative. Replacement of the $\partial \mathrm{H} / \partial \mathrm{nk}$ terms in (1) by difference approximations results in a differential-difference equation for each cell. The coefficients in the difference parts of these equations, called conductances, are linear functions of the product $\rho 2 \bar{R} K_{r}$ which are evaluated at the cell boundaries. Each parameter in this product is averaged by a separate method. The liquid density $p$ at a cell boundary is taken as the arithmetic average of $\rho$ for the two cells sharing the boundary. The intrinsic permeabilities, $\bar{k}$, are computed by a distance weighted, harmonicmean formula. The hydraulic conductivity $K_{r}$ is computed by either a weighted arithmetic mean (the weights are specified in the input data) and a geometric mean, depending on the option chosen in the input data.

The time derivatives in (1) are replaced with a weighted difference scheme permitting the choice, by specifying an input parameter, of the Crank-Nicolson method, the fully implicit method or a "weighted average" of the two methods. The resulting system of difference equations can be written in matrix form as

$$
\left[A^{i-\frac{1}{2}}\right]\left\{H^{i}\right\}=\{R\}
$$

where $i$ is the time step index; [A] is a square matrix that includes all implicit or unknown parts of the conductance, storage and source/sink terms; and $\{R\}$ is a vector of all explicit or known parts of the conductance, storage and source/sink terms. The elements of the matrix $A$ are functions of the implicit parts of conductance terms, the storage term and the source/sink terms and are evaluated at some approximation to the midpoint in time between $t^{j}$ and $t^{i-1}$. It is the dependence of the parameters in these terms on $H$ that makes (4) nonlinear.

VS2D aliows the user to select the method of dealing with the noninearity of (4). An iterative method is used which is analogous to that used in treating the temporal discretization of (1). At one extreme the explicit method no iteration is used. That is $A$ is computed based on conditions at time $t^{i-1}$. At the other extreme, the fully-implicit method, the elements of A are computed based on the conditions at time $t^{i}$. To deal with the iterative determination of $A$ at $t^{i}$ VS2D uses a procedure called implicit linearization. Further options include using the Newton-Raphson method to speed convergence.

At each iteration a system of linear equations is solved. Two methods are avajlable in VS2D, a direct method based on Gaussian elimination, and in iterative method known as 7 ine successive over relaxation or LSOR. The method used is specified in the input data. 


\section{Probabilistic or Statistical Aspects--None.}

Assumptions and Simplifications--The ma in assumptions are:

- Darcy's law is vaid and hydraulic-head gradients are the only significant driving mechanisms for fluid flow.

- The pressure head is a function of volumetric moisture content only.

- The volumetric moisture content, relative hydraulic conductivity, porosity, and fluid density are functions of pressure head only.

- Root activity is a function of depth, time and volumetric moisture content.

- The coordinate axes used for a given problem are colinear with the axes of the intrinsic permeability tensor.

Structure and Level of Detail--VS20 mode1s a variabiy saturated groundwater system as either a cross section or as a cylinder using standard finite difference methods. A maximum of 100 cellis made from at most 100 dimensions in the horizontal or radial direction and at most 200 divisions in the vertical direction is permitted.

Major Variables--Aside from the input parameters the major variables are the total potential of the fluid expressed as the height of a column of liquid.

Applicability, Limitations, Validity and Completeness--The code is applicable to both saturated and unsaturated flow in porous media. The code is limited to plane two-dimensional flow. Steeply dipping beds cannot be adequately simulated.

\section{Reference--}

Lappa]a, E. G. 1981. "Documentation of Computer Program to Solve the Equations of Fluid Flow in Variably Saturated Porous Media," August Preliminary Report, Eventually to be issued as USGS Open-File Report 81-XXX.

Acceptance and Adequacy--This code is based on state-of-the-art research and is generally accepted by the research community as being about as good as is possible given the present level of understanding. 



\section{Suntnary of Code}

Purpose and Scope--MLTRAN was designed as a nondispersive kinetic transport model of two-dimensional transport of dissolved contaminants through mine tailings, pit linings and layered geologic sediments of varying hydraulic characteristics.

Authors--MLTRAN was developed by A. E. Reisenauer, S. K. Gupta, R. W. Nelson, C. R. Cole, and C. A. Newbill at Battelle, Pacific Northwest Laboratories, Richland, Washington. The primary contact is:

A. E. Reisenauer

Battelle, Pacific Northwest Laboratory

P.0. Box 999

Richland, Washington 99352

Telephone: (509) 376-8338

Code Functions--MLTRAN is designed to work in conjunction with the flow code TRUST which solves the transient unsaturated flow problem. MLTRAN utilizes the fluxes defined by TRUST along with media properties and grid configurations to calculate pathlines, fronts and contaminant movement. The method used is based on pathiine kinematics. The code utilizes PNL graphics software and relies heavily on graphical hardware for use in an interactive mode.

Potential Usage--MLTRAN was specifically designed to study "worst-case" situations of low Jevel waste storage sites, where the media is unsaturated. The model is capable of simulating in one- or two-dimensional geometries.

Relation to NRC Issues--Not applicable as no list of issues currently exists for low level radioactive waste treatment. able $\frac{\text { Restric }}{\text { to NRC. }}$

Compatibility with 0ther NRC Codes--MLTRAN is written in FORTRAN. It utilizes PNL graphics software and relies heavily on graphical hardware for use in the interactive mode. This special software is compatible with FORTRAN and thus should not create problems with respect to input/output files and their compatibility with other NRC codes.

\section{Summary of Findings}

General critique--The transport model MLTRAN, consists of six separate subcodes MLSTRT, MLFLUX, MTRVL, MLFRNT, MLPLOR and MLGRID. The model uses finite element principles for the pathline and transport calculations. Using 
the integrated finite difference grid points and distances linking each pair of nodes and the finite element grid description of the TRUST element nodes. MLSTRT generates the direct access files for use by the other MLTRAN subprograms. MLFLUX uses the TRUST flow rates between each pair of nodes for each time plane to estimate the net flow vectors at each finite element node. MLTRVL estimates pathlines and travel times from any given point in the space and time domains.

MLTRVL is executed three times during an andiysis of the waste transport analysis problem. First to determine the water flow travel pathlines, second to estimate the acid front, and third to estimate the radionuclide transport as a function of the position of the acid front. For the acid and radionuclide travel time, the laboratory measured retardation coefficients of the contaminant for the different soils are incorporated into the model. MLFRNT is also executed three times to delineate the travel time of the water, acid and radionuclide front at specified times of interest. MLPLOR plots the moisture content and pressure head for selected times. MI_GRID plots the grid details and material number of each node to verify input geometry.

MLTRAN is designed for interactive graphic oriented computation. The user may exploit these graphics capabilities to insure proper input data prior to executing the computation parts including TRUST, of the model.

Applicabjlity to Medium--MLTRAN is designed to simulate solute transport through variably saturated media subject to varjable initial and boundary conditions. The code is applicable to most porous media transport problems which can be adequately modeled in two-dimensions and for which a nondispersive simulation is adequate.

Sensitivity Analysis--No sensitivity analyses have been published.

Code Verification--Checks have been made with other codes and analytical solutions but no results have been published.

Field Verification--None published.

\section{General Description}

Operating Characteristics--MLTRAN is written in FORTRAN IV and is operationa on Digital Equipment Corporation's PDP $11 / 45$ and PDP $11 / 20$ computers with $32 k$ core memory of 16 -bit words. It relies heavily on graphic capabilities.

Inputs--MLTRAN requires access to the input files used by the program TRUST (Reisenauer, et al. 1982) as well as the file of flux values produced by TRUST. TRUST does not require element node location so these must be input to MLTRAN. Also required are parameters for the plotting device, and plots, cycie specification (water, acid or contaminant), starting point for pathlines to be traced, starting and ending times. 
Outputs--MLTRAN produces both plotted and printed hardcopy. The plots include not only the initial grid definitions for the TRUST integrated finite difference cells but also the pathlines specified for water acid, and/or contaminants. Also, contour plots are made for moisture content, and pressure heads at selected points in time.

Avajlable Documentation--MLTRAN is documented in Reisenauer, et a]. (1981) which serves as a user's manual.

IV. Review of the Theory

Equations--Consider $a_{\rightarrow}$ fluid particle at a given time $t_{0}$, at location $x_{0}, y_{0}$ in a velocity field $\vec{v}(x, y, t)$ interior to a porous flow system. Let a function $\psi(x, y, t)$ follow the particular fluid particle. The convective derivative of $\psi$ must vanish along the path traveled by the fluid particle

$$
\frac{D \psi}{D t}=\frac{\partial \psi}{\partial t}+v_{x} \frac{\partial \psi}{\partial x}+v_{y} \frac{\partial \psi}{\partial y}=0
$$

where, using Darcy's Law and the volumetric mojsture content $\theta$, for partially saturated soil, the pore velocity components are given by

$$
\begin{aligned}
& v_{x}=-\frac{K}{\theta} \frac{\partial \phi}{\partial x} \\
& v_{y}=-\frac{K}{\theta} \frac{\partial \phi}{\partial y}
\end{aligned}
$$

where $K$ is the partially saturated hydraulic conductivity, and $\phi$ is the energy potential. Substituting (2) and (3) into (1) produces a first order partial differential equation in $\psi$ which is solved by the method of characteristics. The characteristic equations are

$$
\begin{aligned}
& \frac{d x}{d t}=-\frac{K}{\theta} \frac{\partial \phi}{\partial x} \\
& \frac{d y}{d t}=-\frac{K}{\theta} \frac{\partial d}{\partial y}
\end{aligned}
$$


which are nothing more than the velocity components expressed as differential displacements on the pathline differential equations that pass through the starting point $x_{0}, y_{0}$ at $t_{0}$.

Now consider a contaminant tracer particle which interacts with the porous matrix in such a way that it is effectively retarded. The above derivation can be carried out but using the retarted time $T$ rather than water travel time. That is in (2) and (3) let

$$
\begin{aligned}
& v_{x}=\left(1+\frac{B_{b} K_{d}}{\theta}\right) v_{x}=-\frac{K}{\theta} \frac{\partial \phi}{\partial x} \\
& v_{y}=\left(1+\frac{B_{b} K_{d}}{\theta}\right) v_{y}=-\frac{K}{\theta} \frac{\partial \phi}{\partial y}
\end{aligned}
$$

Equations (6) and (7) can be solved for the contaminant particle velocities, $v_{x}$ and $v_{y}$. The path followed by the contaminant particle yields

$$
\frac{D \psi_{c}}{D T}=\frac{\partial \psi_{c}}{\partial t}+v_{x} \frac{\partial \psi_{c}}{\partial x}+v_{y} \frac{\partial \psi_{c}}{\partial y}=0
$$

where $\psi_{c}$ is a function following the contaminant particle. Substituting (6) and (7) into (8) yields a first order partial differential equation which is solved by the method of characteristics. The characteristic equations are

$$
\begin{aligned}
& \frac{d x}{d T}=\frac{1}{R} \frac{q x}{\theta} \\
& \frac{d y}{d T}=\frac{1}{R} \frac{q y}{\theta}
\end{aligned}
$$

where

$$
\begin{aligned}
& q_{x}=-k \frac{\partial \phi}{\partial x} \\
& q_{y}=-k \frac{\partial \phi}{\partial y}
\end{aligned}
$$


which are the Darcian flux components;

$$
R=\frac{1}{1+\beta K_{d}}
$$

is the retardation factor; and

$$
B=\frac{B_{d}}{\theta}
$$

is the bulk density of the matrix divided by the volumetric moisture content.

The MLTRAN code solves (9) and (10) numerically to yield pathlines, fronts and contaminant movement throughout the porous matrix.

Numerical Approximations--For TRUST there is no description of elemental nodal coordinates. It primarily needs the node pajrs, distance between the node pairs and the orthogonal distance, representing the intercepted distance of the flow between the given pairs of nodes. For discretization of a given problem the user normally locates the nodes and constructs the integrated finite difference element.

For the purpose of generating pathlines from the velocity vectors stored at each time plane, it is convenient to shift from an integrated finite difference grid to a finite element grid system. The grid point locations are maintained and a new file is required which describes the linking in the finite element quadrature notation, i.e., four points linked in a counter clockwise pattern.

MLTRAN uses linear quadrilateral elements of four nodes while the integrated finite difference grid may have elements formed with more than four sides. In some cases the element might be a triangle. If the integrated finite difference element is not of four sides, the user may be required to redefine the element node of integrated finite difference element by four-sided finite element.

The TRUST code estimation of the flux between nodes is based on the assumption that the potential associated with each nodal point is a function of time only, and the spatial variation of the average properties are independent of time. The flux rate between elements is represented by a simple linear relationship.

Under unsaturated conditions the hydraulic conductivity $(K)$ and the moisture retention (C) are functions of the potential and elevation. Hence, the governing partial differential equation is nonlinear. For numerical simulation, an iterative technique is used until convergence of the potentials used 
for estimating $K$ and $C$, and the predicted potentials are within prescribed limits. The TRUST code adjusts the time steps automatically, starting from small initial values. The initial time frames are very small and generally have insignificant impact on the estimation of the contaminant transport. TRUST values for mass flux between element nodes pairs, and the estimated potentials at pre-selected time planes are saved on magnetic tape or disk fijes.

Let $X_{0}, Y_{0}$ and $X_{1}, Y_{1}$ be the coordinates of two nodes 0 and 1 and 1 et $D$ be the orthogonal intercepted distance between the elements. TRUST saves the total mass flux $\mathrm{m} t$ between 0 and 1 passing through intercept $D$ during a given time increment $\Delta t$. The following steps are used to calculate the net velocity vector $V_{x}^{01}$ and $V_{y}^{01}$ at element node 0 .

1. The mass flow $M_{0}^{\frac{1}{0}}$ is converted to a volume flow rate

2. The estimated $Q$ is resolved into its components parallel to the $x$ and $y$ coordinate system by the following transformation

$$
\begin{aligned}
& Q_{X_{0}}^{01}=A_{0}^{1} \cos (\alpha) \\
& Q_{y_{0}}^{01}=Q_{0}^{1} \sin (\alpha)
\end{aligned}
$$

where

$$
\alpha=\tan ^{-1}\left(\frac{y_{1}-y_{0}}{x_{1}-x_{0}}\right)
$$

3. The above procedure is repeated to estimate $Q_{x} i$ and $Q_{y}^{0}$ where $i=1,2$, $\ldots, n$ ( $n=$ number of nodes connected to element node 0 ).

4. To estimate the Darcian flux components $q_{x}$ and $q_{y}$ the sum

$$
Q_{x}^{0}=Q_{x}^{01}+Q_{x}^{02}+\ldots+Q_{x}^{0 n}
$$

is divided by the sum of the associated $y$ projections of all the intercepts 


$$
\begin{aligned}
& y_{p}=\sum_{i=1}^{h}\left|0_{i} \sin \alpha_{i}\right| \\
& q_{y}^{0}=Q_{x}^{0} / y_{p} .
\end{aligned}
$$

Similarly,

$$
\begin{aligned}
& Q_{y}^{0}=Q_{y}^{01}+Q_{y}^{02} \cdots+Q_{y}^{O n}, \\
& x_{p}=\sum_{i=1}^{n}\left|o_{i} \cos \alpha_{i}\right|
\end{aligned}
$$

and

$$
q_{y}=Q_{y}^{0} / x_{p} .
$$

5. Using the estimated potential of element node 0 and moisture retention properties of the material associated with element 0 , the moisture content $\theta$, is estimated.

6. The net pore water velocity vector at element node 0 , is then defined by

$$
\begin{aligned}
& v_{x}^{0}=q_{x}^{0} / \theta \\
& v_{y}^{0}=q_{y}^{0} / \theta
\end{aligned}
$$

where the vectors are along the $x$ and $y$ axis, respectively.

7. The above process is repeated for all the nodes in the flow system and the results stored in a direct access file for efficient retrieval during pathline estimation. 
The subprogram MLCNP plots the contours of TRUST estimated potentials and moisture contents of interactivily specified time planes. Along with contours the nodal values of potential or moisture content at specified nodes are also plotted. Contours and the nodal values provide a means of checking the TRUST results before tracing pathlines and fronts. The finite elements are defined by four corner points, an interpolation function is defined by the basic functions. This interpolation function is used to construct the controus plotted by MLCNP.

Probabilistic or Statistical Aspects--None.

Assumptions and Simplifications--The main assumptions are:

- Darcy's Law is valid and the hydraulic-head gradients are the only significant driving mechanisms for fluid flow.

- The flux between discretization elements is linear.

Structure and Level of Detail--The integrated finite difference grid of TRUST and the corresponding finite element grid of MLTRAN permit the user to place smaller elements where more detail is wanted and larger elements where detail is less important. The code is confined to two-dimensions.

Major Variables--The primary variables are the pathline coordinates, contaminant particle travel times, and contaminant concentration values.

Applicability, Limitations, Validity and Completeness--The primary limitations are the restriction to nondispersive transport in two dimensions, and the dependence on plotting capabilities. This latter limitation is one which could be removed by software modification. The TRUST code is applicable to both saturated and unsaturated flow problems. Thus, MLTRAN which relies on TRUST for the flux components is applicable to both saturated and unsaturated problems.

\section{References--}

Reisenauer, A. E., S. K. Gupta, R. W. Nelson, and C. A. Newbill. 1981. "Advective Radionuclide Transport with Soil Interaction Under Variably Saturated Flow Conditions." PNL-3994, Pacific Northwest Laboratory, Richland, Washington.

Reisenauer, A. E., K. T. Key, T. N. Narasimhan, and R. W. Nelson. 1982.

"TRUST: A Computer Program for Variably Saturated Flow in Multidimensional, Deformable Media." NUREG/CR-2360, PNL-3975. Prepared for U.S. Nuclear Regulatory Commission by Pacific Northwest Laboratory, Richland, Washington.

Acceptance and Adequacy--MLTRAN is based on state-of-the-art research and is generally accepted by the research community as being as good as is possible at the current level of understanding. 
APPENDIX E

PARTIALLY SATURATED AND MULTIPHASE CODES INVENTORIED--SHORT SUMMARIES 


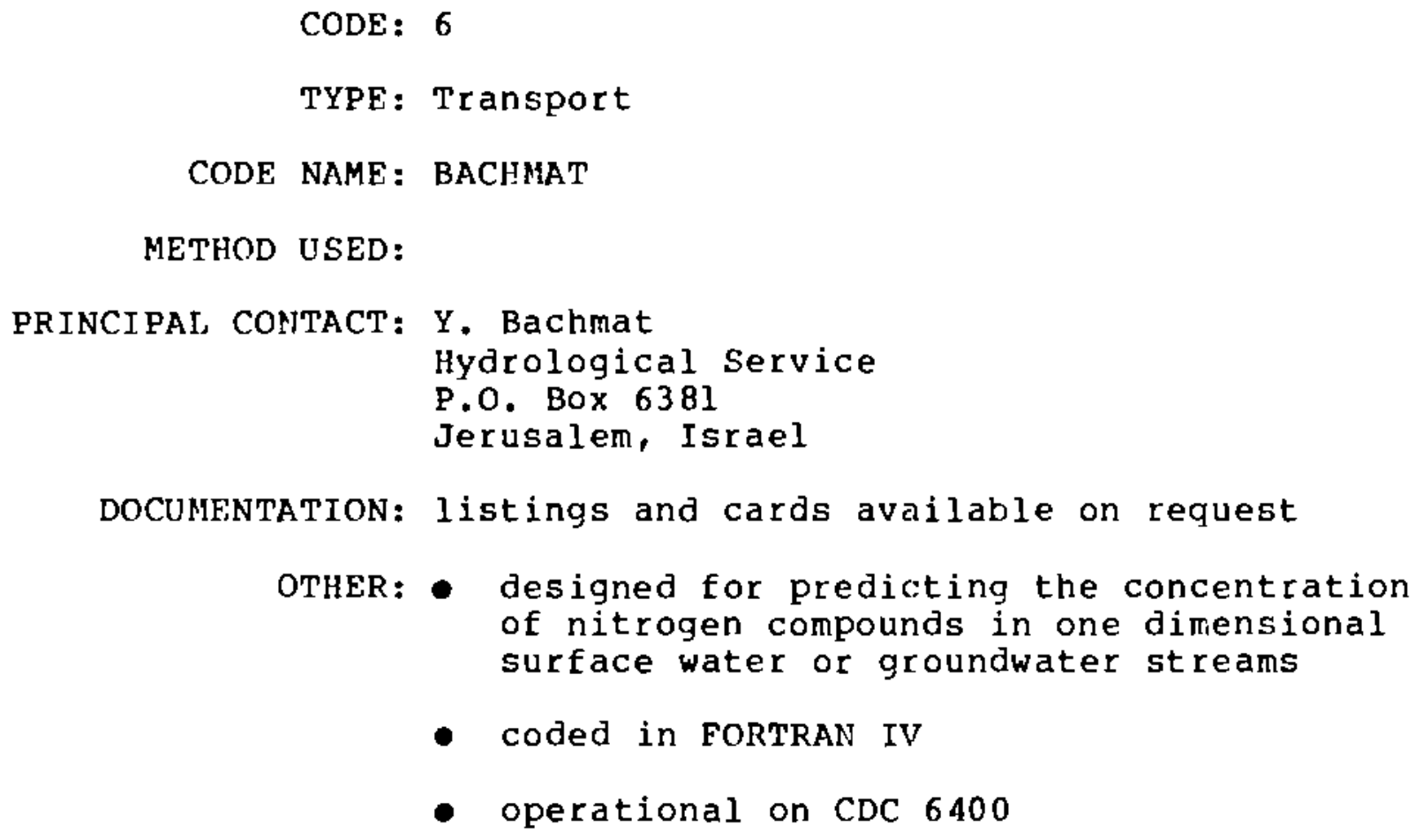


CODE : 7

TYRE: FlOW

CODE NAME: UNFLOW

METHOD USED: 2-dimensional Galerkin finite element

PRINCIRAL CONTACT: John F. Pickens

Dept. of Earth Sciences

Univ. of Waterloo

Waterloo, Ontario

Canada $\mathrm{N} 2 \mathrm{~L} 3 \mathrm{Gl}$

DOCUMENTATION: listings and operating instructions available

from Principal Contact

OTHER: - designed to simulate 2-dimensional (cross-sectional) transient movement of water in full or partially saturated soils

- coded in fortran IV

- operational on IBM $370 / 158$ 


\author{
CODE: 8 \\ TYPE: PlOW \\ CODE NAME: VERGE \\ METHOD USED: 3-dimensional Galerkin finite element \\ PRINCIPAI, CONTACT: M.J. Verge \\ Dept. of Earth Science \\ University of Waterloo \\ Waterloo, Ontario \\ Canada N2L $3 \mathrm{Gl}$ \\ DOCUMENTATION: Use ${ }^{\prime} \mathrm{s}$ Guide, listings in M.J. Verge \\ "A Three-Dimensional Saturated-unsaturated \\ Groundwater Flow Model for Practical \\ Application" Ph.D. Thesis, Univ, of Waterloo, \\ Waterloo, Ontario, Canada (1976). \\ OTHER: - designed to determine hydraulic head in \\ 3-dim. saturated-unsaturated groundwater \\ flow system \\ - coded in FORTRAN IV
}


CODE : 9

TYPE: Coupled Flow and Transport

CODE NAME: SEGOL

METHOD USED: 3-d1mensional Galerkin finite element

PRINCIPAL CONTACT: Genevieve Segol

Bechtel Civil and Minerals, Inc.

P.O. Box 3965

San Francisco, CA 94119

Phone: (415) 768-7159

DOCuMEnTation: User's Guide in: Genevieve Segol "A ThreeDimensional Galerkin Finite Transport in Var1ably Saturated Porous Media, User's Manual", Dept. of Earth Sciences, Univ. of Waterloo, waterloo, Ontario, Canada N2L 3Gl (June 1976).

OTHER: - designed to determine transient concentration of conservative on non-conservative solute in groundwater flow systems

- coded in FORTRAN IV

- operational on IBM $360 / 75$ 
CODE $: 10$

TYPE: Flow

CODE NAME: UNSAT

METHOD USED: 1-dimensional finite differences

PRINCIPAL CONTACT: Frederick W. Bond

Battelle Northwest

P. O. Box 999

Richland, WA 99352

DOCUMFNTATION: - early version described in:

S.K. Gupta, K.K. Tanji, D.R. Nielsen

J.W. Biggar, C.S. Simmons, J.L. McIntrye

"Field simulation of Soil-Water Movement

with Crop Water Estimation", Univ. of Calif.

at Davis, Water Science and Engineering Paper

No. 4013, (Jan. 1978).

- A user's manual is currently being prepared and will be distributed by EPRI.

OTHER: - designed to simulate infiltration, vertical seepage and uptake by plant roots as related to the hydraulic properties of a soil, soil layering, the root growth characteristics of a given crop in a given soil profile evapotranspiration rates, and frequency rate and amount of irrigation.

- coded in FORTRAN IV

- operational on DEC PDP $11 / 70$ 
CODE : 11

TYPE: Flow and Transport

CODE NAME: SUMATRA-1

METHOD USED: 1-dimensional, Hermitian (cubic) finite elements

PRINCIPAL CONTACT: Dr. M. Th. van Genuchten

USDA

U.S. Salinity Lab.

4500 Glenwood Drive

Riverside, CA 92501

Phone: (714) 683-0172

DOCUMENTATION: code listing in: M.Th, van Genuchten, "Mass

Transport in Saturated - Unsaturated Media:

One-dimensional Solutions", document no.78-WR-11

Princeton University, Princeton, NJ

OTHER: - designed to simulate the simultaneous flow of water and solutes in a one-dimensional (vertical) soil profile under transient saturated - unsaturated conditions

- coded in Fortran IV

- the method for solving the flow equations is essentially the same as that used in Code No. 28 (UNSATI).

E.11 
CODE : 12

TYPE: Flow and Transport

CODE NAME: TRANSONE

METHOD USED: One-dimensional Hermitian finite elements used with Galerkin's approximation

PRINCIPAL CONTACT: Dr. M. Th. van Genuchten

USDA

U.S. Salinity Lab.

4500 Glenwood Dr.

Riverside, CA 92501

phone: 714-683-0172

DOCUNENTATION:

OTHER: - designed to solve the equations governing one-dimensional mass transport through unsaturated and saturated porous media 
CODE : 13

TYPE: Flow and Transport

CODE NAME: TRANSTWO

METHOD USED: 2-dimensional finite differences

PRINCIPAL CONTACT: Allen Shapiro

DOCUNENTATION: In preparation (1976)

OTHER: - designed to solve the equations governing two-dimensional mass transport in unsaturated and saturated groundwater flow. 
CODE $: 14$

TYPE: Flow and Transport

CODE NAME: MOBIDIC

METHOD USED: Finite difference used to obtain a system of differential differences equations which are then integrated using a variable step Runge Kutta method.

PRINCIPAL CONTACT: Ph. Couchat

Service de Radioagronomic

C.E.N. Cadamache

13115 - Saint-Paul-lez-Durance

DOCUMENTATION: model description given in "notices": DIFSOL, DFMOD, MULTISOL (in French), Internal report by Cisi Cadarache and G. Le Cardinal.

OTHER: - designed to predict water transfer from soil to plants in a one-dimensional multi-layered soil or 2-dimensional homogeneous soil 
CODE : 15

TYPE: Flow and Transport

CODE NAME: NMODEL

METHOD USED: Finite differences

PRINCIPAL CONTACT: H.M. Selim

Soil Science Department

University of Florida

Gainesville, FL 32611

DOCUMENTATION:

OTHER: - designed to predict water and nitrogen transport and transformation under transient and steady unsaturated water flow in homogeneous or multilayered soils

- coded in FORTRAN 
CODE : 16

TYPE: Flow and Transport

CODE NAME: WATSOL

METHOD USED: 1-dimensional finite difference

PRINCIPAL CONTACT: J.P. Gaudet or R. Haverkamp

Institute de Mecanique de Grenoble

B.P. 53 - Centre de Tri

38041 Grenoble Cedex - France

DOCUMENTATION: - theory and application for water flow:

R. Haverkamp, M. Vauchin, J. Touma, P.J. Wierenga, G. Vachaud," A Comparison of Numerical Simulation Models for One-dimensional Infiltration", to appear in SOIL SCIENCE SOC PROC AM April 1977.

- for solute transport: J.P. Gaudet, "Transfer d'eau et de solute dans la zone non-saturee des sols: Mesures et Modelication", Thesis, Universiti de Grenoble 1977.

- listings available on request

- operating instruction not written (as of Feb. 10, 1977)

OTHER: - designed to simulate and predict water flow with or without solute through the unsaturated zone

- coded in ForTRAN IV - Level H

- operational on IBM 1130

IBM $360 / 67$

CII-IRIS 80 (SIRIS8) 
CODE : 17

TYPE: Transport

CODE NAME: FECTRA

METHOD USED:2-dimensional Galerkin- finite element with Adams-Moulton predictor - corrector algorithm

PRINCIPAL CONTACT: Robert G. Baca or Alan Lu

Research Department

Rockwell Hanford Operations

P.O. Box 250

Richland, WA 99352

DOCUMENTATION: User's Manual: document no. RHO-MA-250

Rockwell Hanford operations

P.O. Box 250

Richland, WA 99352

OTHER: - designed to simulate constituent transport in saturated or unsaturated porous media with complicated or arbitrary geometry

- coded in FORTRAN IV

- operational on CDC 6600 , CYBER 74, UNIVAC 1108 
CODE : 18

TYPE: Flow and Transport

CODE NAME: TARGET

METHOD USED: 2-and 3-dimensional integrated finite differences

PRINCIPAL CONTACT: D. Sharma

Dames and Moore

250 East Broadway, Suite 200

Salt Lake City, Utah 84111

Phone (801) 521-9255

DOCUMENTATION: D. Sharma, "A Comprehensive Mathematical Model

Capable of Predicting Flow, Heat Transfer as well as Chemical-Species Transport in Porous Media", Dames and Moore, Advanced Tech. Group Rep. TN-DN-42

OTHER: - designed to simultaneously solve the transient hydrodynamic and chemical transport equations in unsaturated or saturated media

- coded in FORTRAN IV

- operation on $\mathrm{CDC}-6600$

- Proprietary code 
CODE : 19

TYPE: Transport

CODE NAME: DUGUID-REEVES

METHOD USED: Galerkin finite element in 2-dimensions

PRINCIPAL CỌNTACT:

DOCUMENTATION: Comprehensive description and 1 isting in: J.o. Duguid and M. Reeves, "Material Transport through Porous Media: A finite-element Model", Oak Ridge National Laboratory, Oak Ridge, TN ORNL-4928 (March 1976)

OTHER: - designed to solve the governing transport equations when both absorption and decay of the dissolved constituent are present.

- coded in FORTRAN IV 
CODE : 20

TYPE: Coupled Flow and Transport

CODE NAME: MCCANN

METHOD USED: 2-dimensional finite differences

PRINCIPAL CONTACT: R.A. MCCann or L.E. Wiles

Battelle Northwest

P.O. Box 999

Richland, WA 99352

Phone (509) 375-2488

DOCUMENTATION: analytical developments: L.E. Wiles and R.A. McCann, "Water Coning in Porous Media Resevoirs for Compressed Air Energy Storage", Battelle Northwest, Richland, WA PNL-3470 (June 1981)

OTHER: • coded in FORTRAN IV

- operational on UINIVAC 1110 
CODE : 21

TYPE: Flow

CODE NAME: ALPURS

METHOD USED: 3-dimensional finite difference

(fully implicit)

PRINCIPAL CONTACT: P.P. Bansal or A.S, Odeh

Mobil Research and Development Corp.

Dallas, TX

Phone: (214) 333-6231 (Odeh's phone)

DOCUMENTATION: technical discussion in: P.P. Bansal, J.L. Harper, A.E. McDonald, E.E. Moreland, A.S. Odeh and

R.H. Trimble, "A strongly coupled, fully implicit, three-dimensional, three phase reservoir simulator" SPE 8329 (1979)

application: Aziz S. Odeh, "Comparison of solutions to a three-dimensional black oil reservoir simulation problem", J. OF PET. TECH (Jan 1981) pp. 13-25

OTHER: - designed to solve the equation for three-dimensional three phase, multiwell black oil reservoir

- operational on CDC cyber 172 and 175

- proprietary code 


\author{
CODE : 22 \\ TYPE: Flow \\ CODE NAME: REEVES-DUGUID \\ METHOD USED: 2-dimensional Galerkin finite element
}

PRINCIPAL CONTACT:

DOCUMENTATION: User's manual and $l$ isting in: M. Reeves and J.O. Dugeid, "Water movement through saturated-unsaturated porous media: A finite element Galerkin model", Oak Ridge National

Laboratory, Oak Ridge, TN ORNL-S4927 (Feb. 1975)

OTHER: - coded in FORTRAN IV 
CODE : 23

TYPE: Flow and Transport

CODE NAME: TRANS

METHOD USED: 2-dimensional Galerkin finite element

PRINCIPAL CONTACT: Wynn R. Walker

Colorado State University

DOCUMENTATION: analytical discussion and code listing in:

Wynn R. Walker, James $D$. Sabey and Duane R. Hampton

"Studies of Heat Transfer and Water Migration in

Soils", final report May 1, 1979 to September 30,1980

to U.S. DOE Solar Energy Applications Laboratory,

Colorado State University (April 1981)

OTHER: - designed for the solution of transient coupled heat and moisture flow problems in soils or aquifers for axisymmetric problems

- coded in Fortran 


\section{CODE: 24}

TYPE: Flow

CODE NAME: FEMWATER

METHOD USED: finite-element Galerkin

PRINCIPAL CONTACT: George T. Yeh

Roorn 203

Bldg. 1505

Oak Ridge National Laboratory

P. 0 . Box $X$

Oak Ridge, TN 37830

FTS phone: 624-7285

DOCUMENTATION: analytical discussion and code listing in: G.T. Yeh and D.S. Ward "FEMWATER: a finite element model of water flow through saturated unsaturated porous media. Oak Ridge National Laboratory, Oak Ridge, TN ORNL-5567 (1979)

User's manual in: Yeh, G. T. (1982). "TRAINING COURSE NO. 1: The implementation of FEMWATER (ORNL-5567) Computer Program - Final Report" NUREG/CR-2705

REFERENCES: Pickens, J.F, and G.E. Grisak, "Finite element analysis of liquid flow, heat transport and solute transport in a groundwater flow system: governing equations and model formulation. AECL-TEC-REC-81, National Hydrology Research Institute Inland Waters Directorate, Environment Canada, for Atomic Energy of Canada Limited, Whiteshell Nuclear Research Establishment. (September 1979)

OTHER: - written in FORTRAN IV 


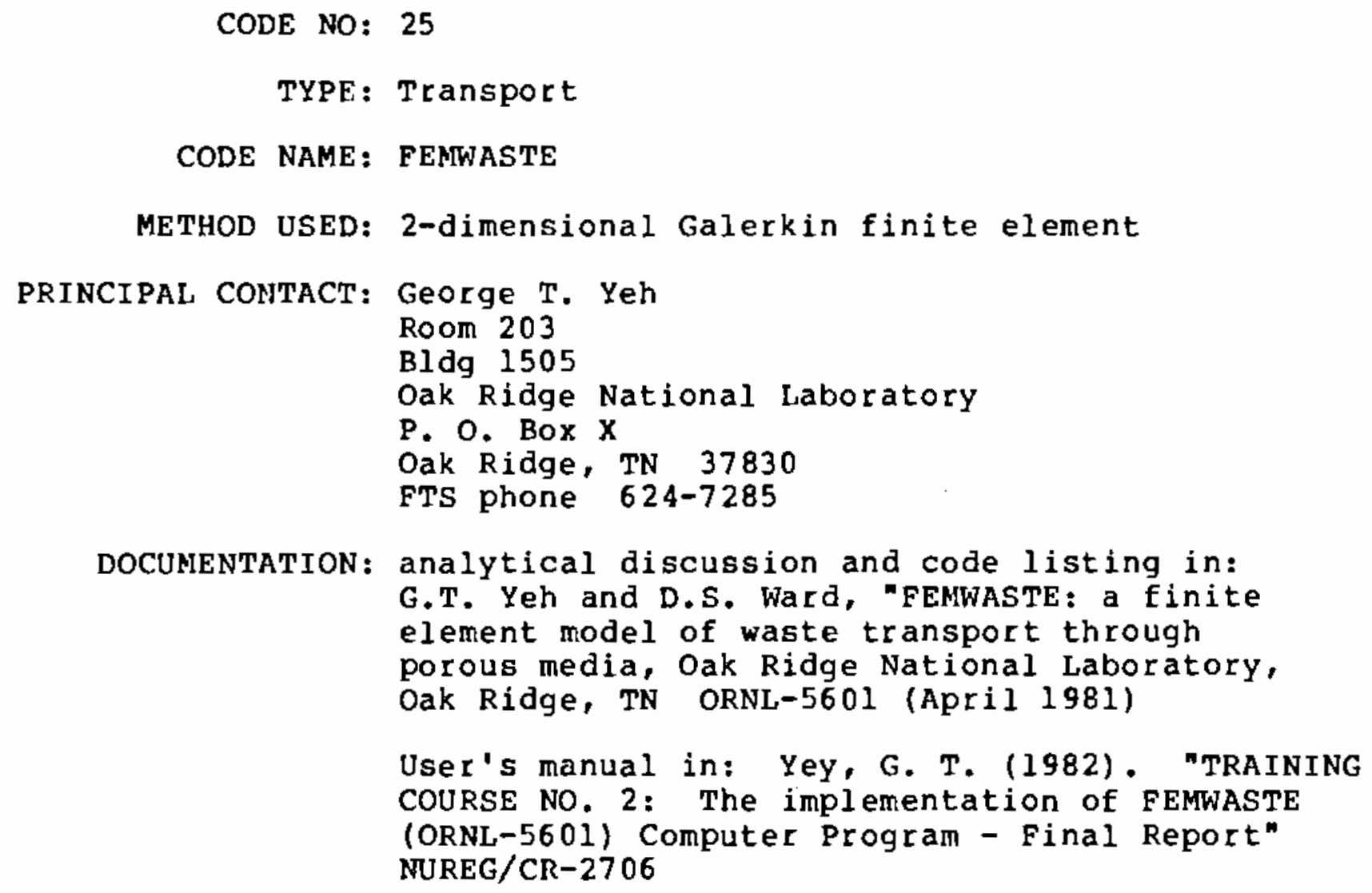

OTHER: - transport mechanisms include: convection, hydrodynamic dispersion, chemical sorption and first-order decay.

- coded in FORTRAN IV 
CODE NO: 26

TYPE: Flow

CODE NAME: UNSAT2

METHOD USED: 2-dimensional finite-element

PRINCIPAL CONTACT: Shlomo P. Neuman

Dept. of Hydrology \& Water Resources

University of Arizona

Tucson, AZ 85717

Phone: (602) 884-4434

FTS: (602) 626-4434

DOCUMENTATION: User's guide and listing in:

S.P. Neuman, R.A. Feddes, and

F. Bresler, "Finite element simulation

of flow in saturated-unsaturated soils

considering water uptake by plants",

$3 \mathrm{rd}$ ann. report, Project AIJ0-SWC-77,

Hydrodynamics and Hydraulic Engineering Lab,

Technion, Haifa, Israel (1974)

OTHER: - designed to compute hydraulic heads, pressure heads, water content, boundary flumes and internal sinks and sources in a saturatedunsaturated non-uniform anisotropic porous medium under nonsteady state conditions. Soil evaporation and evapotranspiration due to plants uptake may also be computed

- written in FORTRAN IV

- operational on IBM 360-370's 
CODE NO: 27

TYPE: Flow

CODE NAME: STGWT/MOGWT

METHOD USED: 1-dimensional finite differences

PRINCIPAL CONTACT: F. De Smedt

Dept. of Hydrology

Faculty of Applied Sciences

Voije Universitait

Brussel, Pleinlean 2

B-1040

Brussels - Belgium

DOCUMENTATION: code listing in: F. De Smedt and A. van Beker, "The groundwater flow in the unsaturated zone" Dept. of Hydrology, Faculty of Applied Sciences, Voije Universitait, Brussel, Pleinlaan 2, B-1040 Brussels - Belgium (Sept. 1974)

OTHER: - designed to solve problems of one-dimensional vertical, unsaturated flow in homogeneous soil

- coded in FORTRAN extended version 4 


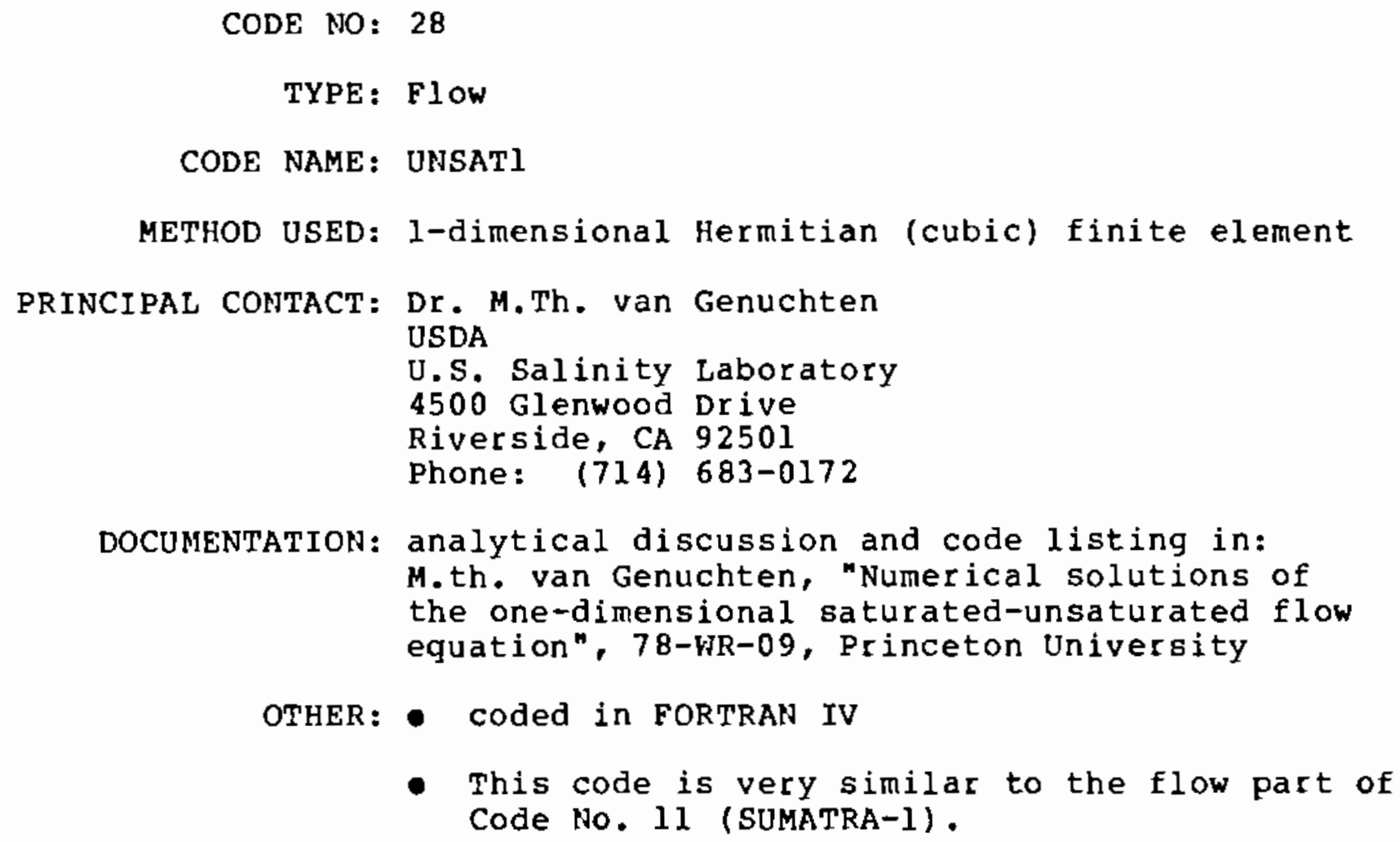

- This code is very similar to the flow part of Code No. 11 (SUMATRA-l). 


\author{
CODE NO: 29 \\ TYPE: FlOW \\ CODE NAME: COOK \\ METHOD USED: 2-dimensional finite difference
}

PRINCIPAL COHTACT:

DOCUMENTATION: analytical discussion in: R.E. Cook, R.H. Jacoby and A.B. Ramesh, "A Beta-Type Reservoir Simulation for Approximating Compositional Effects During Gas Injection", SOC. PET. ENGR. J. (Oct. 1974)

OTHER: - designed to solve 2-dimensional, 2-phase (oil and gas) problems where the fluid compositional effects are significant

- proprietary code 
CODE NO: 30

TYPE: Flow

CODE NAME: GANDALF

METHOD USED:

PRINCIPAL CONTACT: Frank A. Morrison

Lawrence Livermore Laboratory

Livermore, CA

DOCUMENTATION: analytical discussion and code listing in:

Frank A. Morrison, Jr.., "Stability of flow from

a nuclear cavity" UCRL-13799 July 1977

OTHER: - designed to calculate velocities, saturations, marginal stability conditions, and growth rates of instability for multiphase multicomponent

flow in porous media. Design problem was cavity generated by underground nuclear explosion.

- coded in FORTRAN IV

- operational on IBM 360 
CODE NO: 31

TYPE : FLOW

CODE NAME: GPSIM (General Purpose Reservoir Simulator)

METHOD USED: finite, semi implicit, three dimensional

PRINCIPAL CONTACT: Exxon Production Research

DOCUMENTATION: analytical discussion contained in:

A.G. Spillette, J.G. Hillestad and H.L. Stone

"A High-Stability Sequential Solution Approach

to Reservoir Simulation" SPE 4542. Presented

at 48 th Annual Fall Meeting of SPE's of AIME, Las Vegas, Nev., September 30-October 3, 1973.

Application: Aziz S. Odeh, "Comparison of Solutions to a Three-Dimensional Black-Oil Reservoir Simulation Problem", J\&PET TECH (Jan. 1981) pp. 13-25.

OTHER: - designed to solve the equations governing three-dimensional, three phase black oil reservoirs. It can also treat fewer phases and/or dimensions.

- operational on Amdahl 470/V5, IBM $370 / 168$

- proprietary code 
CODE NO: 32

TYPE：FLOW

CODE NAME: TS\&E

METHOD USED:

PRINCIPAL CONTACT: Technical Software \& Engineering Inc. P.O. Box 19533

Dallas, TX 75219

phone (214) 691-4869

DOCUMENTATION: analytical discussion contained in SPE paper no. SPE-4979 which was presented at the 49 th annual fall meeting of SPE's of AIME at Houston, October 1974.

OTHER: - Universal Black Oil Reservoir Simulator, designed to solve the governing equations for three-phase, threedimensional black oil reservoir. It can be used on fewer phases and/or dimensions.

- proprietary code 


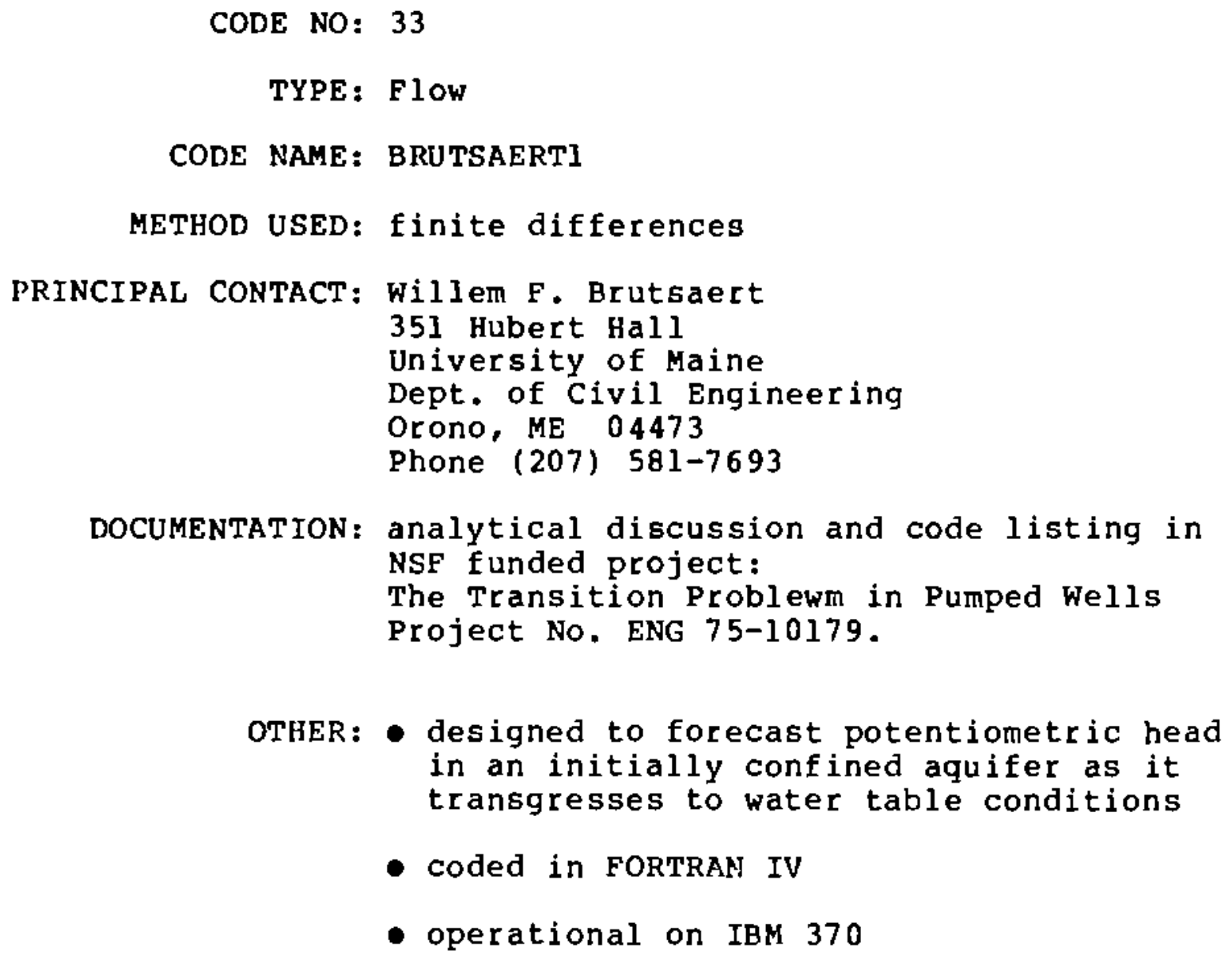


CODE NO: 34

TYPE: Flow and Transport

CODE NAME: WHC (Water, Heat, Chemical Transport)

METHOD USED: Integrated Compartment Method

PRINCIPAL CONTACT: George T. Yeh

Room 203

Bldg. 1505

Oak Ridge National Laboratory

P. O. Box $x$

Oak Ridge, TN 37830

FTS phone: 624-7285

DOCUMENTATION: analytical discussion and code listing in: E.A. Crooks and G.T. Yeh, "WHC: a multidimensional model of water movement, heat flow, and chemical transport in complex aquifer systems", ORNL/TM 7564 , Oak Ridge, TN

OTHER: - designed to solve the governing equations for pressure head, temperature and chemical distribution in saturated-unsaturated porous media.

- coded in FORTRAN IV 
CODE NO: 35

TYPE: Transport

CODE NAME: SCATID (one-dimensional)

METHOD USED: finite differences, uncertain velocity input is used to generate dispersion

PRINCIPAL CONTACT: C.A. Oster

P.O. Box 999

Battelle Northwest

Richland, WA 99352

Phone: (509) 375-2979

DOCUMENTATION: analytical discussion contained in:

C.A. Oster, A.G. Gibbs and D.H. Tang,

"Analysis of a numerical solution to the one-dimension stochastic convection equation"

ADV WATER RESOURCES vol. 4, 1981 (Mar. 81)

OTHER: - requires user to furnish velocity covariance functions. For examples see J.L. Devary and P.G. Doctor. "Geostatistical modeling of pore Velocity", PNL-3789, Pacific Northwest Labs, Richland, Wa (1981).

- coded in FORTRAN IV

- operational on DEC $11 / 70$ 
CODE NO: 36

TYPE: Transport

CODE NAME: SCAT2D (two-dimensional)

METHOD USED: finite differences, uncertain velocity input is used to generate dispersion

PRINCIPAL CONTACT: C.A. Oster

Battelle Northwest

P. O. Box 999

Richland, WA 99352

Phone: (509) 375-2979

DOCUMENTATION: analytical discussion contained in:

C.A. Oster and A.G. Gibbs "A numerical procedure for obtaining the mean solution and variance of the two-dimensional stochastic convection equation". Submitted for publication in ADV. WATER RESOURCES

OTHER: - requires user to furnish velocity covariance functions. For examples see J.L. Devary and P.G. Doctor. "Geostatistical modeling of Pore Velocity", PNL-3789, Pacific Northwest Labs, Richland, wa (1981).

- coded in FORTRAN IV

- operational on DECPDP $11 / 70$ 


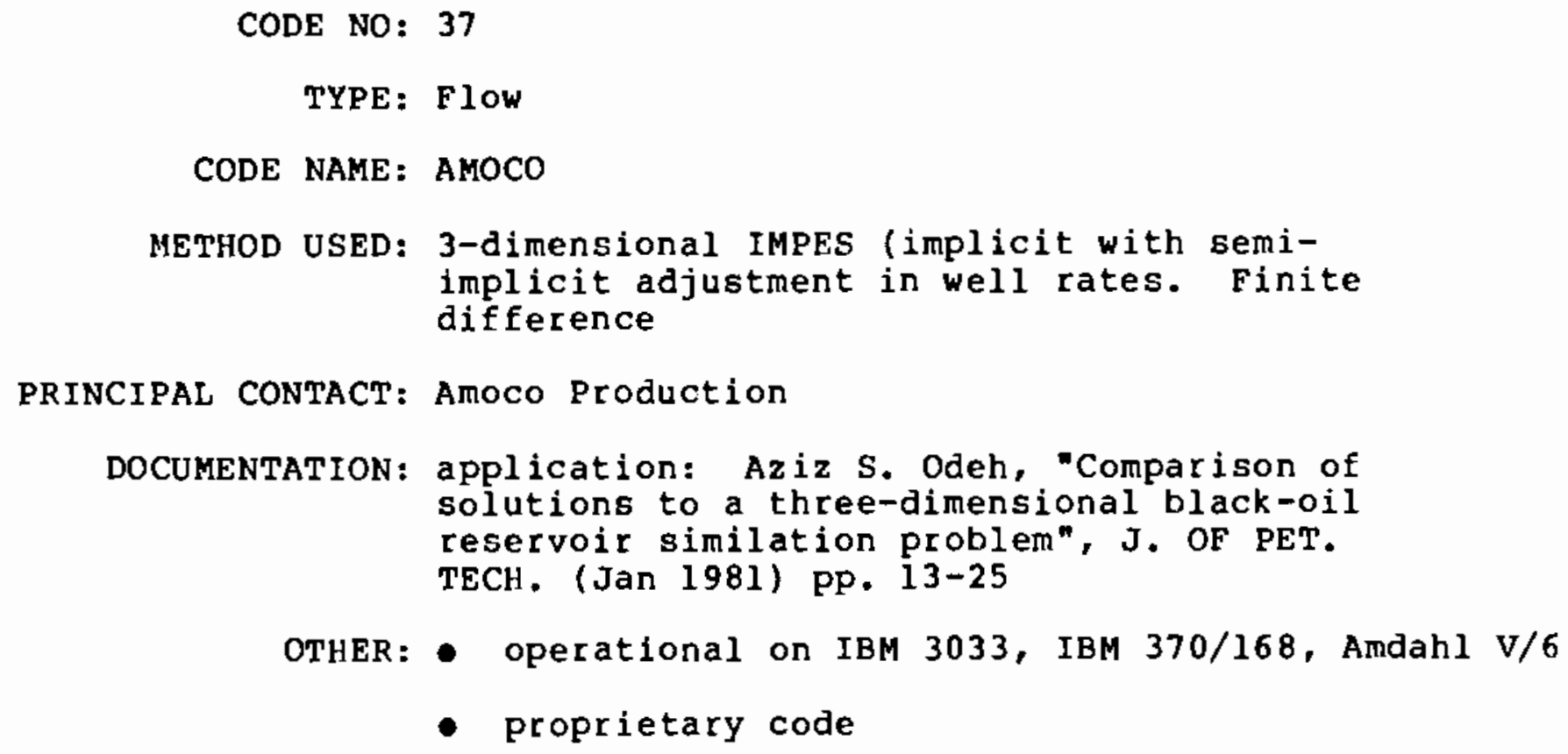

PRINCIPAL CONTACT: Amoco Production

DOCUMENTATION: application: Aziz S. Odeh, "Comparison of solutions to a three-dimensional black-oil reservoir similation problem", J. OF PET. TECH. (Jan 1981) Pp. 13-25

OTHER: - operational on IBM 3033, IBM 370/168, Amdahl V/6

- proprietary code 


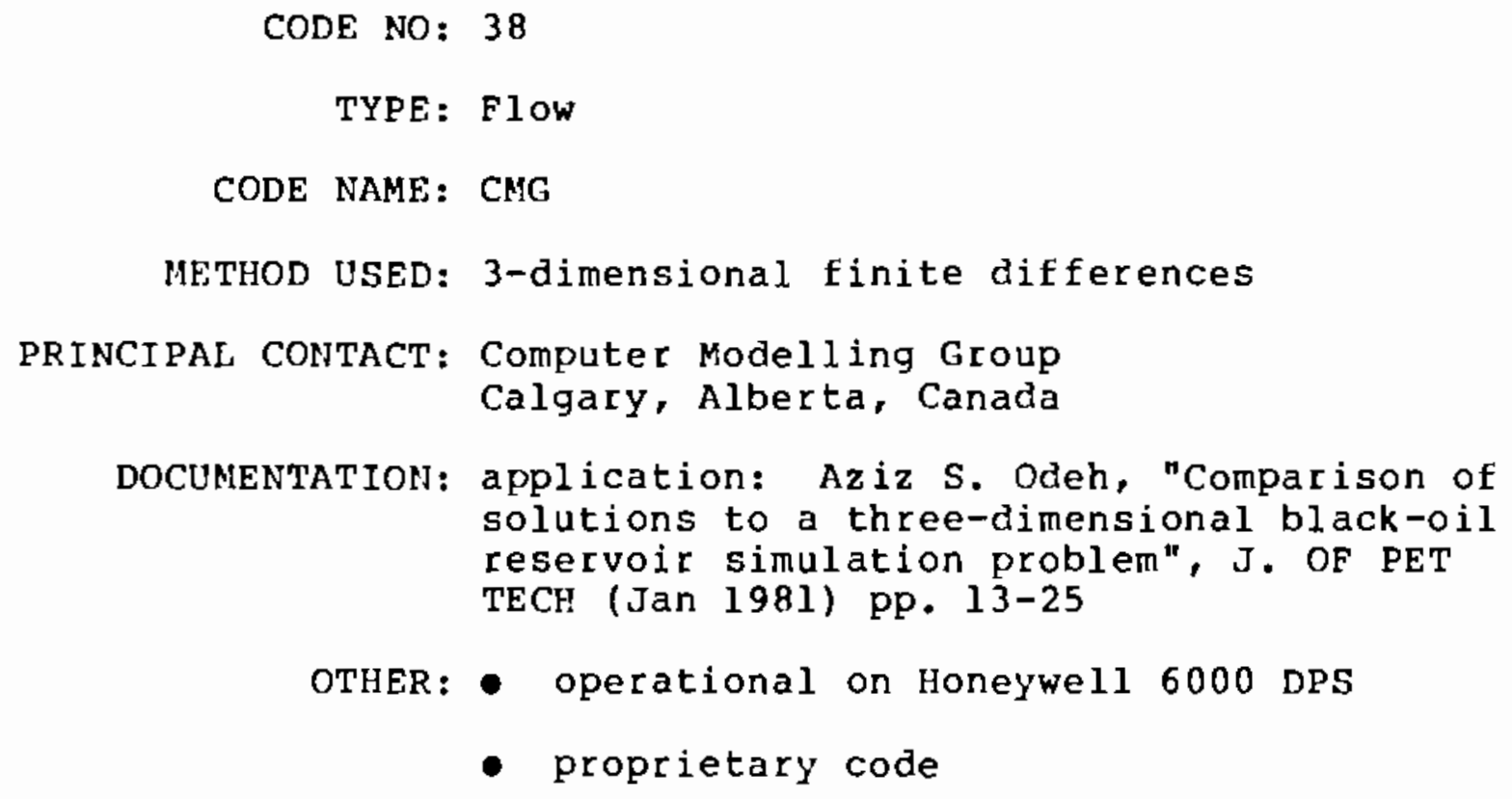


CODE NO: 39

TYPE: FlOW

CODE NAME: BRUTSAERT2

METHOD USED: 2-dimensional, fully implicit finite differences

PRJNCIPAL CONTACT: Willen F. Brutsaert

351 Aubert Hall

University of Maine

Dept. of Civil Engineering

Orono, ME 04473

phone (207) 581-7693

DOCUMENTATION: analytical discussion in:

w. Brutsaert, "A functional iteration technique for solving Richard's Equation Applied to twodimensional infiltration problems", WATER RESERVOIR RESEARCH vol 6, No. 7, (Dec 1971)

OTHER: - designed to compute the temporal and spatial variation of moisture content and water table response, as caused by precipitation, artificial recharge, and irrigation, in a heterogeneous (layered) anisotropic soil profile

- coded in FORTRAN IV

- operational on IBM 360 


\section{CODE NO: 40}

TYPE: Flow

CODE NAME: BETA-II

METHOD USED: 3-dimensional Einite difference

PRINCIPAL CONTACT: INTERCOMP Resources Development Corporation 1201 Dairy Ashford

Suite 200

Houston, TX 77079

DOCUMENTATION: application: Aziz S. Odeh, "Comparison of solutions to a three-dimensional black-oil reservoir simulation problem", J OF PET TECH (Jan 1981) pp. 13-25

OTHER: - designed to simulate two-and three-phase compressible flow in heterogeneous hydrocarbon reservoirs

- operation on Cray-I, Harris/7

- proprietary code 


\author{
CODE NO: 41 \\ TYPE: FlOW \\ CODE NAME: SSC \\ METHOD USED: 3-dimensional finite differences \\ (adaptive implicit method) \\ PRINCIPAL CONTACT: Scientific Software Corporation \\ Denver, CO \\ DOCUMENTATION: application: Aziz S. Odeh, "Comparison \\ of Solutions to a Three-Dimensional \\ Black-Oil Reservoir Simulation Problem", \\ J. OF PET. TECH. (Jan. 1981) pp. 13-25 \\ OTHER: - operational on CDC CYBER 75 \\ - proprietary code
}




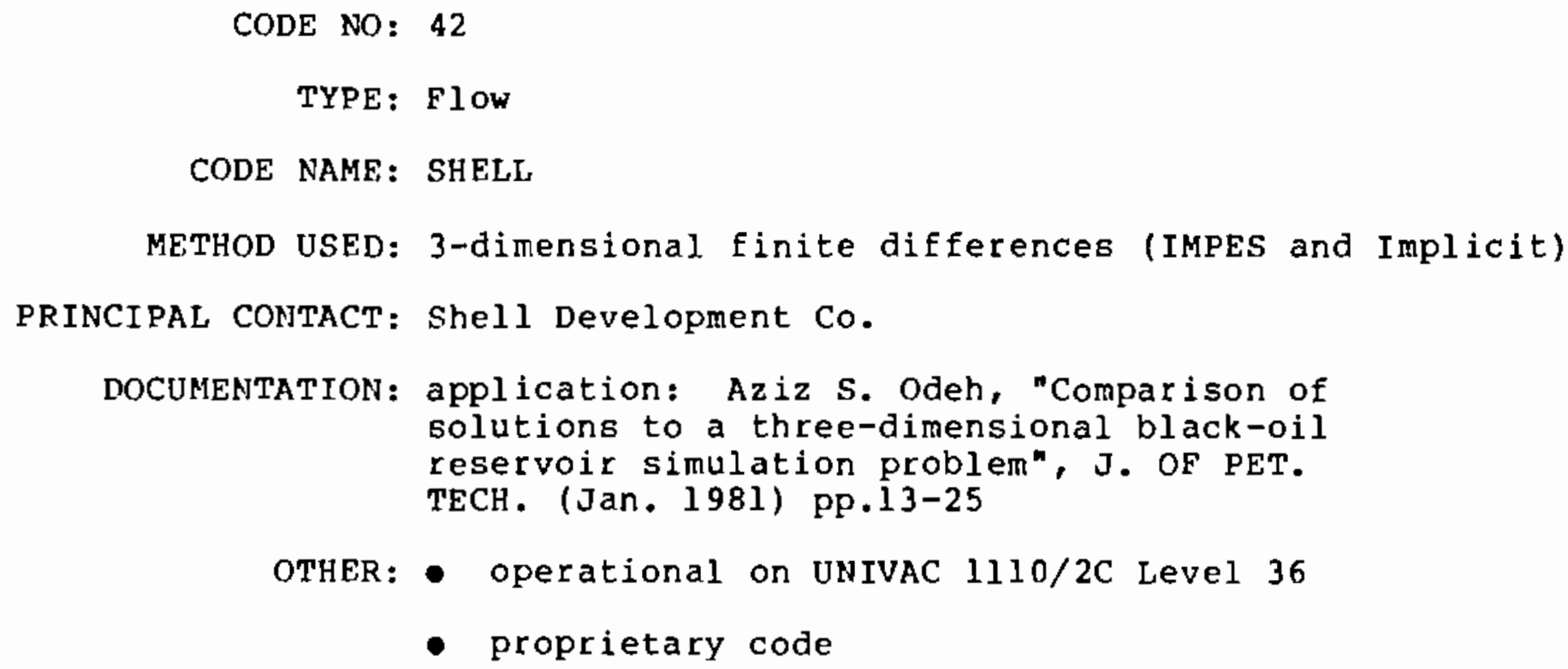


CODE NO: 43

TYPE: Flow and Transport

CODE NAME: SHAMTU

METHOD USED: 1-dimension finite difference, implicit

PRINCIPAL CONTACT: M. Vauclin

Institut de Mecanique de Grenoble

B.P. 53 - Centre de Tri

38041 - Grenoble - Cedes - France

DOCUMENTATION: description, theory and application in:

M. Vauclin, G. Hamon, R. Haverkamp, G. Vachaud

"Simulation des transferts couples mass-chaleur

in milie poreus partiellement - application a la prediction de levaporation sur sol nu in-situ" Communication to Sixth International Heat Transfer Conference (7-11 Aug 1978) Toronto, Canada

OTHER: - designed to predict simultaneous heat and mass transport in the unsaturated zone

- coded in FORTRAN IV Level $\mathrm{H}$

- operational on IBM $1130,360 / 67$, CII-IRIS 80 


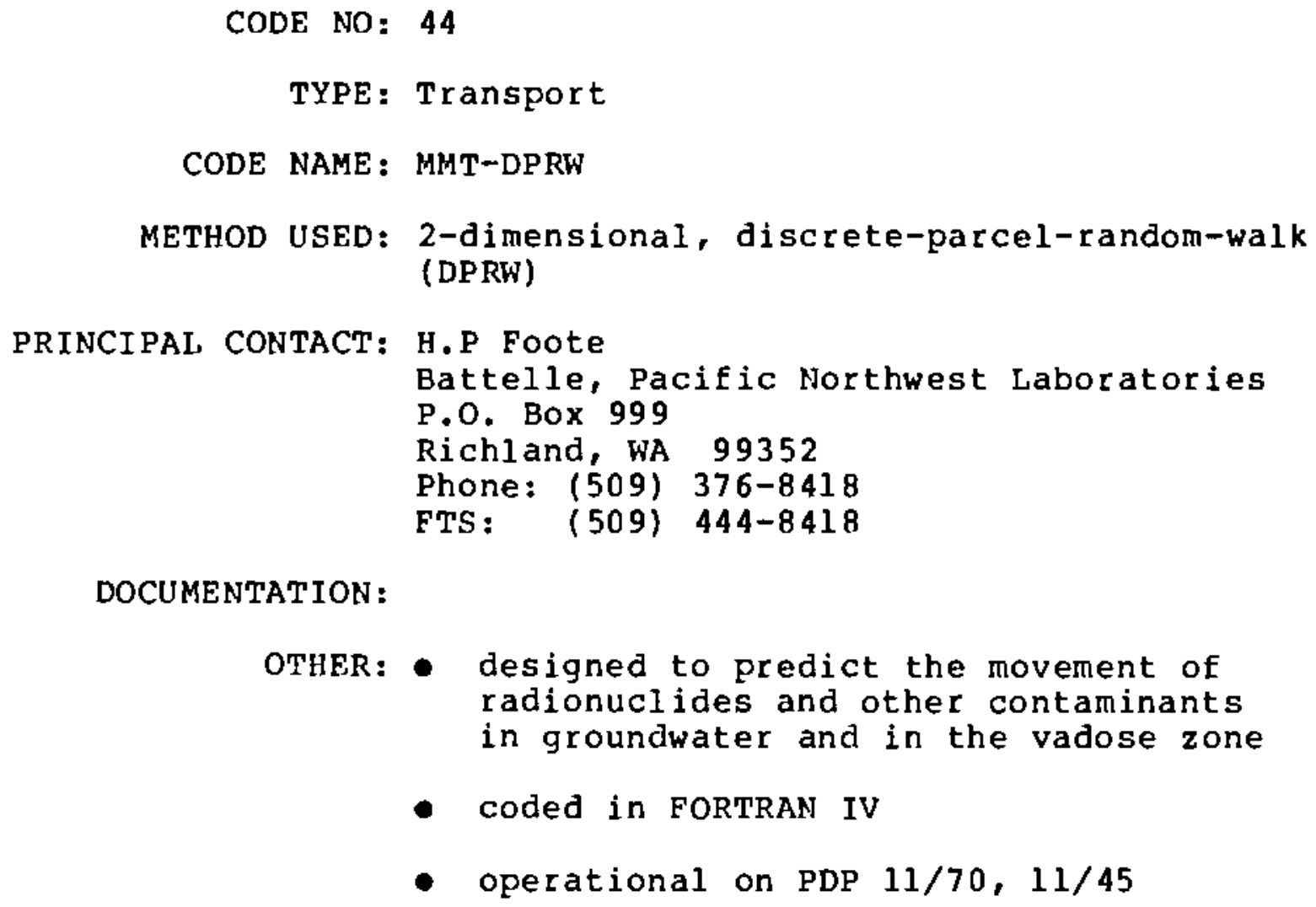

DOCUMENTATION :

OTHER: - designed to predict the movement of radionuclides and other contaminants in groundwater and in the vadose $z$ one

- coded in FORTRAN IV

- operational on PDP $11 / 70,11 / 45$ 
CODE NO: 45

TYPE: Flow

CODE NAME: VS2D

NETHOD USED: 2-dimensional finite differences, either fully implicit or Crank-

Nicholson time discretization

PRINCIPAL CONTACT: E, G. Lappala

Senior Hydrogeologist

Ertec Western, Inc.

3777 Long Beach, CA 90807

Phone: (213) 595-6611/976-1721

DOCUMENTATION: Analytical discussion, user instruction and program listing are contained in:

E. G. Lappala, "Documentation of Computer Program to Solve the Equations of Fluid

Flow in Variably Saturated Porous Media", August 1981, Preliminary report, eventually to be issued as USGS open-file report $81-\mathrm{xxx}$.

OTHER: - coded in FORTRAN

- Capable of treating problems in which part of the solution domain is saturated and part is unsaturated.

- Includes general nonlinear source-sink terms to account for stresses, such as evaprotranspiration.

- Either rectangular or cylindrical coordinates may be used. 
CODE NO: 46

TYPE: Flow

CODE NAME: SUM-2

METHOD USED: 2-dimensional finite element

PRINCIPAL CONTACT: National Institute for water supply

P.O. Box 150

Leinscmendam, The Netherlands

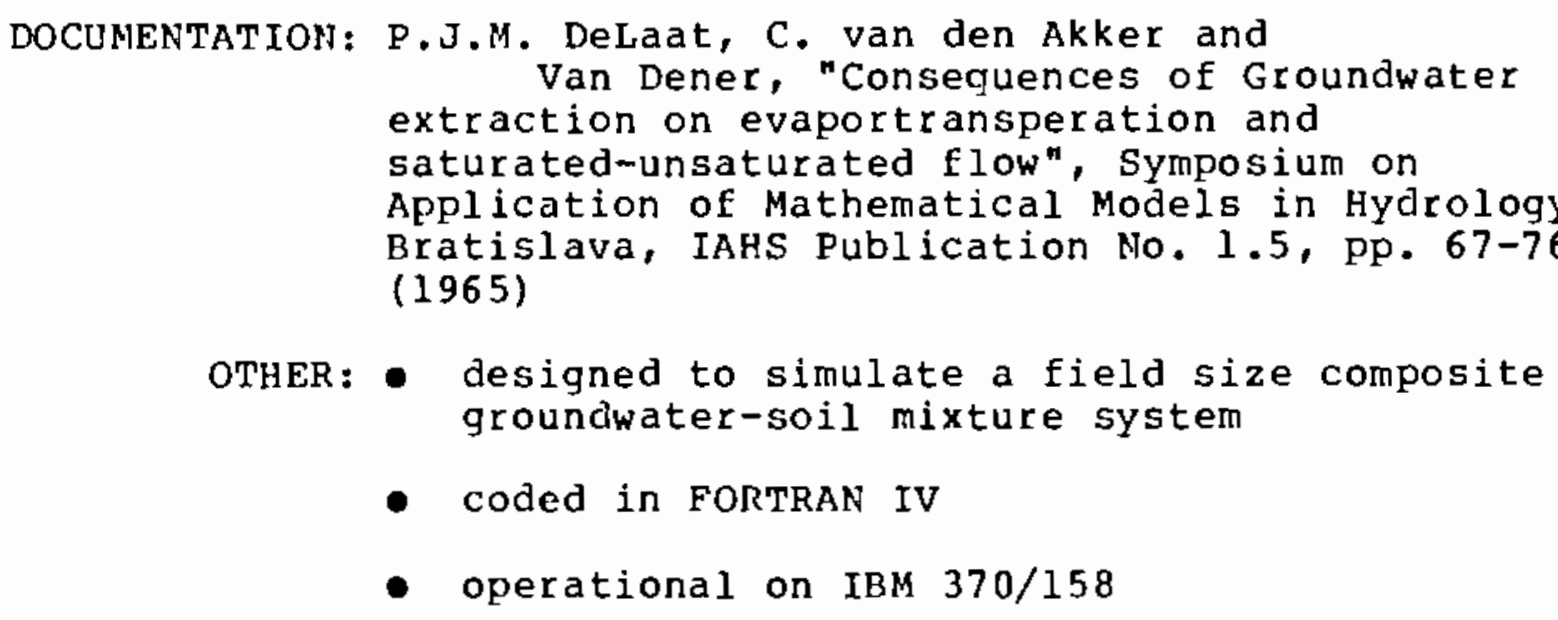




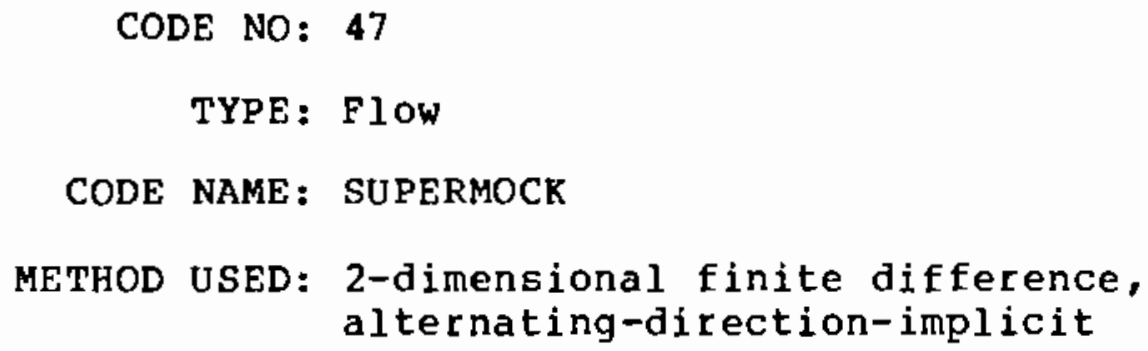

DOCUNENTATION: Model description and program listing appear in: J.E. Read, M.S. Bedinger and J.E. Terry "Simulation procedure for Kodeling Transient Water-Table and Artesian Stress and Response" Open File Report 76-792 (1976)

OTHER: - designed to simulate water tables and artesian stress and response

- coded in FORTRAN IV - h level 


\author{
CODE NO: 48 \\ TYPE: FlOW \\ CODE NAME: DELAAT \\ METHOD USED: 2-dimensional, finite element (variational) \\ PRINCIPAL CONTACT: P.J.M. de Laat \\ International Institute for Hydraulic \\ and Environmental Engineering \\ Oude Delft 95 \\ Delft, The Netherlands \\ DOCUMENTATION: P.J.M. de Laat, "Groundwater extraction and \\ crop production", thesis \\ OTHER: - designed to predict consequences of \\ groundwater extraction on polymetric \\ heads, water balance and crop production \\ - coded in FORTRAN IV - Level G
}




\author{
CODE NO: 49 \\ TYPE: Flow \\ CODE NAME: PORES \\ METHOD USED: 3-dimensional finite difference (fully implicit) \\ FRINCIPAL CONTACT: U.K. Atomic Energy Authority \\ Harwell Research Laboratory \\ Berkshire, England \\ DOCUMENTATION: \\ OTHER: - designed to solve the governing equations \\ for three-dimensional, three phase, \\ multiwell black oil reservoir
}


CODE NO: 50

TYPE: Fluid Flow

CODE NAME: WAFE

METHOD USED: 2-dimensional finite difference

PRINCIPAL CONTACT: Bryan J. Travis

Los Alamos National Laboratory

MS F 665

P.O. Box 1663

Los Alamos, NH 87545

phone FTS: 843-1254

DOCUMENTATION: In preparation.

OTHER: - Special features: coupled heat and two-phase mass transport (air vapor and liquid), accurate treatment of water, separate velocity field for each phase.

- Past applications: confined underground radioactive waste disposal, in-situ fossil energy recovery studies, two-phase flow and tracer studies. 
CODE NO: 51

TYPE: Fluid Flow

CODE NAME: TRIPM

METHOD USED: 2-dimensional finite element

PRINCIPAL CONTACT: Dr. A. B. Gureghian

Project Management Division

Performance Analysis Department

Battelle Columbus

$505 \mathrm{King}$ Avenue

Columbus, $\mathrm{OH} \quad \mathbf{4 3 2 0 1}$

DOCUMENTATION: A.B. Gureghian, "A two-dimensional finite-element model for the simultaneous transport of water and reacting solutes through saturated-unsaturated porous media TRIPM", Argonne National Laboratory, Argonne, IL (1981) ANL/ES-114 (in press Oct. 1981)

REFERENCES: A.B. Gureghian, "Migration of Radionuclide Chains in a Non-Homogeneous Aquifer under Transient SaturatedUnsaturated Flow Conditions", Presented at the 4 th Annual Symposium on Uranium Mill Tailings Management, Colorado State University, Fort Collins, Colorado, oct. 26-27, (1981)

OTHER: includes three-membered radionuclide decay chains written in FORTRAN IV

Run on IBM 37195 


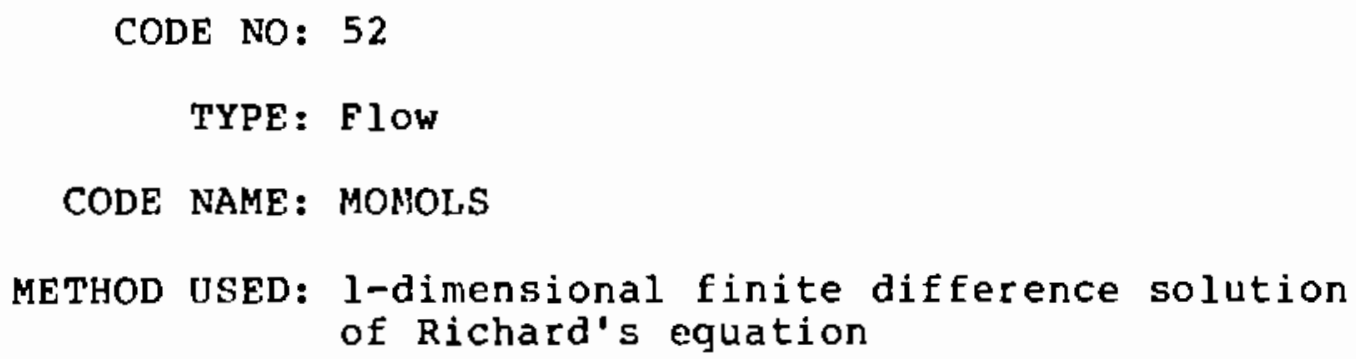


CODE NO: 53

TYPE: Flow Transport

CODE NAME : MARINO

METHOD USED: 2-dimensional Galerkin finite element

PRINCIPAL CONTACT: Professor Miguel A. Marino

Dept. of Land, Air and Water Resources

and Dept. of Civil Engineering

University of California

Davis, CA 95616

DOCUHENTATION: Miguel A. Marino, "Saturated-Unsaturated Modeling of Groundwater Quality in Unconfined Aguifer Systems", OUALITY OF GROUNDWATER, Proceedings of an International Symposium, Noordwijkerhout, The Netherlands, 23-27 March 1981 , W. van Duijvenbooden, P. Glasbergen and H. van Lelyveld (Eds.), STUDIES IN ENVIRONMENTAL SCIENCE vol. 17 Elsevier Scientific Publishing Co., pp. 979-984

OTHER: model includes a term for solutes which undergo first order reactions such as radioactive decay 


\section{CODE NO: 54}

TYPE: Transport

CODE NAME: MLTRAN

METHOD USED: 2-dimensional finite elements

PRINCIPAL CONTACT: A.E. Reisenauer, R.W. Nelson, C.A. Newbill

Battelle Northwest

P.O. Box 999

Richland, Wa 99352

Phone (509) 376-8338

FTS $444-8338$

DOCUMENTATION: A.E. Reisenauer, S.K. Gupta, R.W. Nelson C.A. Newbill "Advective Radionucl ide Transport with soil Interaction Under Variably Saturated Flow Conditions" PNL-3994, Pacific Northwest Laboratory, Richland, Wa. 99352 (Sept. 1981)

OTHER: - Uses data files generated by the program TRUST, Code No 4, for the flow field calculation.

- operational on DEC PDPll/45 computer. 


\author{
CODE NO: 55 \\ TYPE: Flow \\ CODE NAME: TRACR3D \\ METHOD USED: 3-dimensional integrated \\ finite differences
}

PRINCIPAL CONTACT: Bryan J. Travis

Los Alamos National Laboratory

MS F665

P. O. Box 1663

Los Alamos, NM 87545

Phone FTS: 843-1254

DOCUMENTATION: In preparation.

OTHER: - Special features: one or two phase

flow with tracer in either phase

(air or water) Freundlich, Langmuir

sorption, radioactive decay,

capillary effects.

- Past applications: tracer flow in unsaturated conditions, radionuclide transport, tracer flow in fractured system. 

NUREG/CR-2917

PNL-4427

RU

DISTRIBUTION

No. of

Copies

OFFSITE

485 U.S. Nuclear Regulatory Commission Division of Technical Information and Document Control

2 DOE Technical Information Center

J. J. Davis

NRC Office of Nuclear Regulatory Research

Washington, DC 20555

J. B. Martin, Director

Division of Waste Management

Washington, DC 20555

5 D. L. Siefken

NRC Office of Nuclear Material

Safety and Safeguard

Washington, DC 20555
No. of

Copies

ONSITE

50 Pacific Northwest Laboratory

E. M. Arnold

C. R. Cole

D. W. Dragnich

A. F. Gasperino

G. W. Gee (5)

T. L. Jones

C. T. Kincaid

D. W. Mayer

R. W. Nelson (15)

C. A. Oster (24)

C. S. Simmons

S. C. Sneider

Publishing Coordination (KC)(2)

Technical Information (5) 



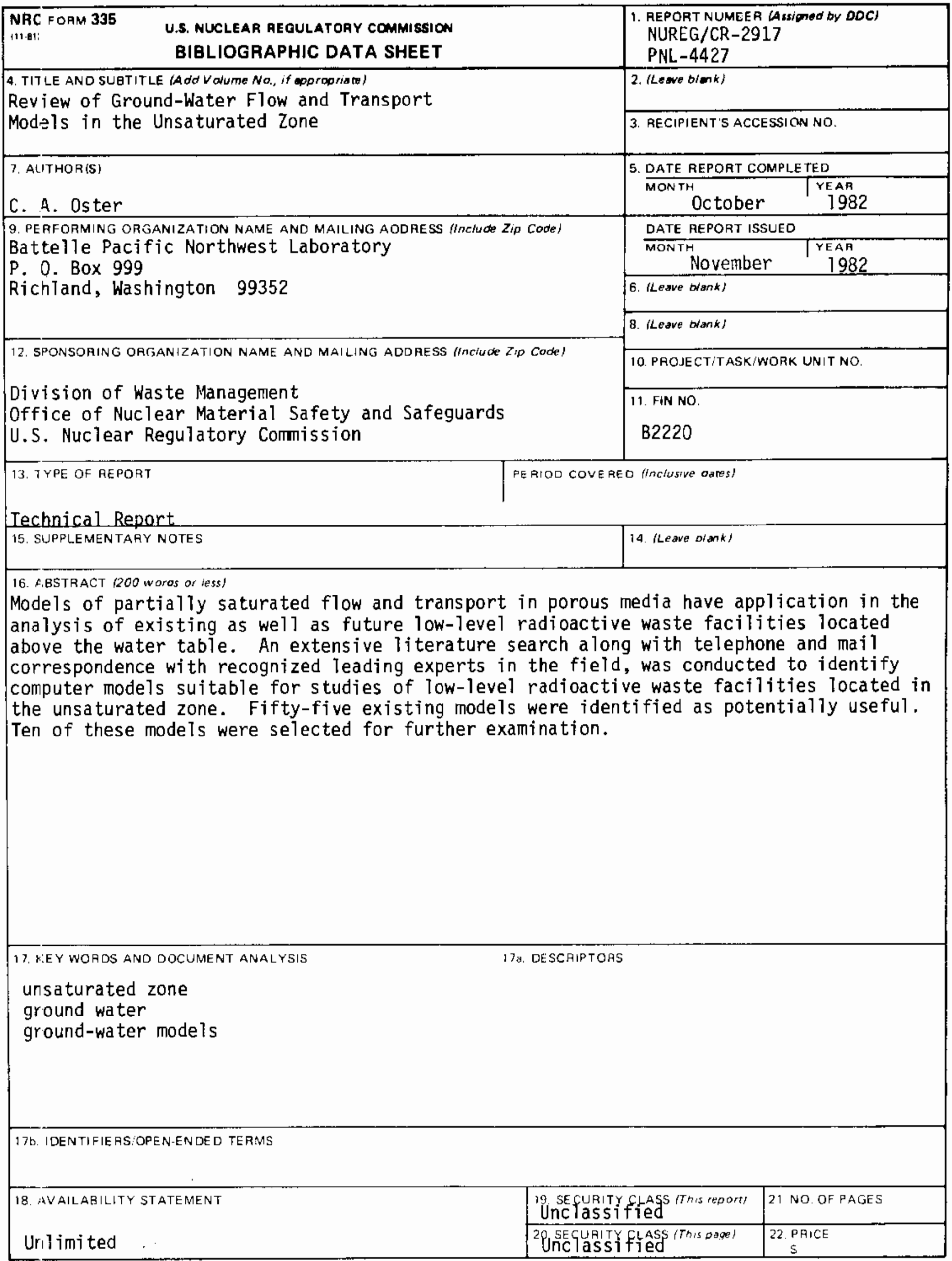


